\title{
THE INFLUENCE OF SURFACE PROPERTIES ON CARBON FIBER/EPOXY MATRIX INTERFACIAL ADHESION
}

\author{
by
}

Hong Zhuang

Thesis submitted to the Faculty of the

Virginia Polytechnic Institute and State University

in partial fulfillment of the requirements for the degree of

MASTER OF SCIENCE

in

Chemistry

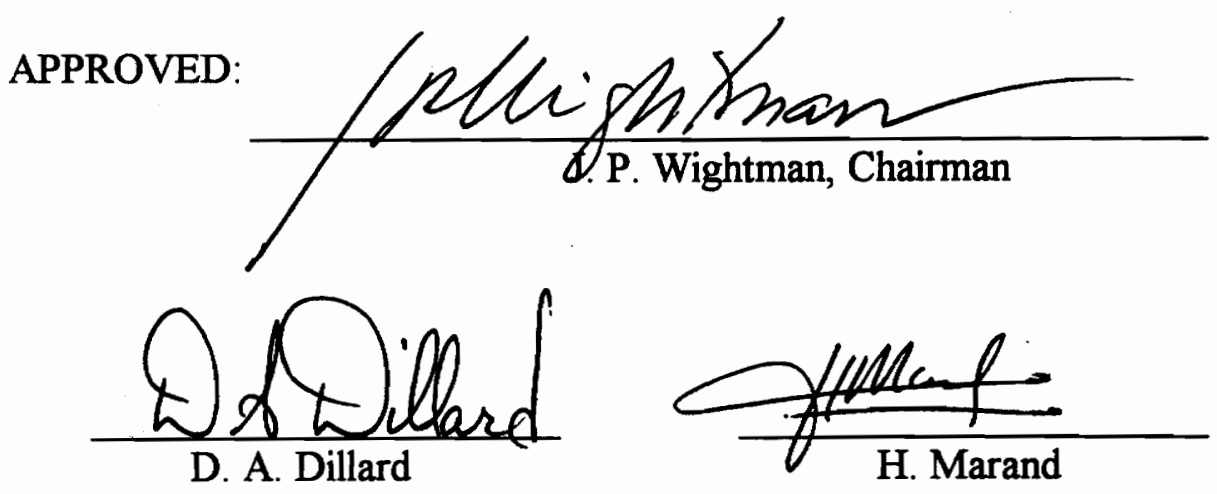

May 1995

Blacksburg, Virginia

Key Words: Surface Property, Carbon Fiber, Interfacial Adhesion 
$c .2$

45
105
195
.43
0.2 


\title{
The Influence of Surface Properties on Carbon Fiber/Epoxy Matrix Interfacial Adhesion
}

\author{
by \\ Hong Zhuang \\ James P. Wightman, Chairman
}

Chemistry

(Abstract)

The mechanical performance of composite materials depends not only on the matrix and the reinforcing fiber, but also to a great extent on the fiber/matrix interfacial adhesion. The focus of this work was to study carbon fiber surface chemical and physical properties and their effects on fiber/matrix adhesion.

Untreated, commercially surface treated and oxygen plasma treated PAN based carbon fibers were used for study. XPS was used to determine fiber surface chemistry. A two-liquid tensiometric method was conducted to determine fiber surface energy and its dispersion and polar components. SEM was used to examine the fiber surface topography.

Commercial surface treatment increased the carbon fiber surface oxygen content and fiber surface energy primarily in the polar component. An even higher level of fiber surface oxygen functionality and polar surface energy were achieved by oxygen plasma treatment. Oxygen plasma treatment also resulted in etching and pitting of AU-4 carbon fiber surface.

Carbon fibers with varying surface properties were incorporated into epoxy matrices. Single fiber fragmentation tests were carried out to evaluate the strength as well as the temperature dependence and humidity durability of interfacial adhesion. Commercially treated carbon fibers which having a higher surface oxygen content and 
higher surface energy clearly produced superior interfacial adhesion, relative to untreated fibers. An even greater level of adhesion was achieved with oxygen plasma treated fibers. Fiber surface roughness improved durability under elevated temperature and relative humidity conditions. The presence of sodium on the fiber surface dramatically decreased durability at high relative humidity. 


\section{ACKNOWLEDGMENTS}

I would like to take this opportunity to express my gratitude to my major advisor, Dr. J. P. Whightman, for his guidance and encouragement throughout this work. My experience of working with him has been greatly gainful both intellectually and personally. I would also like to thank Dr. D. A. Dillard and Dr. H. Marand for serving on my committee and for the very helpful suggestions and discussions.

The financial support of the project by McDonnell Douglas Aerospace is sincerely appreciated.

I would also like to acknowledge the precious and invaluable assistance by Mr. Frank Cromer for his surface analysis advise and technical expertise, Dr. Mark Anderson and Mr. Minghui Zhang for helps in preparing the AS-4-Na fiber, Dr. Jack Lesko and Mr. Scott Case for helping me to understand about Weibull analysis and apply it to this project, Mr. Kermit Kwan and Mr. Charles Tchatchoua for training on the DSC operation, Dr. James Crag and Mr. Jun Lu for giving me the access to their Leitz large polarizing microscope.

A lot of thanks go to the colleagues of our great research group for their assistance and friendship. I sincerely thank Dr. Joannie Chin for training in FTIR spectrometer operating, Dr. Mojee Babai-Cline for her expertise in computer software and all the helps in and out Lab, Dr. Cheryl Heisey for teaching me fiber handling technique, Mr. Shigeo Mori for sharing his industrial experience. Dr. Hideko Oyama for many helpful conversations about interfacial studies and, Dr. Nick Shephard for helps in computer and machining skills,

Finally, special gratitude goes to my husband, Yeudong, for his love, understanding and encouragement throughout this thesis work. I also thank our son, Wilson, for making me perspective and enjoying the beauty of life. 


\section{Table of Contents}

Chapter 1: Introduction.............................................................................................

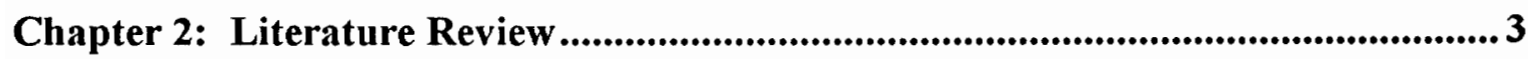

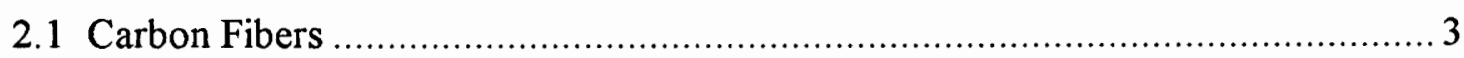

2.1.1 Structure and Properties of Carbon Fibers ……....................................... 3

2.1.2 Manufacture of PAN-Based Carbon Fibers ........................................... 5

2.1.3 Surface Modification of Carbon Fibers ............................................... 10

2.1.3.1 Surface Treatment and Effects on Carbon Fiber Surfaces ................ 12

2.1.3.2 Plasma Treatment and Effects on Fiber Surface............................... 14

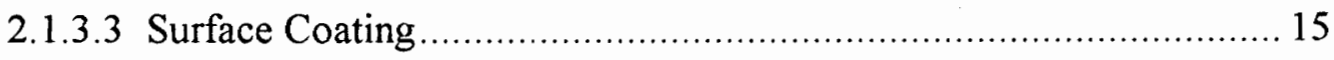

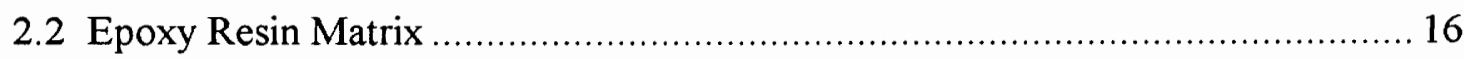

2.3 Fiber/Matrix Interface in Carbon Fiber Reinforced Polymeric Composites ........ 18

2.3.1 Concept of the Fiber/Matrix Interface .................................................... 18

2.3.2 Role of the Interphase in Composite Materials...................................... 18

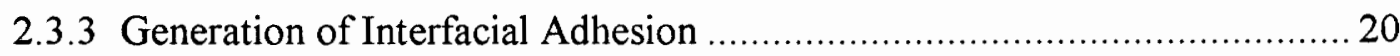

2.3.3.1 Interfacial Chemical and Physical Interactions ............................... 20

2.3.3.2 Mechanical Interlocking due to Fiber Surface Morphology ............ 25

2.3.3.3 Wetting of Fiber Surface by Matrix Material ................................. 25

2.4 Test Techniques for Evaluating Fiber/Matrix Adhesion ….............................. 27

2.4.1 Indirect Mechanical Tests of Fiber/Matrix Adhesion ............................... 27

2.4.2 Direct Mechanical Tests of Fiber/Matrix Adhesion .................................29

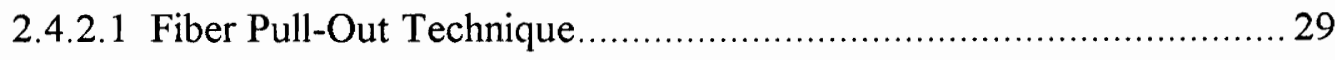

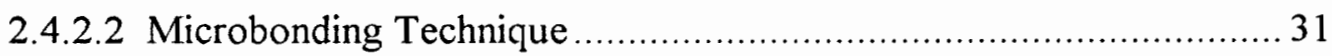

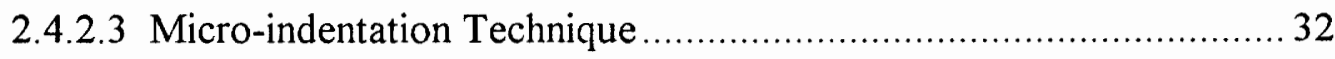

2.4.2.4 Single Fiber Fragmentation Technique ………….......................... 34 


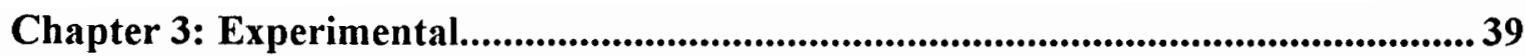

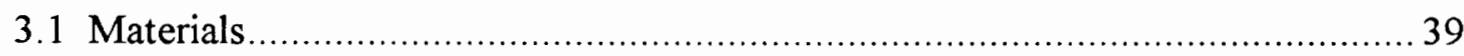

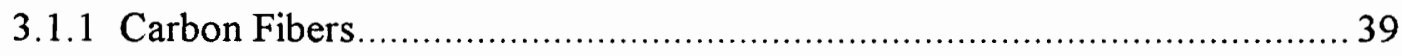

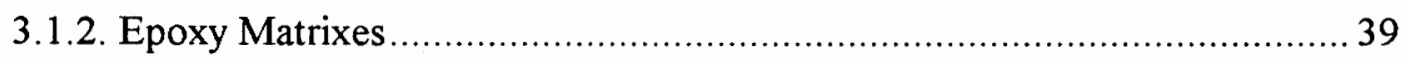

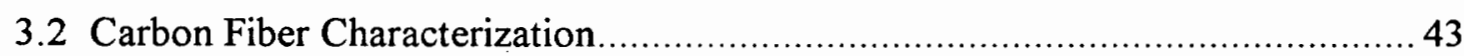

3.2.1 Surface Chemistry by X-ray Photoelectron Spectroscopy (XPS) ….......... 43

3.2.2. Surface Topography by Scanning Electron Microscopy (SEM)................ 43

3.2.3 Surface Energy by Two Liquid Dynamic Contact Angle Analysis.............. 44

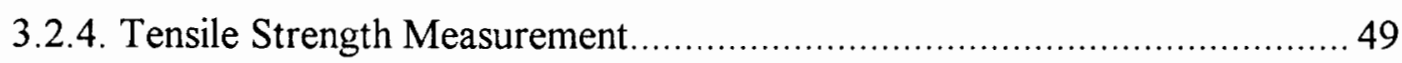

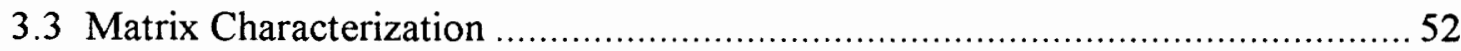

3.3.1 X-ray Photoelectron Spectroscopy (XPS) ………................................ 52

3.3.2 Fourier Transform Infrared Spectroscopy (FTIR) ................................. 52

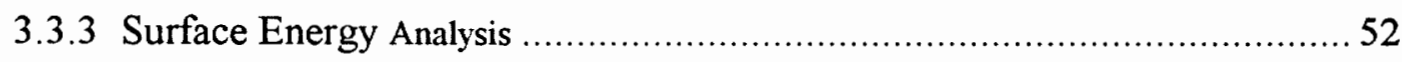

3.3.4 Differential Scanning Calorimetry (DSC) ……..................................... 53

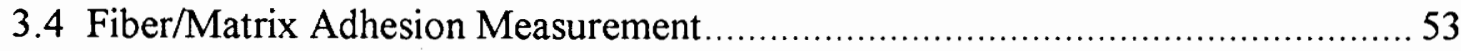

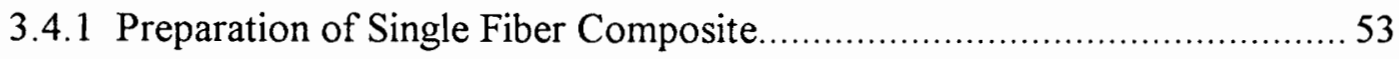

3.4.2 Interfacial Shear Strength by Single Fiber Fragmentation Test ................. 56

3.4.3 Interfacial Shear Strength after Humidity Exposure …............................. 58

3.4.4 Interfacial Shear Strength at Elevated Temperature ................................59

3.5 Plasma Treatment of Carbon Fibers............................................................ 59

Chapter 4: Results and Discussion ...........................................................................60

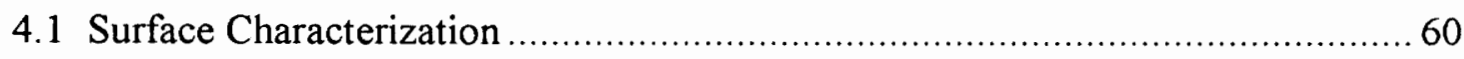

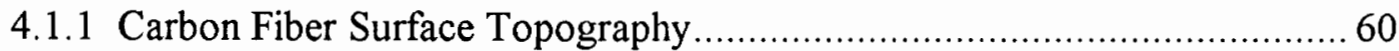

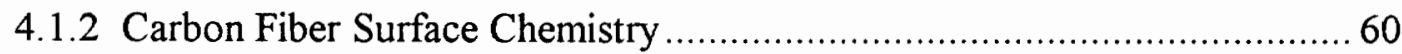

4.1.3 Carbon Fiber Surface Energy ............................................................... 70

4.1.4 Epoxy Matrix Surface Chemistry …………….................................... 76

4.1.5 Epoxy Matrix Surface Energy and Fiber/Matrix Interfacial Work of

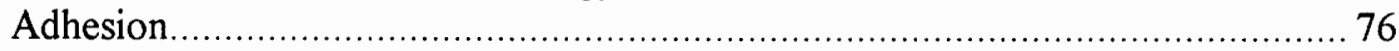

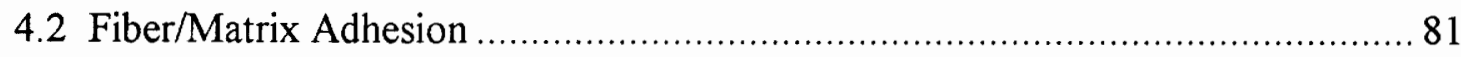


4.2.1 Fiber Tensile Strength at Critical Length........................................ 81

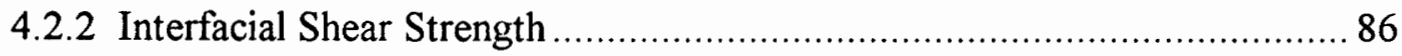

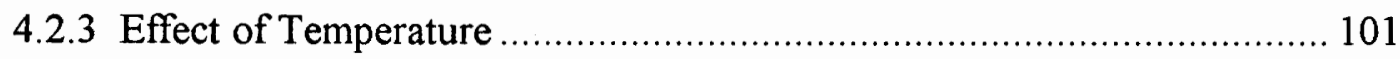

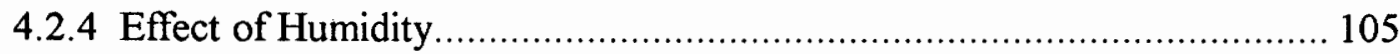

4.2.5 Effect of Carbon Fiber Oxygen Plasma Treatment ............................ 116

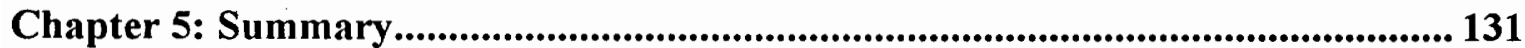

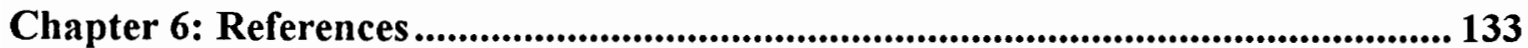




\section{List of Figures}

Figure 2.1 Schematic representation of three-dimensional (a) graphite and (b) turbostratic graphite structure. ${ }^{7}$

Figure 2.2 Comparison of the predictions of Ruland's model for the orientationdependence of the elastic modulus with experimental results obtained for fibers of various types. ${ }^{10}$

Figure 2.3 PAN based carbon fiber process outline 8

Figure 2.4 Dependence of strength and modulus of carbon fibers on heat treatment temperature. ${ }^{13}$

Figure 2.5 The possible functional groups present on oxidized carbon surface. ${ }^{16} \ldots \ldots . .13$

Figure 2.6 Synthesis of diglycidyl ether of bisphenol A (DGEBA) epoxy resin........... 17

Figure 2.7 Characteristics of the fiber/matrix interphase in a composite material. ${ }^{2,54}$.... 19

Figure 2.8 Possible chemical interaction of carbon fiber surface functionalities with epoxy resin. ${ }^{60}$

Figure 2.9 Interfacial shear strength plotted as a function of surface oxygen concentration determined by ESCA for carbon fibers. ${ }^{62}$

Figure 2.10 Balance of surface tensions in a liquid drop resting at equilibrium on a solid surface.

Figure2.11 Schematic representation of indirect tests of interfacial strength. (a) Short beam interlaminar shear test (ILSS). (b) $( \pm 45)_{s}$ tension shear test. (c) Iosipescu shear test. ${ }^{69}$

Figure 2.12 The four commonly used direct tests to measure the interface strength. ${ }^{54,71} 30$

Figure 2.13 Maximum load versus the embedded length in microbond test, (a) AU-4, (b) AS-4, and (c) $15 \mathrm{sec}$. air plasma treated AS-4 carbon fibers with quenched poly(pyridine-bis A) ${ }^{31}$

Figure 2.14 Fiber break process in a single fiber fragmentation test specimen. 35

Figure 2.15 Shear $(\tau)$ and tensile $(\sigma)$ stress distribution along a fiber fragment in single fiber fragmentation test.

Figure 3.1 The structure of (a) epoxy resin Epon 828, (b) amine curing agent mPDA, and (c) amine curing agent Jeffamine DU-700.

Figure 3.2 Schematic illustration of a single fiber in an immiscible two liquid system... 45

Figure 3.3 Single fiber tensile strength measurement. (a) sample preparation (b) measurement. 
Figure 3.4 Schematic representation of the rubber mold used for preparation of single fiber fragmentation specimens..

Figure 3.5 Test apparatus for the single fiber fragmentation technique. 57

Figure 4.1 SEM photomicrographs of carbon fibers. 61,62

Figure 4.2 Atomic concentrations of (a) AS-4 and (b) Panex 33(S) carbon fibers at different take-off angles.

Figure 4.3 Curve fit carbon 1s XPS photoelectron peaks of (a) AU-4, (b) AS-4, (c) Panex 33(U), and (d) Panex 33(S) carbon fibers.

Figure 4.4 Curve fit oxygen 1s XPS photoelectron peaks of (a) AU-4, (b) AS-4, (c) Panex 33(U), and (d) Panex 33(S) carbon fibers. 68

Figure 4.5 Wetting traces obtained from (a) AU-4, (b) AS-4, (c) Panex 33(U) and , (d) Panex 33(S) carbon fibers with immiscible octane/formamide two liquid system.

Figure 4.6 The change of wetting forces of AU-4 carbon fiber by octane/formamide in the (a) advancing and (b) receding modes.

Figure 4.7 Dynamic contact angle analysis plots for (a) AU-4 and AS-4, and (b) Panex 33(U) and Panex 33(S) fibers. 75

Figure 4.8 Contact angle analysis plots for Epon828/mPDA and Epon828/DU-700 resins.

Figure 4.9 Weibull plots of strength distributions for AS-4 fibers at gauge lengths of (a) $1 \mathrm{~mm}$, (b) $12 \mathrm{~mm}$, (c) $20 \mathrm{~mm}$, and (d) $44 \mathrm{~mm}$. 83

Figure 4.10 Weibull plots of strength distributions for Panex 33(S) fibers at gauge lengths of (a) $1 \mathrm{~mm}$, (b) $12 \mathrm{~mm}$, (c) $20 \mathrm{~mm}$, and (d) $44 \mathrm{~mm}$. 84

Figure 4.11 Fiber tensile strengths as a function of gauge length. (a) AU-4, (b) AS-4, (c) Panex 33(U), and (d) Panex 33(S).

Figure 4.12 Weibull plots of fragment lengths by single fiber fragmentation tests with the fiber/Epon828-mPDA system. (a) AU-4 fiber, (b) AS-4 fiber, (c) Panex 33(U) fiber, and (d) Panex 33(S) fiber.

Figure 4.13 Weibull plots of fragment lengths by single fiber fragmentation tests with the fiber/Epon 828-DU700 system. (a) AU-4 fiber, (b) AS-4 fiber, (c) Panex 33(S)fiber 88

Figure 4.14 Relationship between fiber surface oxygen and interfacial shear strength....91

Figure 4.15 Relationship between fiber surface total energy and interfacial shear strength.92

Figure 4.16 Relationship between the reversible work of adhesion and interfacial shear strength. 
Figure 4.17 SEM photomicrograph of the Panex 33(S)/Epon828-DU700 interface...... 95

Figure 4.18 Stress birefringence patterns at multiple fiber break occurs. (a) AU-4, (b) AS-4, and (c) Panex 33(S) in Epon828/mPDA.

Figure 4.19 The change of birefringence pattern with increasing strain in AU-4/Epon828mPDA system. (a) initial break, (b) $1 \%$ more elongation after initial break, (c) $2 \%$ more elongation after initial break.

Figure 4.20 The change of birefringence pattern with increasing strain in AS-4/Epon828mPDA system. (a) initial break, (b) $1 \%$ more elongation after initial break,

(c) $2 \%$ more elongation after initial break 98

Figure 4.21 The change of birefringence pattern with increasing strain in Panex 33(S)/ Epon828-mPDA system. (a) initial break, (b) $1 \%$ more elongation after initial break, (c) $2 \%$ more elongation after initial break.

Figure 4.22 Birefringence patterns after tension has been removed for four hours. (a) AU-4, (b) AS-4 and (c) Panex 33(S) in Epon828-mPDA.

Figure 4.23 Temperature dependence of interfacial shear strength for AU-4, AS-4 and Panex 33(S) fibers in Epon828/mPDA 102

Figure 4.24 Temperature dependence of interfacial shear strength for AU-4, AS-4 and Panex 33(S) fibers in Epon828/Jeffamine DU-700.

Figure 4.25 The influence of exposure time on interfacial shear strength in fiber/Epon828-mPDA system at $23^{\circ} \mathrm{C} 100 \% \mathrm{RH}$. 106

Figure 4.26 The influence of exposure time on interfacial shear strength in fiber/Epon828-mPDA system at $75^{\circ} \mathrm{C} 100 \% \mathrm{RH}$.

Figure 4.27 The influence of exposure time on interfacial shear strength in fiber/Epon828-mPDA system at $23^{\circ} \mathrm{C} 0 \% \mathrm{RH}$. 108

Figure 4.28 The influence of exposure time on interfacial shear strength in fiber/Epon828-mPDA system at $75^{\circ} \mathrm{C} 0 \% \mathrm{RH}$. 109

Figure 4.29 Moisture uptake rates of Epon828/mPDA dogbone samples. 111

Figure 4.30 Proposed degradation mechanism of mPDA cured Epon828 network. .... 114

Figure 4.31 FTIR spectra of mPDA cured Epon828 epoxy resin. (a) original, (b) after 30 days in $23^{\circ} \mathrm{C} 100 \% \mathrm{RH}$, and (c) after 30 days in $23^{\circ} \mathrm{C} 10 \% \mathrm{Na}_{2} \mathrm{CO}_{3}$ aqueous solution.

Figure 4.32 FTIR spectra of mPDA cured Epon828 epoxy resin. (a) original, (b) after 30 days in $75^{\circ} \mathrm{C} 100 \% \mathrm{RH}$, and (c) after 30 days in $75^{\circ} \mathrm{C} 10 \% \mathrm{Na}_{2} \mathrm{CO}_{3}$ aqueous solution. 116

Figure 4.33 AU-4 carbon fiber surface chemistry change as a function of oxygen plasma treatment time. 
Figure 4.34 Panex 33(U) carbon fiber surface chemistry change as a function of oxygen plasma treatment time.

Figure 4.35 Curve fit carbon 1s XPS photoelectron peaks of (a) AU-4 original, (b) Panex 33(U) original, (c) $90 \mathrm{sec} . \mathrm{O}_{2}$ plasma treated $\mathrm{AU}-4$, and (d) ) $90 \mathrm{sec} . \mathrm{O}_{2}$ plasma treated Panex 33(U) fibers. .................................................. 120

Figure 4.36 Curve fit oxygen 1s XPS photoelectron peaks of (a) AU-4 original, (b) Panex 33(U) original, (c) $90 \mathrm{sec} . \mathrm{O}_{2}$ plasma treated AU-4, and (d) ) $90 \mathrm{sec}$. $\mathrm{O}_{2}$ plasma treated Panex 33(U) fibers.

Figure 4.37 Change of fiber topography by oxygen plasma. (a) AU-4 original, and (b) AU-4 90 sec. Plasma, (c) Panex 33(U) original, and (d) Panex 33(U) 90 sec. Plasma. 125,126

Figure 4.38 Polar component of fiber surface energy as a function of oxygen plasma treatment time. 128

Figure 4.39 Interfacial shear strength as a function of oxygen plasma treatment time in AU-4 fiber and Epon 828/mPDA resin system. 129

Figure 4.40 Interfacial shear strength as a function of oxygen plasma treatment time in Panex 33(U) fiber and Epon 828/mPDA resin system. 130 


\section{List of Tables}

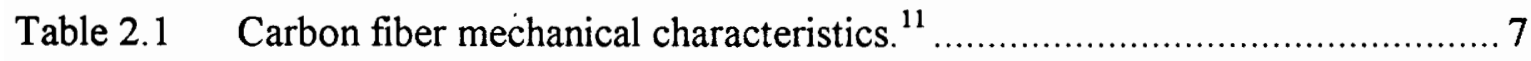

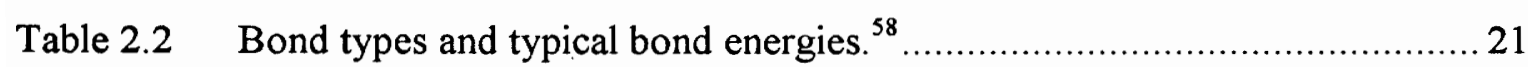

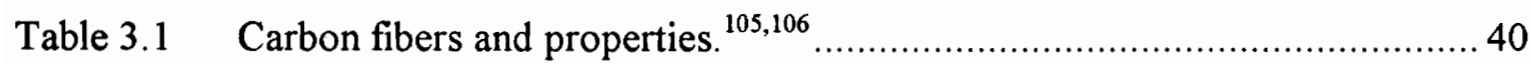

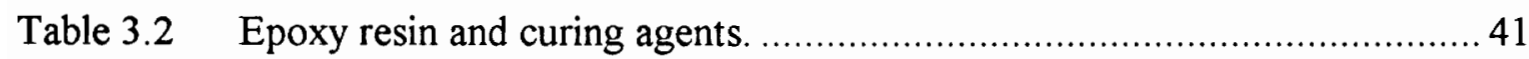

Table 3.3 Surface free energies of liquids used for two-liquid dynamic contact angle

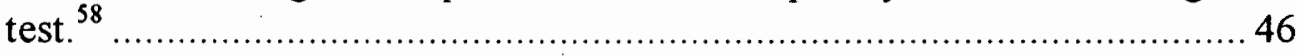

Table 3.4 Liquids used for epoxy resin surface energy measurement and their surface

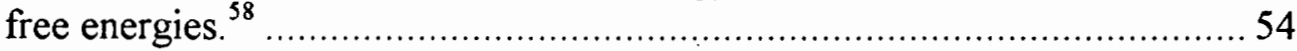

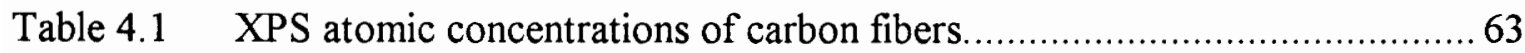

Table 4.2 Carbon 1s photopeak curve fit results of carbon fibers..............................67

Table 4.3 Oxygen 1s photopeak curve fit results of carbon fibers. .............................69

Table 4.5 Carbon fiber perimeters (p) and diameters (d) measured from hexane wetting force and SEM.

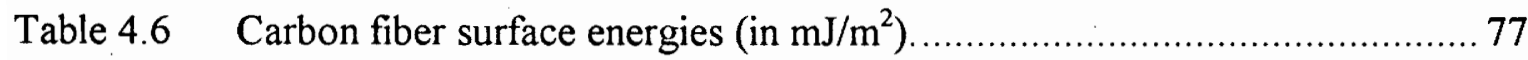

Table 4.7 XPS atomic concentrations of epoxy resins. ........................................... 78

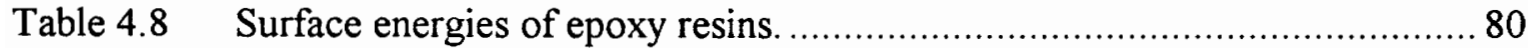

Table 4.9 Reversible work of adhesion (in $\mathrm{mJ} / \mathrm{m}^{2}$ ) between carbon fibers and epoxy

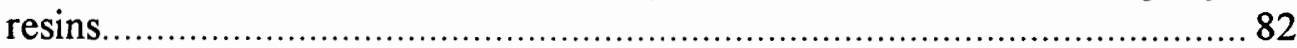

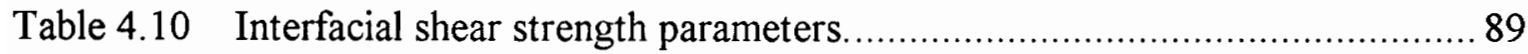

Table 4.11 The effects of sodium and moisture on carbon fiber properties............... 112

Table 4.12 Carbon 1s photopeak curve fit results of oxygen plasma treated carbon fibers.

Table 4.13 Oxygen 1s photopeak curve fit results of oxygen plasma treated carbon fibers. 


\section{Chapter 1: Introduction}

In recent years, the technological demand for materials that exhibit improved strength and stiffness characteristics has led to considerable research and development in the field of fiber-reinforced resin-matrix composites. The high mechanical strengths, high moduli of elasticity, and low densities of fibers made from such substances as carbon, boron, and glass, when combined with the toughness of various epoxy, polyester, and polyimide resins, produce a class of materials possessing specific tensile properties that can match or exceed (depending on the fiber-matrix combination) those of the best metal alloys currently in production. This is important because materials that are strong, stiff, and in addition, lightweight are valuable for many applications such as aircraft, automobiles and some recreation equipment.

A composite is an arrangement of reinforcing fibers in various configurations held together by a cohesive matrix. The fibers constitute the major load bearing element of the composite and the role of the matrix is to both distribute the internal stress and protect the fibers from the environment. Factors which determine the mechanical performance of a composite are the strength and modulus of the fiber, the strength and chemical stability of the matrix resin, and, the interfacial integrity between fiber and resin. The importance of the nature and degree of fiber/matrix interfacial adhesion on the mechanical performance has been well established. ${ }^{1-3} \mathrm{~A}$ weak interface tends to improve impact strength and fracture toughness of the composite by resisting cracks that would otherwise propagate through the matrix. A strong interface, on the other hand, insure effective stress transfer through the interface and improves delaminative off-axis strength. To achieve optimum performance, some compromise is needed between very strong and very weak interfacial adhesion. 
As composite material systems become increasingly sophisticated to meet everincreasing performance requirements, it has become more important to control the interaction between the reinforcing fibers and matrix materials. The major challenge here is the lack of fundamental understanding and knowledge about the reinforcement/matrix system which contribute to the establishment of the interface. It has been recognized that the state of the fiber surface substantially affects the quality of interfacial adhesion..$^{4-6}$ However, basic and specific correlations are still incomplete.

It was the objective of this work to explore extensively the effects of physical and chemical aspects of fiber surfaces to the establishment and durability of interfacial adhesion in carbon fiber reinforced polymeric composites. Surface analytical techniques were utilized to obtain properties of untreated, commercially surface surface treated, and plasma treated carbon fibers. The contributions of fiber surface characteristics to fiber/matrix adhesion were evaluated. 


\section{Chapter 2: Literature Review}

\subsection{Carbon Fibers}

High-strength, high-modulus reinforcing fibers are the backbone of the advanced high-performance composites. Today, numerous types of fibers are commercially available. These fibers range from polymeric fibers, such as aramid and extended-chain polyethylene, and ceramic fibers such as silicon carbide and alumina, to carbon fibers. Among these, carbon fibers are by far the most used because of their low density, high modulus and strength, and stability at elevated temperature.

\subsubsection{Structure and Properties of Carbon Fibers}

The unique properties obtainable in carbon fiber-resin matrix composites are directly attributable to the properties of the carbon fibers themselves, which, in turn, are directly attributable to the highly anisotropic nature of the graphite crystal.

The graphite crystal is composed of many layers of carbon atoms which are stacked one on top of another ${ }^{7,8}$ as shown in part (a) of Figure 2.1. In the basal plane of the layers, the carbon atoms are linked together in a hexagonal pattern by very strong covalent bonds. As a result, the theoretical tensile modulus of elasticity and ultimate tensile strength of the plane is very high. On the other hand, relatively weak van der Waals bonds hold the layers together in a direction normal to the basal plane. Consequently, the mechanical properties of the crystal in this direction are much poorer. In a graphite fiber, the structure of the crystallites is not perfect as in a single graphite crystal but, instead, slightly distorted forming a "turbostratic" graphite as shown in part (b) of Figure 2.1. However, the orientation of the graphite layers is still more or less parallel to the fiber axis. ${ }^{9}$ As a result, longitudinal properties of the carbon fiber are strong especially as the degree of alignment of the basal planes parallel to the fiber axis increases. The study of Ruland and his co-workers has been cited by reference 10 , showing that the strong dependence of 


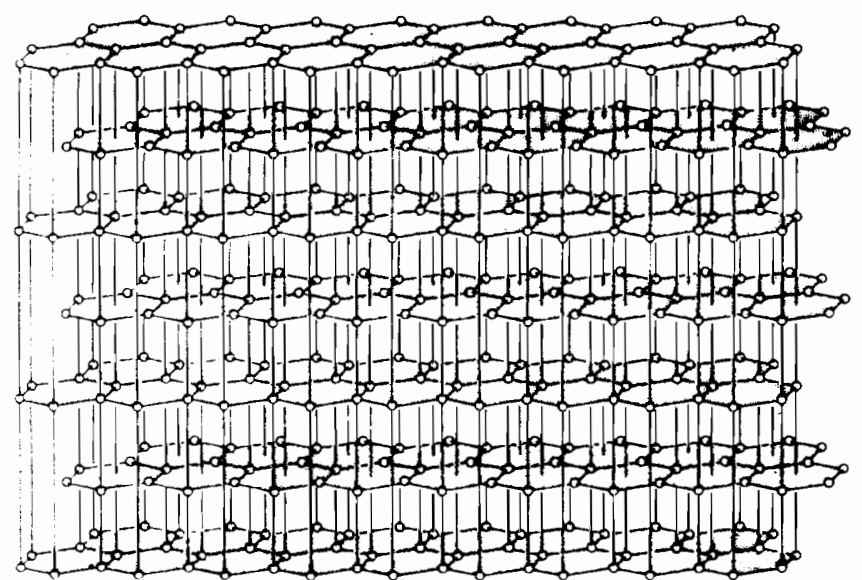

(a)

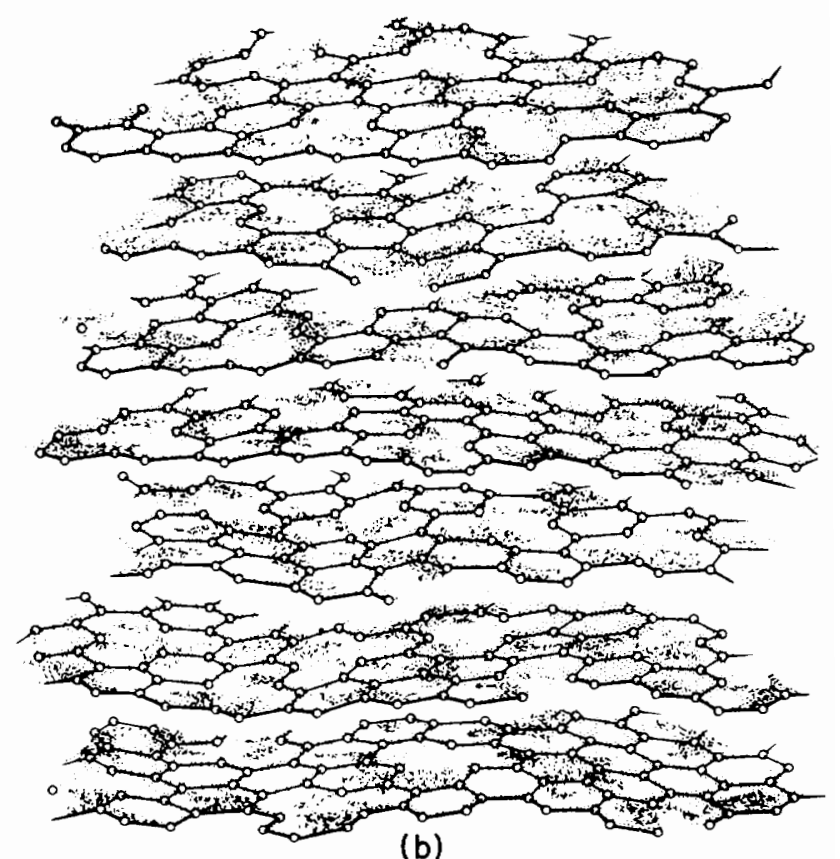

(b)

Figure 2.1 Schematic representation of three-dimensional (a) graphite and (b) turbostratic graphite structure. ${ }^{7}$ 
modulus on orientation which is observed experimentally for fibers of many different types is accurately predicted by the theoretical model, as shown in Figure $2.2{ }^{10}$ The strength of carbon fibers is also affected by the number of flaws and defects present and their magnitude?

Generally, carbon fibers are classified ${ }^{11}$ into three major groups of mechanical characteristics as listed in Table 2.1: standard or aerospace grade, intermediate modulus (IM), and high modulus (HM). To date, most sales have been with the general performance standard-grade carbon fiber, and this is likely to continue as long as the present applications continue in production. The newer aerospace (and some recreation) applications, however, are primarily involved with the high performance IM and HM carbon fibers.

\subsubsection{Manufacture of PAN-Based Carbon Fibers}

The production of carbon fibers is based on the high-temperature pyrolysis of organic precursor fibers. The primary organic precursor materials for pyrolysis into carbon fibers having good properties are polyacrylonitrile (PAN), pitch, and rayon. Rayon, the raw material used for the first high-performance carbon fibers ${ }^{12}$, was the dominant precursor material in the 1960s and 1970s. However, because of its low carbon yield, high processing cost, and limited physical properties, rayon-based fibers are used for less than 1 percent of commercial carbon fibers today. Pitch-based carbon fibers have potential advantages of low cost for raw materials, high yield of carbon, and high tensile modulus that results from its high degree of molecular orientation. However, because of the limited manufacturing experience and relatively lower strength of carbon fiber by pitch, PAN is now the dominant starting material for carbon fiber manufacture.

Polyacrylonitrile (PAN)-based carbon fibers represent approximately 90 percent of all carbon fiber sales worldwide. ${ }^{11}$ The processes by which PAN is converted to carbon fibers are well documented in the literature $e^{4,8,11}$ and a flow diagram is given in Figure 2.3. 


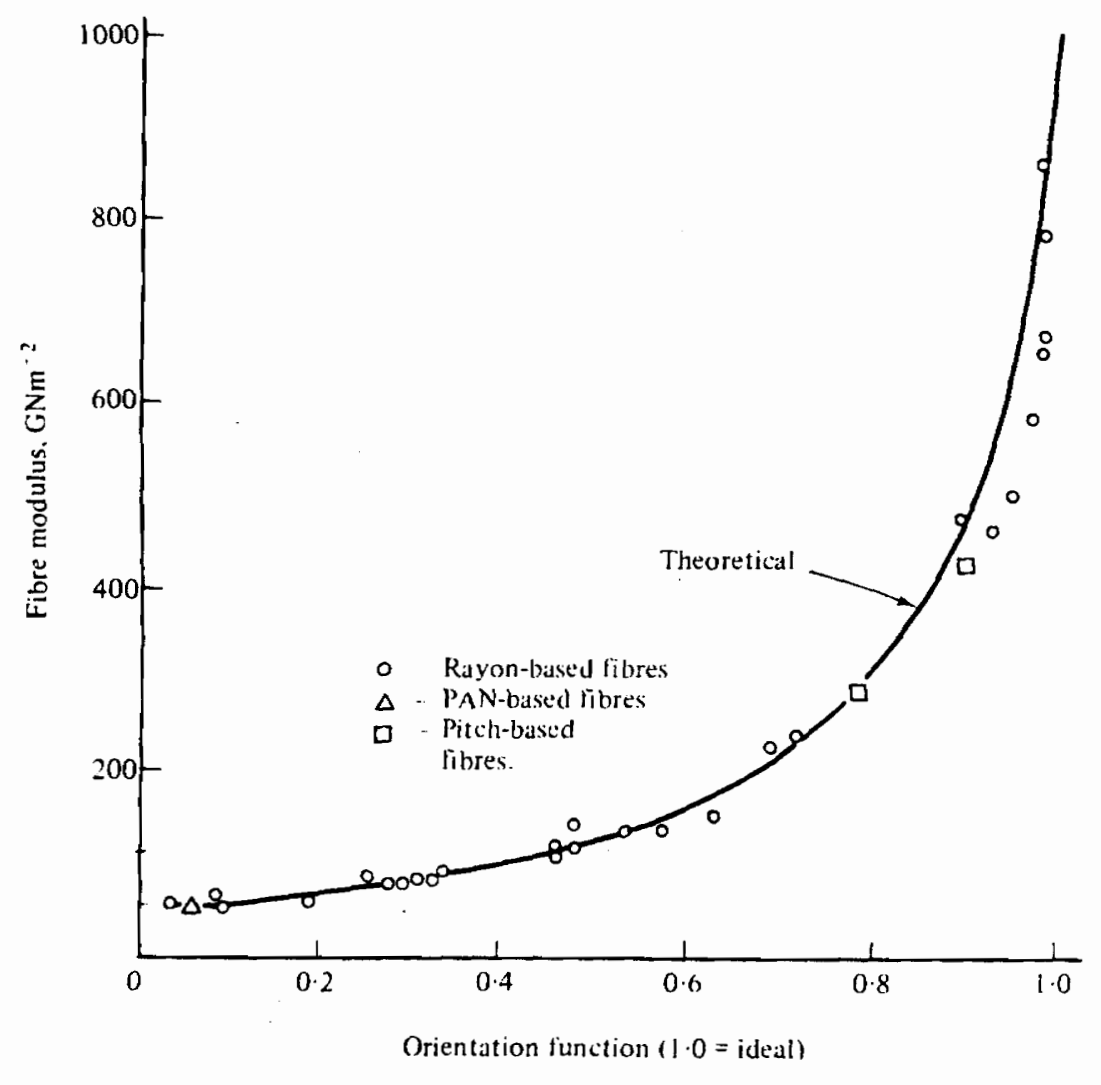

Figure 2.2 Comparison of the predictions of Ruland's model for the orientationdependence of the elastic modulus with experimental results obtained for fibers of various types. ${ }^{10}$ 
Table 2.1 Carbon fiber mechanical characteristics. ${ }^{11}$

\begin{tabular}{|c|c|c|c|}
\hline Grade & $\begin{array}{l}\text { Product } \\
\text { Modulus } \\
(\mathrm{GPa})\end{array}$ & $\begin{array}{c}\% \text { Strain to } \\
\text { Failure }\end{array}$ & Development Activity \\
\hline \multirow[t]{2}{*}{ Standard } & $32-35$ & 1.6 & Lower Cost \\
\hline & $32-35$ & 2.0 & Increased Strain to failure \\
\hline $\begin{array}{l}\text { Intermediate } \\
\text { Modulus (IM) }\end{array}$ & $40-50$ & 2.0 & $\begin{array}{c}\text { Improved Composite Balance of } \\
\text { Properties (Compression, Toughness) }\end{array}$ \\
\hline & & & Increased Strain to Failure \\
\hline $\begin{array}{l}\text { High Modulus } \\
\qquad(\mathrm{HM})\end{array}$ & $55-85$ & 1.0 & Increased Modulus \\
\hline
\end{tabular}


Process Outline
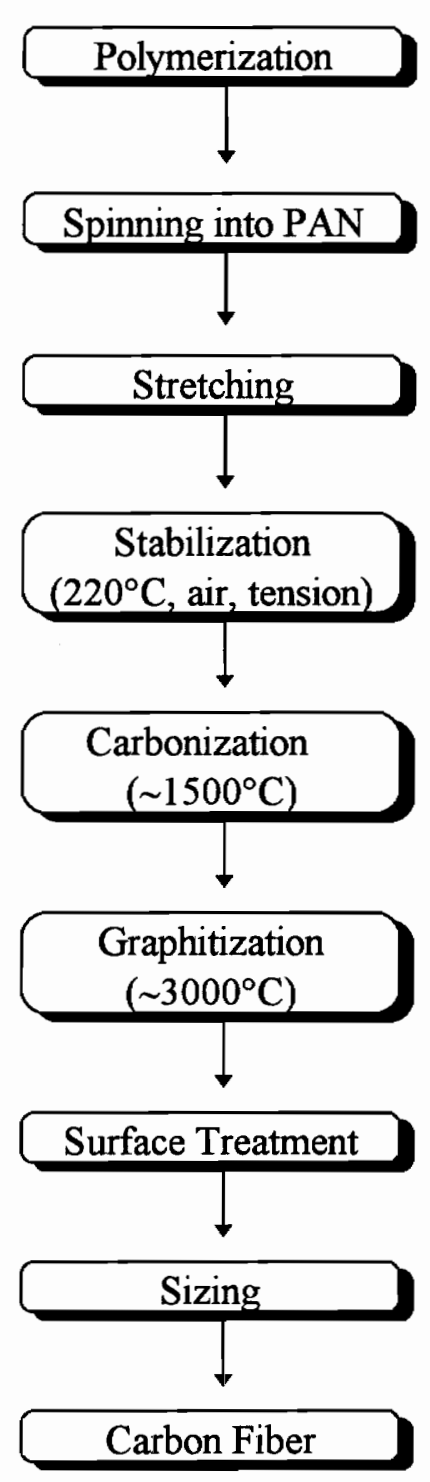

\section{Chemistry}

$-\left(\mathrm{CH}_{2}-\mathrm{CHCN}\right)_{n}$

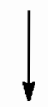<smiles>N=CC1CN=C2NCC(C(O)C3CC4C(=N)C5CC(CC(N)=O)CN=C5NC4=NC3=O)CC2CC1C=N</smiles>

(PAN “Ladder” Structure)<smiles>C1C[Te]1</smiles>

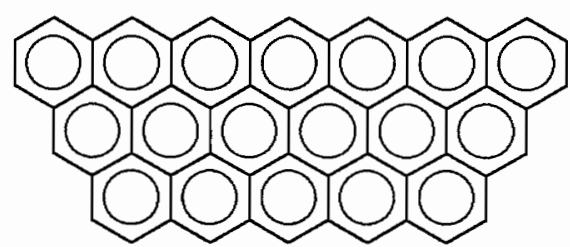

(Graphite-like Structure)

Figure 2.3 PAN based carbon fiber process outline. 
Generally, a solution of either PAN or its acrylic copolymer is wet spun into a coagulating bath and then the fibers are washed, stretched, and dried. The molecular structure and properties of the as-spun fibers are significantly influenced by the spinningprocess variables. A preferred orientation in the precursor parallel to the fiber axis is formed by stretching the fibers to some ten times of their original length, which is necessary in order to obtain high-performance properties in the carbonized fibers. The cross section of fibers formed by wet spinning process is usually circular.

It is very important to stabilize the fiber against the orientation relaxation phenomenon that would tend to occur during the high temperature carbonization process. Since the glass transition temperature of PAN fibers is quite low compared to the carbonization temperature, a stabilization process must be employed to either increase the inherent stiffness of the PAN molecules or "tie" the molecules together in order to limit or totally eliminate the relaxation. Stabilization of PAN involves heating the fiber in air to temperatures ranging from $200^{\circ} \mathrm{C}$ to $300^{\circ} \mathrm{C}$. By this process, $\mathrm{PAN}$ molecules cyclize to form a "ladder" structure which leads to thermal stability due to the inherent stiffness of the "ladder" as well as the carbon-carbon double bonds.

Carbonization is the process of pyrolyzing stabilized PAN fiber into carbon fiber in an inert atmosphere at temperatures ranging from 1000 to $1500^{\circ} \mathrm{C}$. Cross linking reactions occur between adjacent PAN chains with elimination of $\mathrm{H}_{2} \mathrm{O}, \mathrm{HCN}$, and $\mathrm{N}_{2}$, with the result that carbon atoms arrange to aromatic ring structures. It is during this stage that the high mechanical property levels found in most commercially available carbon fibers are developed. The development of these properties is directly related to the formation and orientation of turbostratic graphite-like structure or ribbons within each individual fiber. For this purpose, fibers are actually stretched during pyrolysis.

In general, graphitization heat treatments are specifically carried out at temperatures up to $3000^{\circ} \mathrm{C}$ in order for carbon crystallite structure to become more graphite-like. As the temperature of the final treatment is increased, the degree of 
graphitization increases and the fiber achieves a higher modulus. However, the high treatment temperature also increases fiber flaws and thus the strength is decreased. Commercial fibers are usually produced by controlling the process to optimize either modulus or strength. Figure 2.4 shows the relationship between strength and modulus of PAN based fiber as a function of heat treatment temperature ${ }^{13}$. Additional strengthening can be obtained by hot stretching fibers above $2000^{\circ} \mathrm{C}$ when plastic deformation occurs. This process of strain-graphitization has been described by Johnson et al. ${ }^{14}$, who showed that the degree of preferred orientation, the fiber strength, and the elastic modulus all increased markedly during stretching.

Finally, the continuous carbon fiber is surface treated and coated with a sizing agent prior to winding the filaments on bobbins. The surface treatment is a modification of the fiber surface intended to promote adhesion to the matrix resin in the composite. The sizing promotes handleability and wettability of the fiber with the matrix resin. Both surface treatment and sizing will be dealt with more detail in the following section.

\subsubsection{Surface Modification of Carbon Fibers}

The control of the interface state is critical for the performance of composites. Fiber surface modifications by surface treatment and sizing have been recognized as versatile methods for tailoring the fiber-matrix interface so that optimum composite properties can be achieved.

As reviewed by many authors ${ }^{4,8,15,16}$, carbon fiber surface modification techniques have been developed to improve composite properties since 1948. Surface treatments that improve the interfacial shear strength by a factor of up to 2-3 times are available. Types of surface treatments used include conventional surface treatment, plasma treatment, and coating. 


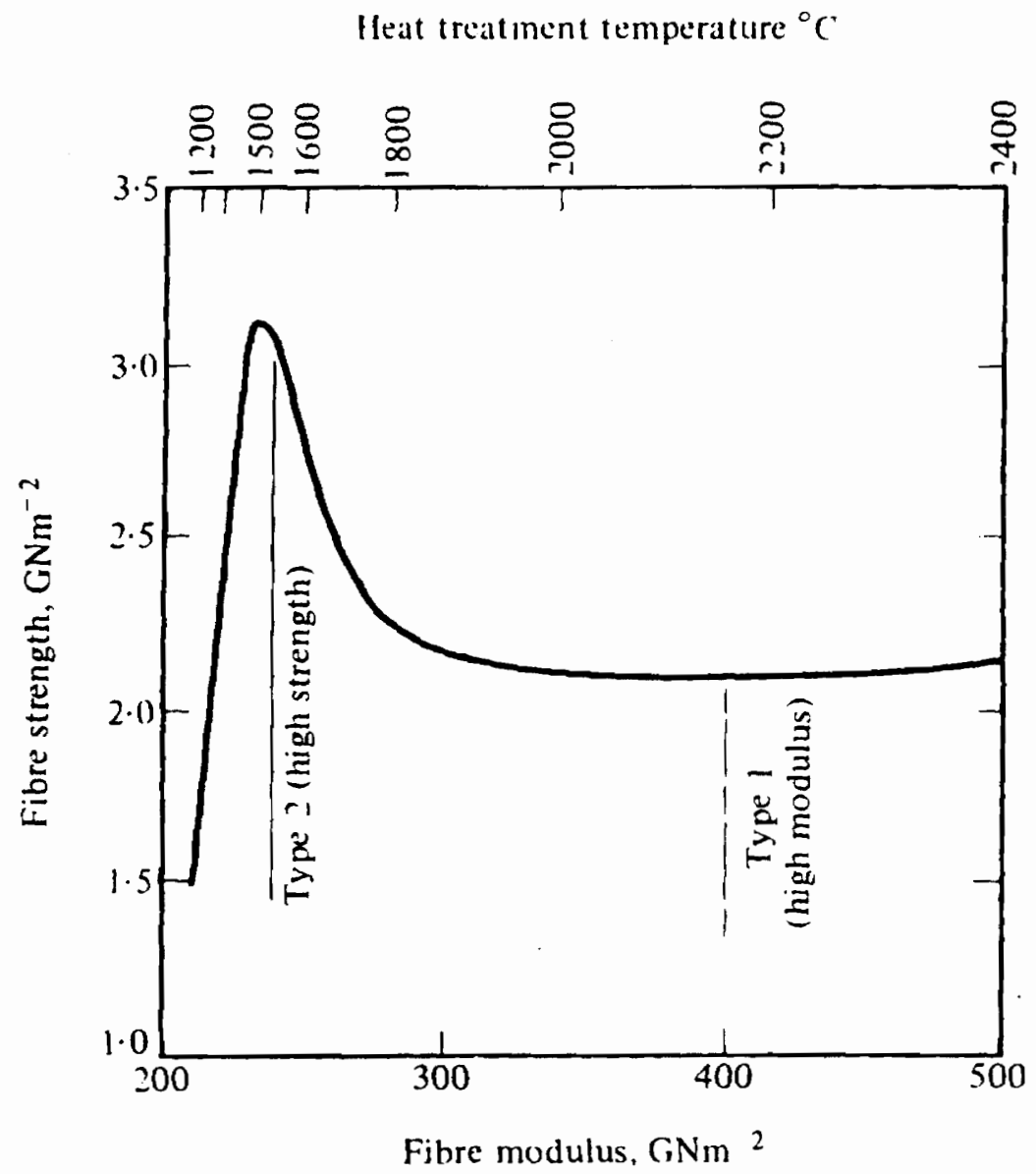

Figure 2.4 Dependence of strength and modulus of carbon fibers on heat treatment temperature. $^{13}$ 


\subsubsection{Surface Treatment and Effects on Carbon Fiber Surfaces}

Industry applied carbon fiber surface treatments during the past twenty years have been essentially (a) wet oxidative: by electrochemical oxidation (anodization) or by immersion of fibers into a solution of oxidizing agents such as nitric acid and chromic acid, and (b) dry oxidative: oxidation in air or oxygen. Electrochemical oxidation is the most widely used surface treatment. ${ }^{16}$

The effects of surface treatment on the chemistry of the fiber surface have been studied using numerous direct and indirect techniques including titration, $\mathrm{x}$-ray photoelectron spectroscopy, Auger spectroscopy, secondary ion mass spectroscopy, infrared spectroscopy, Raman spectroscopy, and ultra-high vacuum analysis. ${ }^{16-21}$ The most useful technique is X-ray photoelectron spectroscopy (XPS). Surface oxygen and nitrogen contents increased significantly with surface treatment. Attempts to deduce the chemical functionality of the surface chemical groups detected on the fiber surface indicate that the most probable functionalities present are carboxylic, phenolic, lactone and carbonyl groups $^{16,22}$ as shown in Figure 2.5. Nitrogen present on the surface may be chemisorbed as $\mathrm{C}-\mathrm{O}-\mathrm{N}$ and amine groups. ${ }^{23}$ It was hoped that by introducing one or more of these functional groups they would chemically interact with the matrix resin (e.g., epoxy) or activate the cure process promoting strong interfacial adhesion between fiber and resin.

The total free energy of carbon fiber surface increases with surface treatment primarily through an increase in the "polar" component ${ }^{19,24,25}$, or Lewis acid-base (electron acceptor-donor) character ${ }^{26}$, or active sites. ${ }^{21,25}$ The increase paralleled the functionalization of the fiber surface. A good correlation between the surface oxygen concentration and the change in polar/dispersive ratios for low and high modulus surface treated fibers has been reported by Drzal and co-workers. ${ }^{19,24}$ 


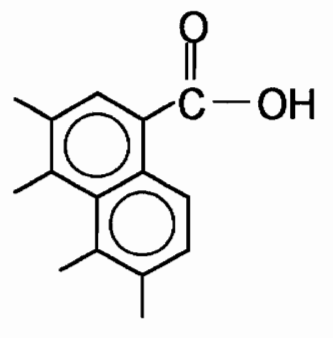

Carboxyl

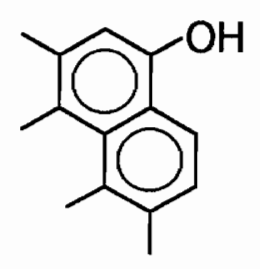

Phenolic Hydroxyl<smiles></smiles>

Quinone-type Carbonyl

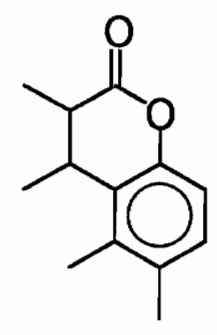

Normal Lactone

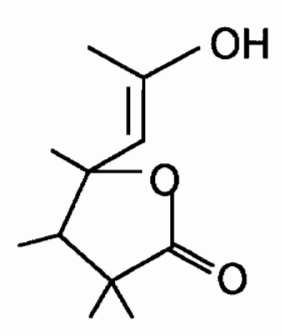

Fluorescene-type Lactone<smiles>C=Cc1ccc(C=C)c2c1C(=O)OC2=O</smiles>

Carboxylic Acid Anhydride

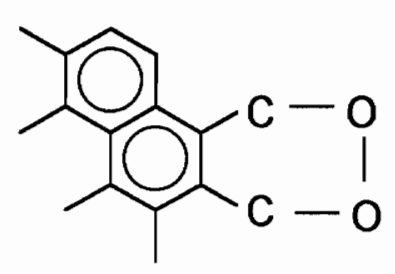

Cyclic Peroxide

Figure 2.5 The possible functional groups present on oxidized carbon surface. ${ }^{16}$ 
Some results indicated surface treatment increased surface area ${ }^{21,27}$ Others, on the other hand, found no significant increase in surface area had taken place with surface treatment for carbon fibers. ${ }^{24,25,28}$

The mechanisms by which fiber surface treatments improve interfacial adhesion is controversial. There appear to be at least three major mechanisms contributing to the strength of the fiber/resin bonding:

- The interaction (either physical or chemical) between fiber and resin due to increased carbon fiber surface energy or functionality;

- Better adherence of resin to fiber due to removal of fiber surface contamination or weak boundary surface layers; and,

- Mechanical interlocking due to the penetration into pits and channels on fiber surface brought about by surface pretreatment.

In most cases the increase of surface functionality, increase of surface free energy, change of surface area, and removal of weak boundary crystallite layers are occurring simultaneous, and so the relative importance of these factors to the enhancement of interfacial adhesion is difficult to assess.

\subsubsection{Plasma Treatment and Effects on Carbon Fiber Surface}

In recent years, low temperature gaseous plasmas have been used in carbon fiber surface modification. It has been well documented that plasma treatment is capable of inducing significant changes in fiber surfaces and properties of carbon fiber composites. ${ }^{16,29-33}$ Gases used for carbon fiber plasma treatment include air, oxygen, nitrogen, argon, ammonia, fluorine, carbon dioxide, and vaporizable organic species.

It has been shown that exposing the fiber to gas plasma can introduce a much higher concentration of functional groups on the immediate surface of the fiber compared with conventional electrochemical surface treatment. ${ }^{34,35}$ In general ${ }^{36,37}$, oxygen and argon 
plasma increased the oxygen functionality (in the forms of $\mathrm{C}-\mathrm{O}, \mathrm{C}=\mathrm{O}, \mathrm{O}-\mathrm{C}=\mathrm{O}$ ), nitrogen and ammonia plasma increased nitrogen functionality (in the forms of $-\mathrm{NH}_{2},-\mathrm{C}=\mathrm{NH}$ ), while air plasma increased both oxygen and nitrogen functionalities on the fiber surface. ${ }^{35}$ Oxidizing plasmas such as air and oxygen are more reactive with the carbon surface than either nitrogen, ammonia, or argon plasmas. Jones and Sammann attributed this difference to differences in the reactivity of the species present in the oxidizing plasma. ${ }^{35}$

Oxygen plasma increased the surface free energy and wettability which correlated with increased oxygen functionality. The polar component was dramatically increased while the dispersive component was decreased slightly. ${ }^{38-40}$ Usually, plasma treatment results in etching and pitting the fiber surface. ${ }^{36,38,39}$

Plasma polymerization of organic species is used to deposit polymer films on carbon fibers to tailor the fiber surface chemistry and the properties of the fiber/matrix interphase. $^{32,41,42}$

\subsubsection{Surface Coating}

Organic coatings (sizings) in an amount of $0.5-7 \mathrm{wt} . \%$ are typically applied by the manufacturer by nonelectro- or electro-deposition ${ }^{43,44}$. The most commonly employed coating materials, termed as finish or size, are polyvinyl alcohol, epoxy, polyimide, or water. These coatings are applied to both untreated and surface-treated fibers. It is found that an appropriate size serves several functions ${ }^{45,46}$ : (1) as a binder to keep the filaments together to improve the handleability, (2) as a lubricant to increase abrasion resistance of the fiber, (3) as a coupling agent to promote durable bonding between the fiber and matrix ${ }^{21}$, and (4) as a wetting agent to assist in resin contact with the fiber and thereby improve fiber/matrix adhesion. In recent works, ${ }^{46-48}$ based on the understanding of interfacial phenomena, ductile materials are used as sizing to produce a tough crack resistant interphase with some success in controlling/designing composite properties. 


\subsection{Epoxy Resin Matrix}

The matrix in a composite serves three main functions: (1) it holds the fibers together, (2) it distributes the load between the fibers, and (3) it protects the fibers from the environment.

Although common matrix for fairly low-stress application composites is polyester resin, the majority of advanced composite uses epoxy resin as matrix material. The advantages of epoxies are high bonding strength to reinforcing materials, broad range of properties, good chemical stability, low cure shrinkage, no cure volatile and relatively straightforward processing conditions. ${ }^{49-51}$

Figure 2.6 shows the commercial synthesis of a commonly used epoxy resin diglycidyl ether of bisphenol A (DGEBA). DGEBA is obtained by reacting epichlorohydrin with bisphenol $\mathrm{A}$ in the presence of sodium hydroxide. ${ }^{52}$ The reaction occurs in two steps: (1) the formation of a chlorohydrin intermediate and (2) the dehydrohalogenation of the intermediate to the glycidyl ether.

Epoxy resin requires curing (crosslinking) to obtain useful properties. The curing reactions are normally accomplished by polyadditions of terminal epoxy groups with amine or anhydride curing agents. ${ }^{52}$ For the epoxy-amine system, the reaction between aliphatic amines and epoxy groups will usually proceed at room temperature. However, when rigid aromatic amines are used, heat is needed and resultting in a stronger cured product. The $\mathrm{C}-\mathrm{N}$ bond formed is stable against most inorganic acids and alkalis but is less stable against organic acids than the $\mathrm{C}-\mathrm{O}-\mathrm{C}$ linkage formed by an anhydride curing agent. For the epoxy-anhydride system, acceleration is needed and elevated temperature is usually employed to effect full conversion. The ester bond formed in the anhydride system is stable in organic acids and in some inorganic acids, but decomposes in alkalis. ${ }^{49}$

The properties of the cured resin are directly related to the chemical structure. Several generalizations can be made: ${ }^{49}$ 


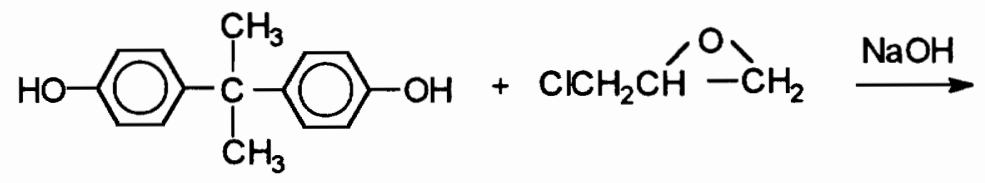

Bisphenol A Epichlorohydrin

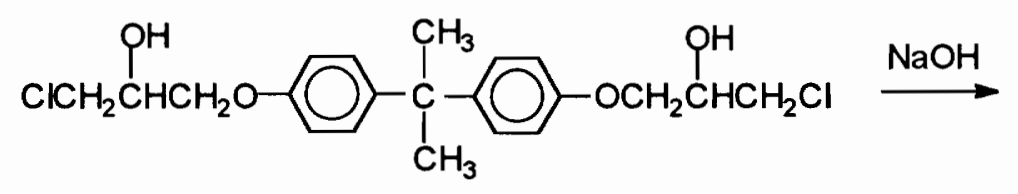

Chlorohydrin Intermediate<smiles>CC(COc1ccc(C(C)(C)C(C)(C)Oc2ccc(C(C)(C)c3ccc(OCC4CO4)cc3)cc2)cc1)C(C)(C)c1ccc(OCC2CO2)cc1</smiles>

Diglycidyl Ether of Bisphenol A (DGEBA)

$+\mathrm{NaCl}, \mathrm{H}_{2} \mathrm{O}$

Figure 2.6 Synthesis of diglycidyl ether of bisphenol A (DGEBA) epoxy resin. 
- The greater the number of aromatic rings a cured epoxy resin contains, the greater is its thermal stability and chemical resistance. The replacement of aromatic molecular sections by aliphatic or cycloaliphatic sections imparts greater flexibility and extensibility to the cured resin, provided that the crosslink density is not increased.

- A higher crosslink density results in better chemical resistance and higher heat distortion temperature.

- A lower crosslink density can improve toughness and reduce shrinkage during cure.

\subsection{Fiber/Matrix Interface in Carbon Fiber Reinforced Polymeric Composites}

\subsubsection{Concept of the Fiber/Matrix Interface}

In composite materials, the term "interface" has been used to designate an "interfacial region" which is intermediate between the matrix and the reinforcement and has properties different from those of the two bulk phases. ${ }^{53}$ The term "interphase" has been recently employed to emphasize the three dimensional nature of this region. ${ }^{2,53}$

The interphase region in a composite was visualized by Herrera-Franco and Drzal using the schematic illustration in Figure 2. $7^{2,54}$ which considers fiber morphology, fiber topography, fiber surface chemistry, adsorbed material, coatings on the fiber, and matrix in close proximity to the fiber surface.

\subsubsection{Role of the Interphase in Composite Materials}

The mechanical performance of composite materials depends not only on the matrix and reinforcing fiber, but also to a great extent on the interfacial adhesion. The fiber/matrix interface functions as the critical region where stresses acting on the matrix are transferred to the stiff fibers. A compromise is needed between a system with high bond strength (for efficient load transfer between fiber, but poor fracture toughness) and systems with lower bond strength (which will not be as efficient, but will give higher fracture toughness). 
If the fiber/matrix interfacial bond strength is too high, a failure crack may propagate through the matrix and fiber without turning. The composite will fracture as a brittle material and failed specimens will show clean fracture surfaces. A weak interphase, on the other hand, reduces many properties including shear, off-axis and compression strength of unidirectional composites, strength and modulus in short fiber composites, and also delamination and splitting resistance. Durability with respect both to fatigue loading and unfavorable environments is also reduced by a poor interface. ${ }^{55,56}$ At an intermediate bond strength, cracks propagating transversely through the resin or fiber may turn at the interface and travel along the fiber direction. This results in absorption of considerable energy. Composites that fail by this mode are tough materials. Failed specimens will show considerable fiber pull-out and the fracture surfaces will be very rough, with lengths of fiber being visible. ${ }^{1-3,57}$

\subsubsection{Generation of Interfacial Adhesion}

As mentioned above, some controllable optimum interphase is desired. Only moderate success has been reported and significant progress here requires a knowledge of exactly what constitutes the optimum interphase. Possible mechanisms which constitute the carbon fiber and polymeric matrix interface are summarized below.

\subsubsection{Interfacial Chemical and Physical Interactions}

Fiber/matrix interfacial adhesion may occur because of the interatomic and intermolecular interactions between fiber and matrix surface atoms and molecules when they achieve sufficiently intimate molecular contact. The most common such forces are van der Waals forces. Also, chemical bonding, hydrogen bonding, and donor-acceptor interactions may occur across the interface. Table 2.2 lists these possible bond types together with an estimated range of magnitude of their respective bond energies. ${ }^{58}$ 
Table 2.2 Bond types and typical bond energies. ${ }^{58}$

Type

Bond Energy

$(\mathrm{kJ} / \mathrm{mol})$

Primary bonds

Ionic

$600-1100$

Covalent

$60-700$

Metallic

$110-350$

Donor-acceptor bonds

Bronsted acid-base interaction

Up to 1000

(i.e. up to a primary ionic bond)

Lewis acid -base interactions

Up to 80

Secondary bonds

Hydrogen bonds

Hydrogen bonds involving fluorine

Up to 40

Hydrogen bonds excluding fluorine

$10-25$

van der Waals bonds

Permanent dipole-dipole interactions

$4-20$

Dipole-induced dipole interactions

Less than 2

Dispersion (London) Forces

$0.08-40$ 
The secondary force interactions universally exist in all systems. Hunstsberger ${ }^{59}$ calculated the attractive forces between two planar bulk phases due solely to dispersion forces. The result showed that even at a separation of one nanometer the attractive forces would result in a joint strength considerably higher than most practical adhesive joints. The poorer adhesive joint strength observed in practice is the result of air voids, defects or geometric features.

The chemical bonding between the matrix and reinforcing fiber is potentially very important in establishing interfacial adhesion. In the case of carbon fiber/amine cured epoxy system, it is believed that strong chemical bonds could be formed during the curing process. These bonds form by the reactions of fiber surface amine and hydroxyl groups with resin epoxide group or/and fiber surface acidic carboxylic and phenolic groups with resin basic amine groups ${ }^{30,60,61}$ as illustrated in Figure 2.8.

Solid state analysis techniques have had difficulty in directly determining the type and extent of chemical bonding at the actual fiber/matrix interface. However, in their research on the effect of surface treatment on interfacial adhesion, Drzal and coworkers ${ }^{62}$ measured the surface oxygen concentration and the fiber/matrix interfacial shear strength (IFSS) of surface treated fibers (HMS and AS). The fibers were heated in hydrogen up to $750^{\circ} \mathrm{C}$ and the IFSS measured with heat treated fibers decreased slightly but not to the value of the untreated fibers (HMU and $\mathrm{AU}$ ) even though the oxygen level was below that of the untreated fibers. The results are shown in Figure 2.9. A similar result was found by Harvey ${ }^{63}$ et al. These results show that carbon fiber surface treatment removed weakly bound crystallites from the original untreated fiber surface and hence provide a superior surface to which the resin could adhere. Kozlowski and Sherwood ${ }^{64}$ also investigated the different mechanisms of removing these crystallites depending on the $\mathrm{pH}$ of the electrolyte used. Some other researchers, on the other hand, have claimed a direct correlation between fiber surface oxygen concentration and interfacial strength. ${ }^{21}$ 


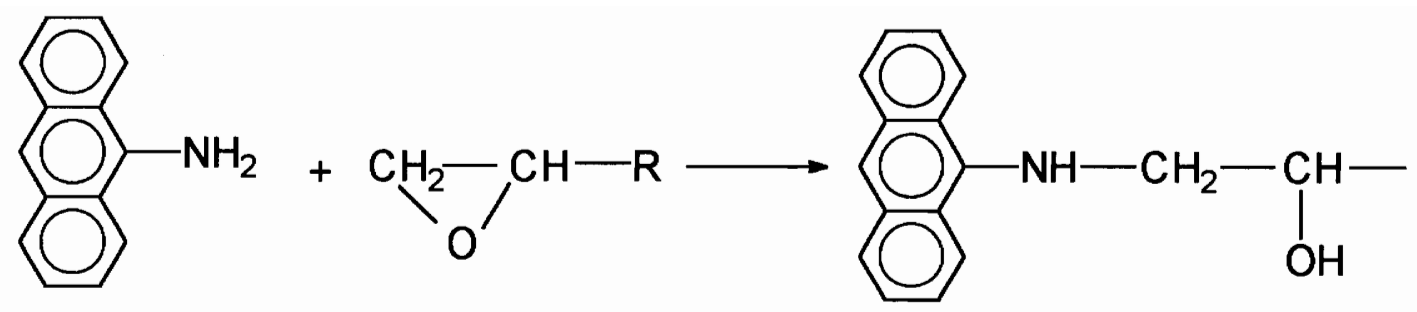

fiber

resin

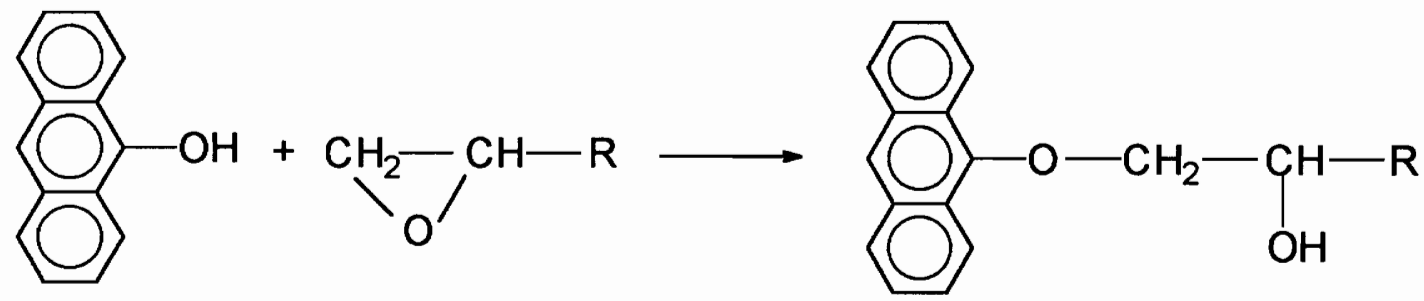

fiber resin

Figure 2.8 Possible chemical interaction of carbon fiber surface functionalities with epoxy $\operatorname{resin}^{60}$. 


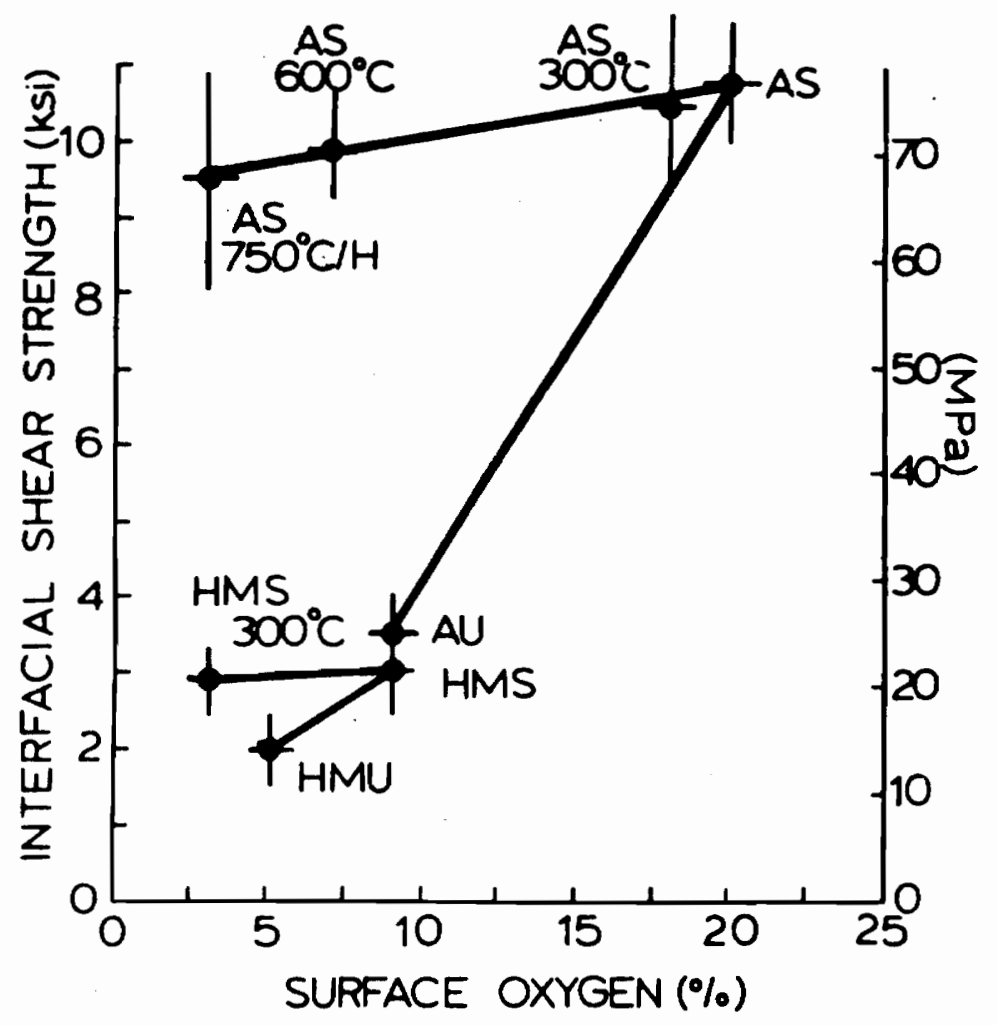

Figure 2.9 Interfacial shear strength plotted as a function of surface oxygen concentration determined by ESCA for carbon fibers. ${ }^{62}$ 


\subsubsection{Mechanical Interlocking due to Fiber Surface Morphology}

Many fibers have a featured surface roughness which lead to "mechanical anchorage" of matrix materials. The importance of this "mechanical interlock" for good and durable adhesion has been one of the major themes of adhesion science. The good adhesion formed against fiber surface irregularities is associated with energy absorption by extensive plastic deformation of the penetrated matrix during failure ${ }^{65}$ or increased number of potential bonding sites along the fiber surface ${ }^{66}$. Results have been reported that improved interfaces result from increased fiber surface roughness by plasma etching ${ }^{67}$ or surface treatment. ${ }^{21,27}$

\subsubsection{Wetting of Fiber Surface by Matrix Material}

The two mechanisms mentioned above are based on good wetting of the reinforcing fiber by the fluid matrix resin for immediate contact which is formed by a high fiber surface energy. ${ }^{68}$ Wetting can be described by reference to a liquid drop resting on a solid surface as shown in Figure $2.10 .^{58}$ The thermodynamic equilibrium at the three-phase contact point is expressed by the Young equation:

$$
\gamma_{\mathrm{SV}}=\gamma_{\mathrm{SL}}+\gamma_{\mathrm{LV}} \cos \theta
$$

where $\gamma_{\mathrm{SV}}, \gamma_{\mathrm{SL}}$ and $\gamma_{\mathrm{LV}}$ represent the surface tensions of the solid/vapor, solid/liquid and liquid/vapor interface. The contact angle is $\theta$ and $\gamma_{\mathrm{Sv}}$ is the surface free energy of the solid substrate in equilibrium with vapor and may be considerably lower than the surface free energy of the solid in vacuum, $\gamma_{\mathrm{s}}$. The difference is defined as the equilibrium spreading pressure, $\Pi_{\mathrm{s}}$ :

$$
\gamma_{\mathrm{s}}=\gamma_{\mathrm{Sv}}+\Pi_{\mathrm{S}}
$$

Thus, Equation 2.1 may be rewritten as:

$$
\gamma_{\mathrm{S}}=\gamma_{\mathrm{SL}}+\gamma_{\mathrm{LV}} \cos \theta+\Pi_{\mathrm{S}}
$$




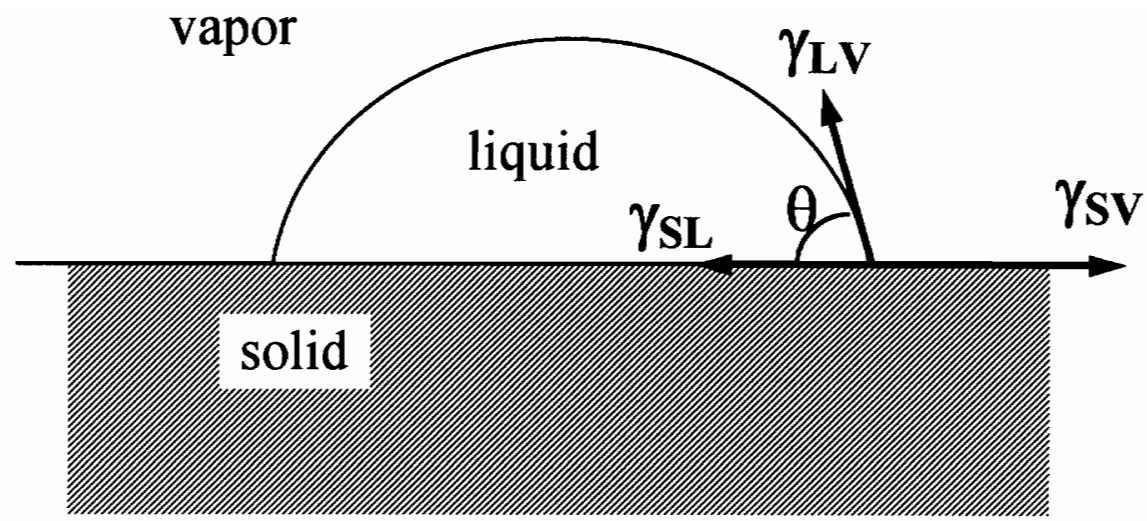

Figure 2.10 Balance of surface tensions in a liquid drop resting at equilibrium on a solid surface. 
When $\theta=0^{\circ}$, the liquid spontaneously spreads over the solid surface and is said to wet completely; nonwetting occurs when $\theta>90$. For spontaneous wetting to occur, the solid surface free energy should be high enough so that:

$$
\gamma_{\mathrm{S}} \geq \gamma_{\mathrm{SL}}+\gamma_{\mathrm{LV}}+\Pi_{\mathrm{S}}
$$

Surface treatments have been proven to be efficient in increasing surface free energies of virgin carbon fibers and subsequent interfacial adhesion.

\subsection{Test Techniques for Evaluating Fiber/Matrix Adhesion}

As mentioned above, mechanical properties especially those dependent on transverse and shear properties of a composite are directly affected by the interfacial adhesion of the fiber/matrix interphase. A key aspect in controlling composite properties is the ability to measure and evaluate the quality of the interface. The effectiveness of interfacial adhesion is usually evaluated by interfacial shear strength (IFSS) which has been measured by either direct or indirect methods with model or real composites.

\subsubsection{Indirect Mechanical Tests of Fiber/Matrix Adhesion}

With indirect mechanical tests, fiber/matrix adhesion information is obtained by measuring properties of real composites which depend in an unequivocal way on the interfacial strength. The most popular method is by far the short beam shear (SBS) or interlaminar shear strength (ILSS) test, which generates a composite shear strength directly related to the interface strength. The $( \pm 45)_{\mathrm{S}}$ tension shear test and Iosipescu shear test are used as well. ${ }^{69}$ The geometry of these tests is described in Figure 2.11

It must however be emphasized that shear strength from these tests also depends on the fiber/matrix shear stiffness ratio (controlling the stress concentrations around the fiber), on the matrix shear strength (an upper boundary), on the composite quality (fiber 


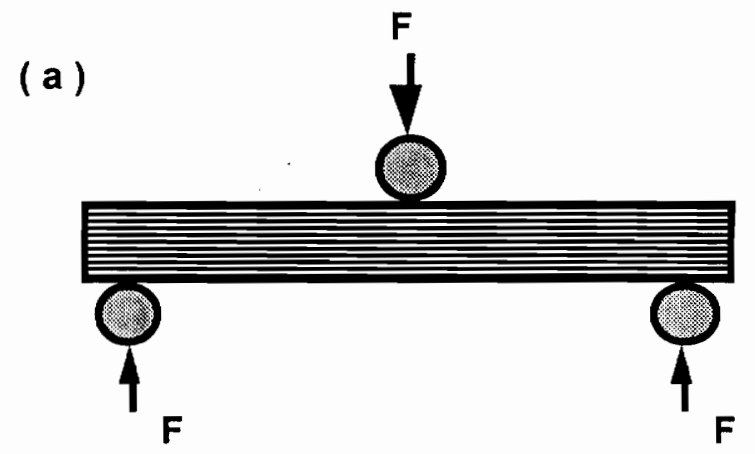

(b)

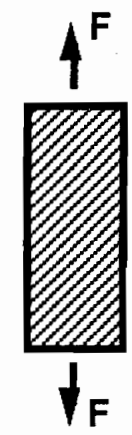

(c)

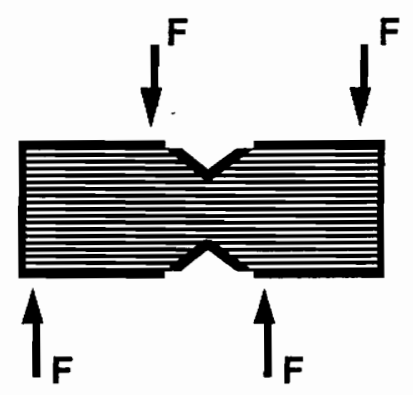

Figure2.11 Schematic representation of indirect tests of interfacial strength. (a) Short beam interlaminar shear test (ILSS). (b) $( \pm 45)_{\text {S }}$ tension shear test. (c) Iosipescu shear test. ${ }^{69}$ 
distribution and void content), and on the fiber compressive strength (controlling premature failure) ${ }^{70}$

\subsubsection{Direct Mechanical Tests of Fiber/Matrix Adhesion}

An extensive number of papers have been published reporting directly measured data on the interfacial shear strength between fiber and matrix using various test methods. To date, the single fiber pull-out test, the single fiber microbonding test, the single fiber fragmentation test, and the micro-indentation test are the four most popular methods used for characterizing the interface of composite materials. These four methods are illustrated schematically in Figure 2.12. Although a full understanding of the load transfer mechanism and failure modes involved in each technique and their relationships to the observed behavior of composite properties is still incomplete, successes have been obtained in evaluating the quality of the fiber/matrix interphase and relevant composite properties.

\subsubsection{Fiber Pull-Out Technique}

The fiber pull-out experiment was perhaps the first one devised to measure interfacial shear strength ${ }^{72}$ during the early stages of polymer composite development. This test is believed to possess some of the characteristics of fiber pull-out in real composites. The test specimen is a single fiber embedded a short distance into or through a block or disk of matrix resin. Load is exerted to pull the fiber out of resin as depicted in Figure 2.12 (a). The value of force needed for debonding is measured and used to calculate the interfacial strength.

The simplest analysis assumes that the shear stress is uniformly distributed over the interface area and the interface fails at a interfacial shear strength $(\tau)$ so that the debonding force $(F)$ is a linear function of embedded length $L$ for a fiber of diameter $2 r$ :

$$
F=2 \pi r \tau L
$$

Such a linear relationship is seldom observed, except at very small embedded lengths. 


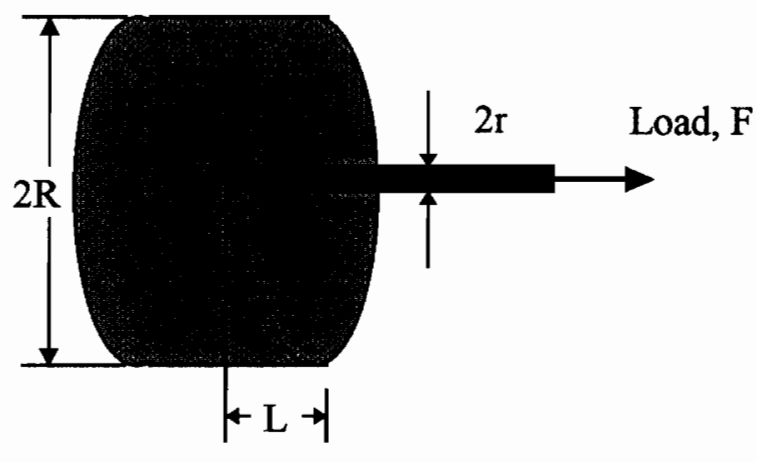

(a) Pull Out

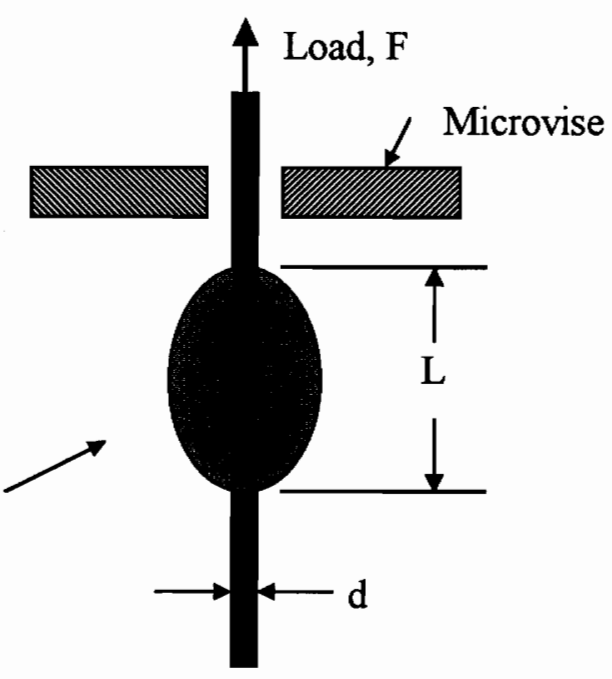

(b) Microbond

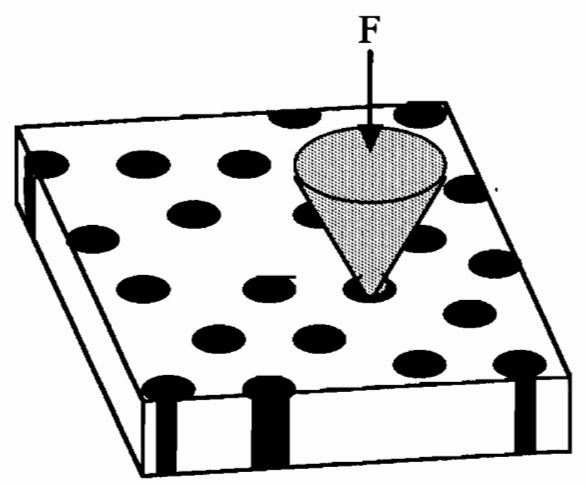

Microdroplet

(c) Micro-indentation

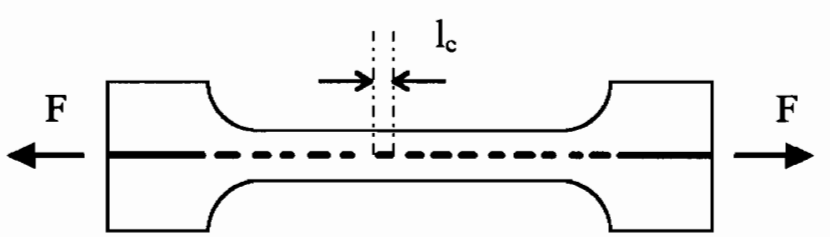

(d) Single Fiber Fragmentation

Figure 2.12 The four commonly used direct tests to measure the interface strength. ${ }^{54,71}$ 
For longer lengths, a maximum stress criterion is used. The interface is assumed to fail when the maximum stress reaches a fail stress. Shear lag analyses, ${ }^{73,74}$ and finite element analyses have been performed to obtain the stress distribution at the fiber-matrix interface. ${ }^{54}$ Energy criteria ${ }^{75}$ instead of stress criterion have been used with some success. The friction at the interface after debonding has been taken into consideration also. ${ }^{76}$

The advantages of the fiber pull-out technique include: (1) it can be used to estimate debonding forces as a function of bonding area while retaining geometric symmetry; (2) it gives independent information about the friction that follows debonding; and (3) it may, in favorable circumstances, be used to estimate interfacial pressure. Its disadvantages include experimental difficulty and high fiber Poisson's shrinkage stresses, which reduce the interfacial pressure.

\subsubsection{Microbonding Technique}

The microbonding technique is a current variation of the fiber pull-out technique developed by Miller et al. ${ }^{77,78}$ to avoid some of the difficulties in fiber pull-out sample preparation. When composite material developed to the stage that a high level of fiber/matrix interfacial adhesion is established and the fiber diameter is small $(<10 \mu \mathrm{m}$ for carbon fibers), the length of fiber embedded in the matrix must be less than a critical length $(50 \text { to } 150 \mu \mathrm{m})^{78}$ in order to pull the fiber out the matrix instead of breaking it. Pullout test specimens with such small fiber embedded depth may be quite difficult to prepare.

Microbonding technique involves preparing a small droplet of resin on a single fiber and then shearing it by a pair of blades to debond as shown in Figure 2.12(b). The interfacial shear strength $\tau$ is calculated from the measured debonding force $F_{\max }$, the embedded length $\mathrm{L}$, and the fiber diameter $\mathrm{d}$ according to:

$$
\tau=F_{\max } / \pi d l
$$

An average value of $\tau$ is determined by many separate pull outs or by evaluating the slope of a best fit linear regression ${ }^{31}$ from plots of $F_{\max }$ versus embedded area as shown in Figure 
2.13. This method has been widely used for measuring interfacial adhesion strength ${ }^{31,71,79}$ because it is a rapid and simple technique. The major advantages and disadvantages of the microbonding technique in additional to that of pull out test are: (1) This technique can be used for almost any fiber/matrix combination; (2) Data scatter is large because the test is very localized and the debonding force is affected by the resin droplet geometry, fiber free length and the width of the gap between the supporting blades; (3) Properties of the resin can be different from that in the composite because of the large surface/volume ratio.

\subsubsection{Micro-indentation Technique}

This is an in situ measurement of the debonding strength on real or single fiber composite specimens first suggested by Mandell et al ${ }^{80}$ Sectioned composite laminates are used in this test where a load is applied to an indenter to debond or slide an individual fiber segment from the supporting matrix as shown in Figure 2.12 (c). The interfacial shear stress is calculated for each fiber under examination using a simplified axisymmetric finite element analysis of the stress field. The parameters used for finite element analysis are indentation load, displacement and fiber, matrix properties ${ }^{80,81}$. Results show that failure is dominated by the interfacial shear stress component which reaches a maximum value at a distance of approximately one-half the fiber diameter below the contact surface. It is assumed that debonding initiates at this point due to the maximum shear stress and quickly spreads over an area of the circumference of fiber and up to the surface.

The microindentation technique has been successfully applies to glass and carbon fibers in various thermosetting, thermoplastic as well as ceramic matrices. ${ }^{80-83}$

This technique has two major advantages: (1) Equipment is commercially available and can be carried out relatively easily, and (2) It may be applied to fibers in a real composite so that the result represents the real microstructural features and fabrication conditions. Its disadvantages are: (1) The results could be sensitive to the sample 

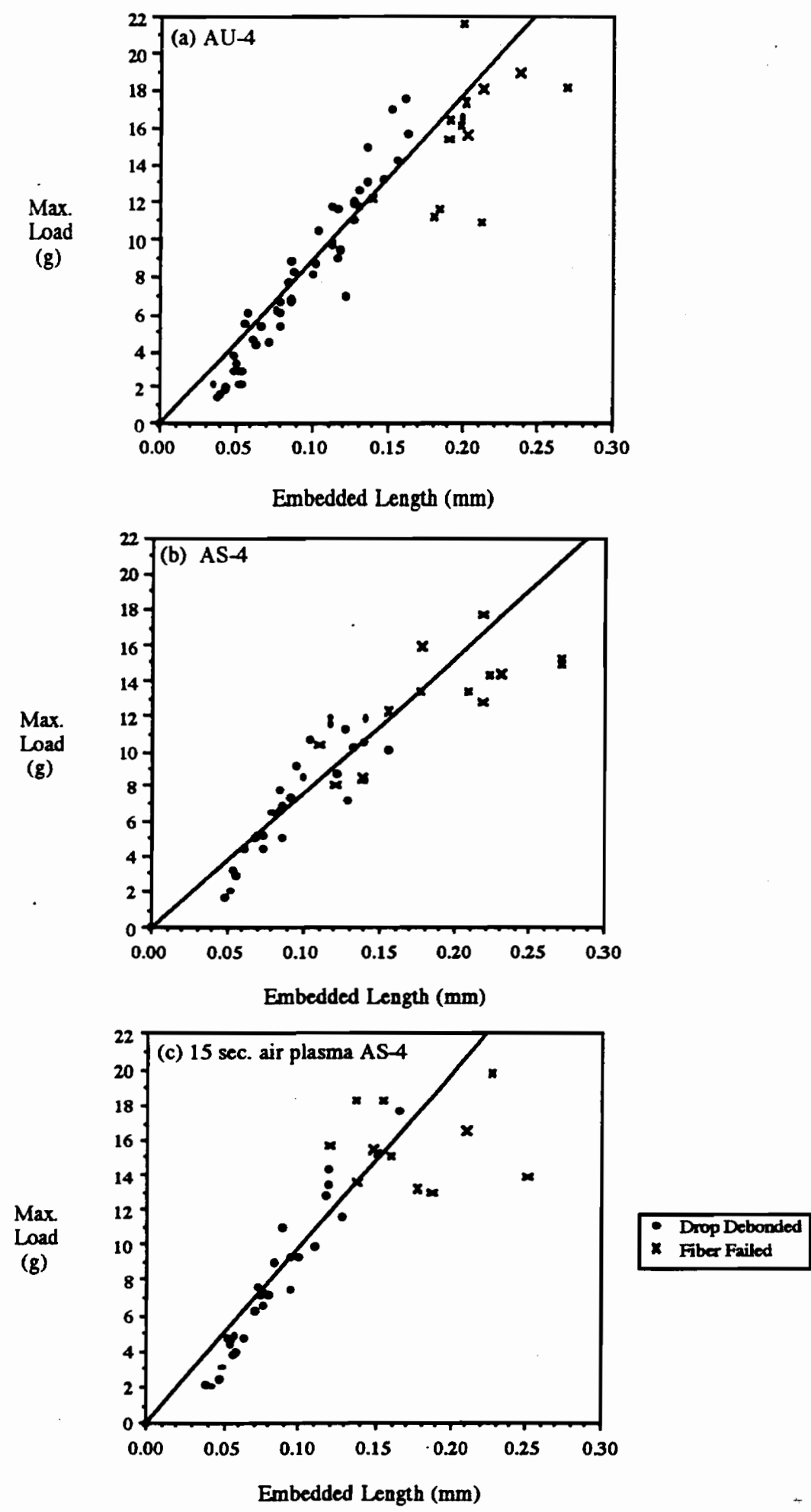

Figure 2.13 Maximum load versus the embedded length in microbond test, (a) AU-4, (b) AS-4, and (c) $15 \mathrm{sec}$. air plasma treated AS-4 carbon fibers with quenched poly(pyridine-bis A). ${ }^{31}$ 
preparation and polishing, and (2) It produces a Poisson expansion which increases the interfacial pressure.

\subsubsection{Single Fiber Fragmentation Technique}

The single fiber fragmentation technique and its analysis procedure have been used with small variations by many authors to investigate the influence of matrices ${ }^{84,85}$, fibers ${ }^{86,87}$ and fiber surface treatment ${ }^{30,62,88}$ on interfacial adhesion. With this method, the stress transfer capacity of the fiber/matrix interface is evaluated by a model single fiber composite. The specimen is usually a dog bone shaped coupon which is composed of a single fiber embedded in a polymeric matrix as shown in Figure 2.12 (d). When the specimen is pulled in tension axially, the tensile load is transmitted to the fiber by the fiber/matrix interface. The tensile stress is much more concentrated in the fiber because of the large difference in moduli between the two materials. As a result, increasing stress will result in the fiber fracture at some point. Further increase in stress will result in repetition of this process until a limiting size is reached which is defined as critical fragment length, $l_{c}$, as shown in Figure 2.14. The interface of fragments with length shorter than the "critical length" can not transmit stress high enough to break the fiber. The capacity of the fiber/matrix interface to transfer stress can be reflected by this critical length in terms of the interfacial shear strength, $\tau$ :

$$
\tau=\frac{\sigma_{f}}{2} \frac{d}{l_{c}}
$$

where $d$ is the fiber diameter and $\sigma_{\mathrm{f}}$ is the fiber strength at critical length. The critical length $l_{c}$ can be conveniently measured to get the interfacial shear strength and thus the adhesion strength of fiber/matrix interface can be evaluated.

This technique was originally developed by Kelly and $\operatorname{Tyson}^{89}$ who observed a multiple fiber fracturing phenomenon in a system consisting of a low concentration of brittle tungsten fibers imbedded in a copper matrix. They also proposed the quantitative 

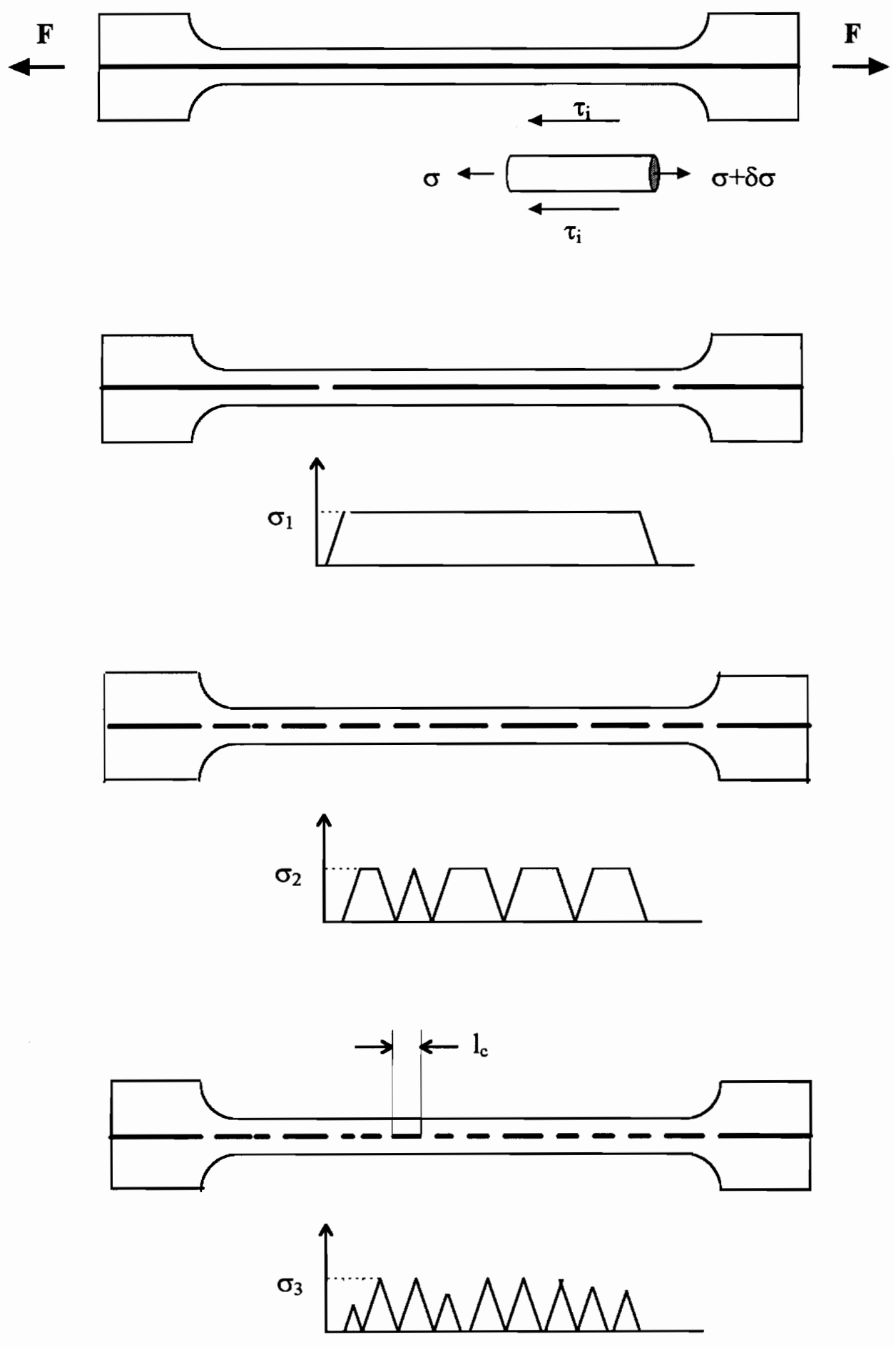

$$
\sigma_{1}<\sigma_{2}<\sigma_{3}
$$

Figure 2.14 Fiber break process in a single fiber fragmentation test specimen. 
derivation associated with the fiber fracturing process assuming that the interface shear stress is uniformly distributed along the fragment and that the stress transfer is limited by perfectly plastic matrix shear yield stress as shown in Figure 2.15(a). The fiber breaks if the tensile stress builds up to the fiber tensile strength $\sigma_{\mathrm{f}}$ and the critical fiber length $l_{\mathrm{c}}$ is approximated by:

$$
\sigma_{\mathrm{f}}=\tau 1_{\mathrm{c}} / \mathrm{r}
$$

or,

$$
l_{\mathrm{c}}=\mathrm{r} \sigma_{\mathrm{f}} / \tau
$$

Fiber fragment lengths ranging from $l_{d} / 2$ to $l_{c}$ are formed since fragments longer than $l_{c}$ would break into two pieces.

Polymer composite researchers adopted the procedure and equation to evaluate the quality of interface by calculating the $\tau$ value from experimentally measured values of $1_{c}$. The $\tau$ is no longer a matrix property, but an interfacial property defined as interfacial shear strength. The use of equation (2.7) implies a constant shear stress across the interface which can hardly be met in real fiber/matrix systems.

Many analytical models have been developed to estimate the actual non-uniform stress distribution(Figure 2.15 (b)) in the fiber fragmentation test. $\mathrm{Cox}^{90}$ utilized an elastic shear lag analysis to predict the shear along the length of an embedded fragment. Some researchers used partial debonding or total debonding mold and took into consideration the frictional forces ${ }^{91,92}$. Whitney and Drzal ${ }^{93}$ presented a stress function approach to predict more accurately the axisymmetric stress distribution around an isolated fiber segment. More recently, Nairn ${ }^{94}$ developed a three-dimensional axisymmetric solution for the stresses around breaks in an embedded fiber using variational mechanics. Several finite element analyses of the stress state around embedded fiber fragments have also been carried out. ${ }^{95,96}$ The influence of the interphase region has also been investagated. ${ }^{97,98}$ 
(a)

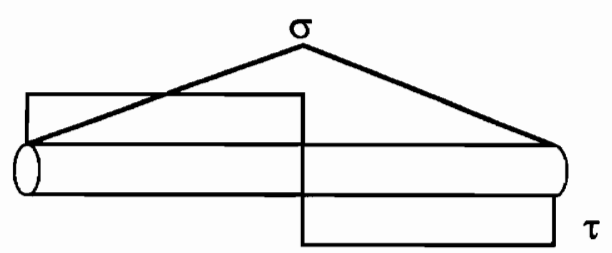

(b)

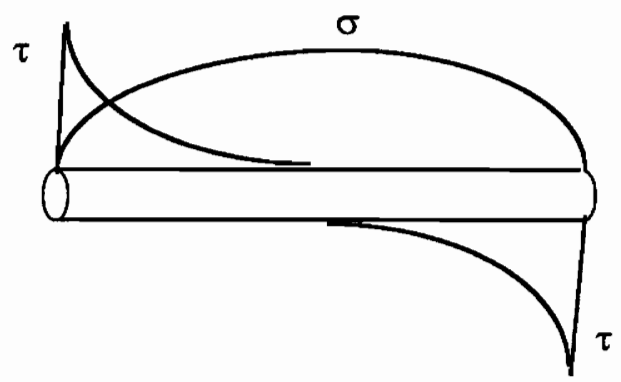

Figure 2.15 Shear $(\tau)$ and tensile $(\sigma)$ stress distribution along a fiber fragment in single fiber fragmentation test. (a) Kelly's model and (b) Real segment. 
Advantages of this test are: (1) Many data points are generated over a wide range of points along a single fiber, so the results are less sensitive to local variations in the fiber surface; (2) With transparent matrices, the failure process can be observed under polarized light; (3) Fewer measurement parameters are involved in the characterization.

Disadvantages include: (1) the specimen has to be loaded to a fairly large strain level (above $3 \%$ ) to allow sufficient fiber breaking, thus only relatively flexible resins can been used; (2) The fiber strength needs to be known at the critical length; (3) Transverse normal stresses could be higher due to Poisson effects, resulting in a higher interfacial shear stress; (4) The matrix should be transparent for observing fiber breakage.

Many efforts have been devoted to overcome the inherent shortcomes of the technique. For brittle matrix systems, the methods developed by Jacques and Favre ${ }^{99}$, and Lee and Holguin ${ }^{100}$, used a single fiber coated or laminated with brittle resin and then embedded in a bulk ductile resin for a fragmentation test. An acoustic emission technique has been developed for the measurement of fiber fragment length distributions in opaque matrices. ${ }^{101,102}$ It has been observed that the acoustic and direct optical observations lead to consistent results. Some variations of the single fiber fragmentation test ${ }^{103,104}$ have been developed to avoid the intrinsic problems such as the fiber strength at critical length, the stress distribution along fiber fragments and the critical fragment state in a typical single fiber fragmentation test. 


\section{Chapter 3: Experimental}

\subsection{Materials}

\subsubsection{Carbon Fibers}

Two untreated [AU-4, Panex 33(U)] and two commercially surface treated [AS-4, Panex 33(S)] Polyacrylonitrile (PAN) based medium modulus carbon fibers were used for this study. The fiber sources and some properties provided by the producers are summarized in Table 3.1. ${ }^{105.106}$ To study the effect of surface sodium, AS-4-Na fiber was prepared from AS-4 by electro-adsorption conducted under $-1.5 \mathrm{~V}$ in $10 \mathrm{wt} . \% \mathrm{Na}_{2} \mathrm{CO}_{3}$ solution for 10 minutes.

\subsubsection{Epoxy Matrixes}

Amine cured epoxy systems were selected for this study. This chemistry is representative of the majority of aerospace applications. ${ }^{107}$ A difunctional epoxy, diglycidyl ether of bisphenol-A (DGEBA), Epon ${ }^{\circledR} 828$, was cured with a stoichiometric amount of either an aromatic amine, $\operatorname{mPDA}(1,3-$ phenylene diamine), or an aliphatic amine, Jeffamine ${ }^{\circledR}$ DU-700 (an amine terminated urea condensate of polypropylene glycols). The details and structures of these resin components are shown in Table 3.2 and Figure 3.1. The cure schedule for all cases was two hours at $75^{\circ} \mathrm{C}$ and two hours at $125^{\circ} \mathrm{C}$. 
Table 3.1 Carbon fibers and properties. ${ }^{105,106}$

\begin{tabular}{lcccc}
\hline Fiber & Producer & $\begin{array}{c}\text { Surface Oxidative } \\
\text { Treatment }\end{array}$ & $\begin{array}{c}\text { Tensile Modulus } \\
(\mathrm{GPa})\end{array}$ & $\begin{array}{c}\text { Tensile Strength } \\
(\mathrm{GPa})\end{array}$ \\
\hline AU-4 & Hercules & Untreated & 221 & 3.93 \\
AS-4 & Hercules & Treated & 221 & 3.93 \\
Panex 33(U) & Zoltek & Untreated & na & na \\
& & Treated & 228 & 3.6 \\
\hline
\end{tabular}


Table 3.2 Epoxy resin and curing agents.

\begin{tabular}{lccc}
\hline & Manufacturer & $\begin{array}{c}\text { Molecular Weight } \\
(\mathrm{g} / \mathrm{mole})\end{array}$ & $\begin{array}{c}\text { Stoichiometric } \\
\text { Ratio Amount }\end{array}$ \\
\hline Epon $^{\circledR} 828$ & Shell Chemical Co. & $\sim 380$ & 100 \\
mPDA & Aldrich Chemical Co. & 108.14 & 14.5 \\
Jeffamine & Texaco Chemical Co. & 920 & 124 \\
\hline
\end{tabular}


(a)

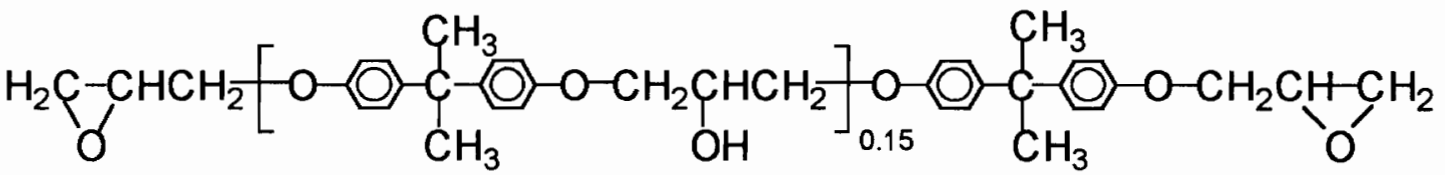

(b)<smiles>NCc1cccc(N)c1</smiles>

(c)

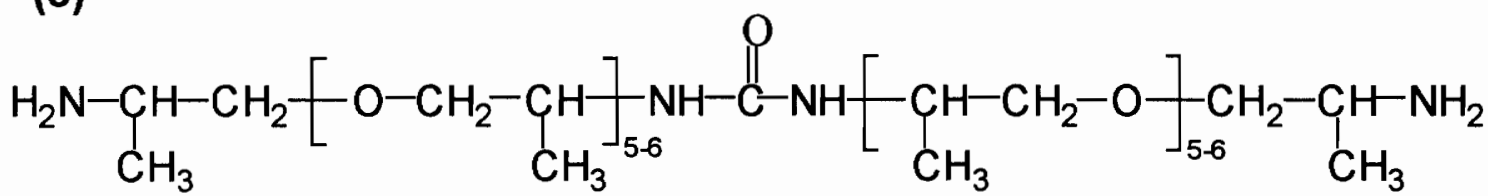

Figure 3.1 The structure of (a) epoxy resin Epon 828, (b) amine curing agent mPDA, and (c) amine curing agent Jeffamine DU-700. 


\subsection{Carbon Fiber Characterization}

\subsubsection{Surface Chemistry by X-ray Photoelectron Spectroscopy (XPS)}

The carbon fiber surface chemistry was measured by a Perkin-Elmer PHI $5400 \mathrm{x}$ ray photoelectron spectrometer with an achromatic $\mathrm{Mg} \mathrm{K \alpha}$ x-ray source $(1253.6 \mathrm{eV})$. All spectra were collected with the $\mathrm{x}$-ray source operated at $15 \mathrm{kV}$ and $400 \mathrm{~W}$. The spot size used was $1 \mathrm{~mm} \times 3 \mathrm{~mm}$ and the take-off angle was $45^{\circ}$ unless otherwise noted. The spectrometer was typically run at the $10^{-8}$ torr vacuum range.

Three segments of $12 \mathrm{~K}$ carbon fiber tow were positioned $60^{\circ}$ to each other on an aluminum sample mount and were held in place by an aluminum ring. The sample was aligned so that the top bunch of fiber was $45^{\circ}$ to the position of photoelectron analyzer because it was found that there was less deviation in atomic concentration with about $10^{\circ}$ change in alignment angle compared with the case when the fiber was either parallel $\left(0^{\circ}\right)$ or $90^{\circ}$ to the axis of the analyzer.

For each sample, a wide survey scan $(0-1100 \mathrm{eV}, 44.75 \mathrm{eV}$ pass energy) was first carried out for element identification. Narrow multiplex scans (ranging from 20 to $30 \mathrm{eV}$ ) were then taken for all the significant peaks for atomic concentration analysis and curve fitting. Data acquisition and analysis were performed with an Apollo 3500 series computer, using PHI software version 4.0. Binding energies were normalized to that of graphite carbon at $284.6 \mathrm{eV}$.

\subsubsection{Surface Topography by Scanning Electron Microscopy (SEM)}

An ISI SX-40 scanning electron microscope was used to examine the fiber surface topography. Carbon fibers were secured on a copper sample holder by $\operatorname{Scotch}^{\text {TM }}$ tape and sputter coated with gold to eliminate charging by incident electron beam. The secondary electron imaging was obtained at usually $15 \mathrm{kV}$ accelerating voltage and $10 \mathrm{~K}$ magnification. 
Two methods were employed to get fiber diameters in this study. The first one was measuring the fiber diameter directly from SEM photomicrographs. The second method was calculating the diameter from the wetting forces of the fibers by hexane with an assumed zero contact angle against the fibers. Fiber diameters from the SEM were used for calculations of fiber tensile strength and interfacial shear strength; diameters from wetting forces were used for calculations in fiber surface energy analysis.

\subsubsection{Surface Energy by Two Liquid Dynamic Contact Angle Analysis}

The two-liquid tensionmetric technique developed by Schultz et al. ${ }^{108}$ was used to access carbon fiber surface energies and their dispersive and polar components. This method is based on the measurement of the wetting force of a single fiber by an immiscible two-liquid system as shown in Figure 3.2. The upper liquid was a series of non-polar nalkanes and the bottom liquid was polar formamide. The liquids used and their surface energies are listed in Table 3.3. The theories involved in this measurement are briefly described below.

It was proposed by Fowkes ${ }^{109}$ and Schultz et al. ${ }^{110}$ that the surface free energy of a pure phase, $\gamma_{a}$, could be represented by the sum of the contributions from different types of force components, generally a dispersion and a polar component, such that:

$$
\gamma_{\mathrm{a}}=\gamma_{\mathrm{a}}{ }^{\mathrm{d}}+\gamma_{\mathrm{a}}{ }^{\mathrm{p}}
$$

This assumption holds true for low energy surface like polymers. It is assumed that this assumption holds true for graphite fibers also since they are more similar to polymer surfaces than to high energy surfaces where this assumption is not valid. ${ }^{19}$

Fowkes ${ }^{111}$ later proposed that the geometric mean of the dispersion force components is a reliable prediction of the interaction energies at the $a / b$ interface caused by dispersion forces. Thus, for interactions involving only dispersion forces:

$$
\gamma_{a b}=\gamma_{a}+\gamma_{b}-2\left(\gamma_{a}^{d} \gamma_{b}^{d}\right)^{1 / 2}
$$




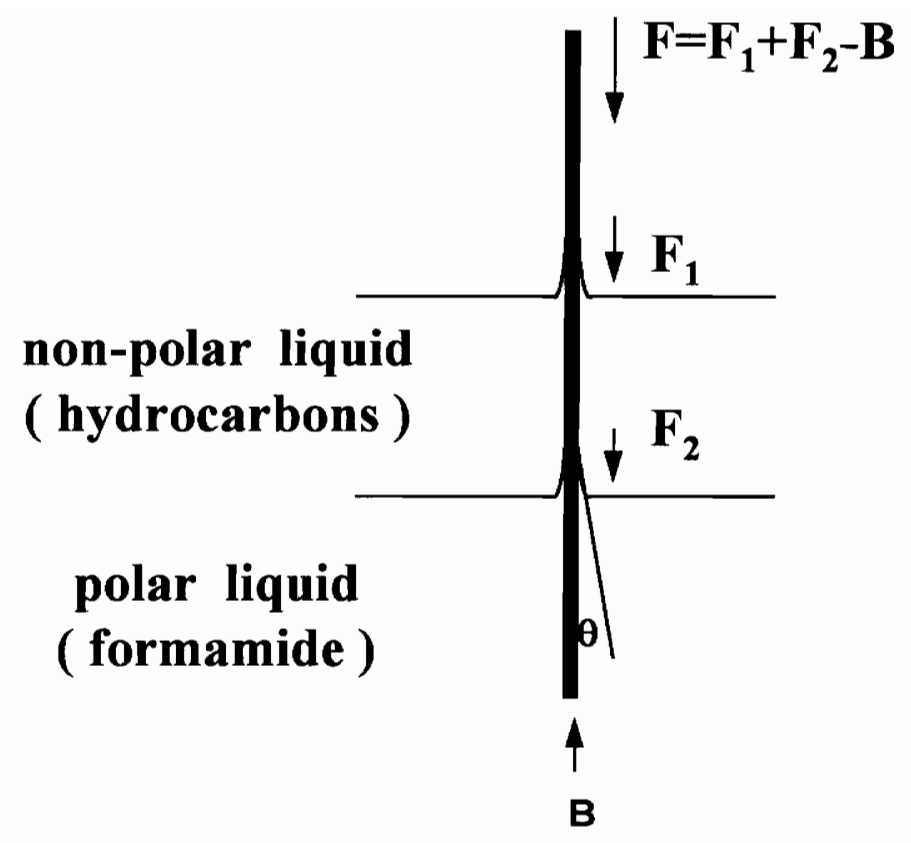

Figure 3.2 Schematic illustration of a single fiber in an immiscible two liquid system. 
Table 3.3 Surface free energies of liquids used for two-liquid dynamic contact angle test. $^{58}$

\begin{tabular}{|c|c|c|c|c|c|}
\hline \multirow[b]{2}{*}{ Liquid } & \multirow[b]{2}{*}{ Source } & \multirow[b]{2}{*}{ Purity } & \multicolumn{3}{|c|}{ Surface free energy $\left(\mathrm{mJ} / \mathrm{m}^{2}\right)$} \\
\hline & & & $\gamma_{L}^{d}$ & $\gamma_{\mathrm{L}}^{\mathrm{p}}$ & $\gamma_{\mathrm{L}}$ \\
\hline & & $99+\%$ & & & \\
\hline formamide & Aldrich & $\begin{array}{c}\text { spectrophotometric } \\
\text { grade }\end{array}$ & 32.3 & 26.0 & 58.3 \\
\hline n-hexane & Fisher & optima & 18.4 & 0.0 & 18.4 \\
\hline n-octane & Aldrich & $\begin{array}{c}99+\%, \\
\text { gold label }\end{array}$ & 21.8 & 0.0 & 21.8 \\
\hline n-decane & Fisher & certified & 23.9 & 0.0 & 23.9 \\
\hline n-dodecane & Aldrich & $99 \%$ & 25.4 & 0.0 & 25.4 \\
\hline n-tetradecane & Aldrich & $99 \%$ & 26.7 & 0.0 & 26.7 \\
\hline n-hexadecane & Fisher & certified & 27.6 & 0.0 & 27.6 \\
\hline
\end{tabular}


Tamai et al. ${ }^{112}$ introduced an energy term, $-\mathrm{I}_{\mathrm{ab}}$, into Equation 3.2 to account for the interaction by non-dispersion forces. Owens and Wendt ${ }^{113}$, by analogy with the work of Fowkes, have proposed that $I_{a b}$ may be expressed by the relation $2\left(\gamma_{a}^{p} \gamma_{b}^{p}\right)^{1 / 2}$ and Equation 3.2 becomes:

$$
\gamma_{a b}=\gamma_{a}+\gamma_{b}-2\left(\gamma_{a}^{d} \gamma_{b}^{d}\right)^{1 / 2}-2\left(\gamma_{a}^{p} \gamma_{b}{ }^{p}\right)^{1 / 2}
$$

In the solid carbon fiber/hydrocarbon/formamide system, by combining Equation 3.3 with the Young equation (Equation 2.1) at the fiber/hydrocarbon/formamide three phase line and neglecting the spreading pressure, the following equation can be deduced:

$$
\gamma_{\mathrm{F}}-\gamma_{\mathrm{H}}+\gamma_{\mathrm{H} / \mathrm{F}} \cos \theta_{\mathrm{S} / \mathrm{H} / \mathrm{F}}=2\left(\gamma_{\mathrm{S}}{ }^{\mathrm{d}}\right)^{1 / 2}\left[\left(\gamma_{\mathrm{F}}^{\mathrm{d}}\right)^{1 / 2}-\left(\gamma_{\mathrm{H}}\right)^{1 / 2}\right]+2\left({\gamma_{\mathrm{F}}}^{\mathrm{p}} \gamma_{\mathrm{S}}^{\mathrm{p}}\right)^{1 / 2}
$$

where $\gamma_{F}, \gamma_{F}^{d}, \gamma_{F}^{p}$ are the surface free energy of formamide and its dispersive and nondispersive components respectively, $\gamma_{\mathrm{H}}$ is the surface free energy of the hydrocarbon, $\gamma_{\mathrm{S}}{ }^{\mathrm{d}}$, $\gamma_{\mathrm{S}}^{\mathrm{p}}$ are the dispersive, non-dispersive components of carbon fiber surface free energy respectively, and, $\gamma_{\mathrm{H} / \mathrm{F}}$ is the interfacial energy of hydrocarbon/formamide.

When a fiber is immersed in the two liquid system, the total exerted force is composed of three components, $F_{1}$, the wetting force at the fiber/air/hydrocarbon interface, $F_{2}$, the wetting force at the fiber/hydrocarbon/formamide interface, and $B$, the effect of buoyancy acting on the length of fiber immersed. In the present case, B is negligible since the fiber diameter is so small $(7 \mu \mathrm{m})$ that $\mathrm{B}$ is of the order of $10^{-8} \mathrm{~N}$ whereas $F_{1}$ and $F_{2}$ are of the order of $10^{-4} \mathrm{~N}$.

At the fiber/hydrocarbon/formamide interface, $F_{2}$ is given by:

$$
\mathrm{F}_{2}=\mathrm{p} \quad \gamma_{\mathrm{H} / \mathrm{F}} \cos \theta_{\mathrm{S} / \mathrm{H} / \mathrm{F}}
$$

where $\mathrm{p}$ is fiber perimeter and $\theta_{\mathrm{S} / \mathrm{H} / \mathrm{F}}$ is the contact angle at this interface. Substituting Equation 3.5 into Equation 3.4 gives: 


$$
\gamma_{F}-\gamma_{H}+F_{2} / p=2\left(\gamma_{S}^{d}\right)^{1 / 2}\left[\left(\gamma_{F}^{d}\right)^{1 / 2}-\left(\gamma_{H}\right)^{1 / 2}\right]+2\left(\gamma_{F}^{p} \gamma_{S}^{p}\right)^{1 / 2}
$$

A plot of experimentally measured data $\left[\gamma_{F}-\gamma_{H}+F_{2} / p\right]$ versus $\left[\left(\gamma_{F}^{d}\right)^{1 / 2}-\left(\gamma_{H}\right)^{1 / 2}\right]$ will yield a straight line with the slope and intercept providing a solution to the fiber surface energy terms $\gamma_{\mathrm{s}}^{\mathrm{d}}$ and $\gamma_{\mathrm{s}}^{\mathrm{p}}$.

For the measurement of fiber surface energy by this method to be valid, the formamide should displace the hydrocarbon during fiber advancing and hydrocarbon should displace formamide during fiber receding. The displacement criteria have been derived by Shanahan et al. ${ }^{114}$ and are given below:

advancing:

$$
I_{S / F}^{p}>2\left[\sqrt{\gamma_{S}^{d}}-\sqrt{\gamma_{H}}\right]\left[\sqrt{\gamma_{H}}-\sqrt{\gamma_{F}^{d}}\right]
$$

receding:

$$
I_{S / F}^{p}<2\left\{\gamma_{F}^{p}-\left[\sqrt{\gamma_{S}^{d}}-\sqrt{\gamma_{F}^{d}}\right]\left[\sqrt{\gamma_{F}^{d}}-\sqrt{\gamma_{H}}\right]\right\}
$$

A single carbon fiber carefully cut and handled to avoid damage or contamination was attached to a nichrome wire with a fast curing cyanoacrylate adhesive. The two-liquid tensionmetric test was performed on a Cahn 322 Dynamic Contact Angle Analyzer. The nichrome wire/fiber was suspended from the arm of the microbalance while a precise elevator raised or lowered the test liquids at a speed of $20 \mu \mathrm{m} / \mathrm{min}$ to probe the fiber. Wetting force data were recorded at 1 second intervals for dynamic and static advancing immersion and receding emersion contact angles. The static advancing wetting forces, the plateau force reading when the advancing immersion was stopped, were used to calculate the carbon fiber surface energies. Fiber perimeters were determined using the wetting forces by hexane, assumed to completely wet the fibers.

There were two concerns in using the literature liquid surface energy data: (1) the liquids are not $100 \%$ pure and the nature of the impurity might be different from that of the literature sources and, (2) the alkane/formamide systems are not absolutely immiscible. The slight mutual dissolution might change the surface energies. For verification purpose, the surface energies of alkanes in equilibrium with formamide and formamide after being 
mixed with decane were measured by the Wilhelmy slide method. Cover glass slides were used for the $\mathrm{C}_{6}-\mathrm{C}_{12}$ alkanes and freshly gold coated cover glass slides were used for the $\mathrm{C}_{14}-\mathrm{C}_{16}$ alkanes and formamide because hysteresis was observed for these latter liquids measured with cover glass slides.

\subsubsection{Tensile Strength Measurement}

The carbon fiber tensile strength $\left(\sigma_{\mathrm{f}}\right)$ at the critical length is needed to get the interfacial shear strength $\tau$. Since fiber strength is a function of gauge length and direct measurement of $\sigma_{\mathrm{f}}$ at gauge length of $l_{\mathrm{c}}$ is difficult, it is necessary to extrapolate fiber strengths measured at longer gauge lengths. In this study, the estimation of the fiber strength at $l_{c}$ has been made using a linear logarithmic dependence of tensile strength on gauge length. This method of extrapolation was proposed by Asloun $e t$ al ${ }^{115}$ who considered several types of extrapolation and found that this was the simplest and most accurate method.

The linear logarithmic extrapolation is based on the weakest link theory of strength. A commonly used statistical model for strength is a two-parameter Weibull equation:

$$
\mathrm{F}=1-\exp \left[-\mathrm{L}(\sigma / \beta)^{\alpha}\right]
$$

where $F$ is the probability of failure up to a stress level $\sigma, L$ is the fiber gauge length, $\beta$ is a scale parameter, and $\alpha$ is a shape parameter. From this equation, a plot of $\ln \ln (1 / 1-F)$ versus $\ln \sigma$ should yield a straight line. The parameters $\beta$ and $\alpha$ can be derived by the maximum likelihood or linear regression approach.

The mean value $\bar{\sigma}$, of the carbon fiber can be calculated from these parameters by using:

$$
\bar{\sigma}=\beta \mathrm{L}^{-1 / \alpha} \Gamma\left(1+\frac{1}{\alpha}\right)
$$


with a standard deviation of:

$$
S=\left\{\beta^{2}\left[\Gamma\left(\frac{\alpha+2}{\alpha}\right)-\Gamma^{2}\left(\frac{\alpha+1}{\alpha}\right)\right]\right\}^{1 / 2}
$$

Equation 3.10 shows that a plot of $\ln \bar{\sigma}$ versus $\ln \mathrm{L}$ should be a straight line with a slope of $-1 / \alpha$.

Fiber tensile strengths were measured of single filaments at gauge lengths of $\mathrm{mm}, 12 \mathrm{~mm}, 20 \mathrm{~mm}$, and $44 \mathrm{~mm}$. A fiber was attached to aluminum tabs with a room temperature cure epoxy adhesive. The distance between the tabs was determined by a PTFE spacer to define the gauge length. The setup was held by two strips of construction paper as shown in Figure 3.3 (a). In the case of the $1 \mathrm{~mm}$ gauge length, the fiber was mounted across a cut of a paper tab.

After the adhesive cured, one of the tabs was hung to a Mettler PM300 balance and the other tab was griped by a microvise which could be moved vertically by an adjustable motor controlled elevator. The schematic representation of the measurement apparatus is shown in Figure 3.3 (b).

When the sample was secured in position, the strips of paper were burnt with a solder iron and the fiber was pulled in tension by moving the microvise downward. Force was measured by the balance and recorded by a personal computer. The carbon fiber strength at gauge length of $44 \mathrm{~mm}$ was measured at a cross-head speed of $10 \mu \mathrm{m} / \mathrm{sec}$ and strengths at all other lengths were measured at $5 \mu \mathrm{m} / \mathrm{sec}$. Twenty data points were collected for each gauge length. 


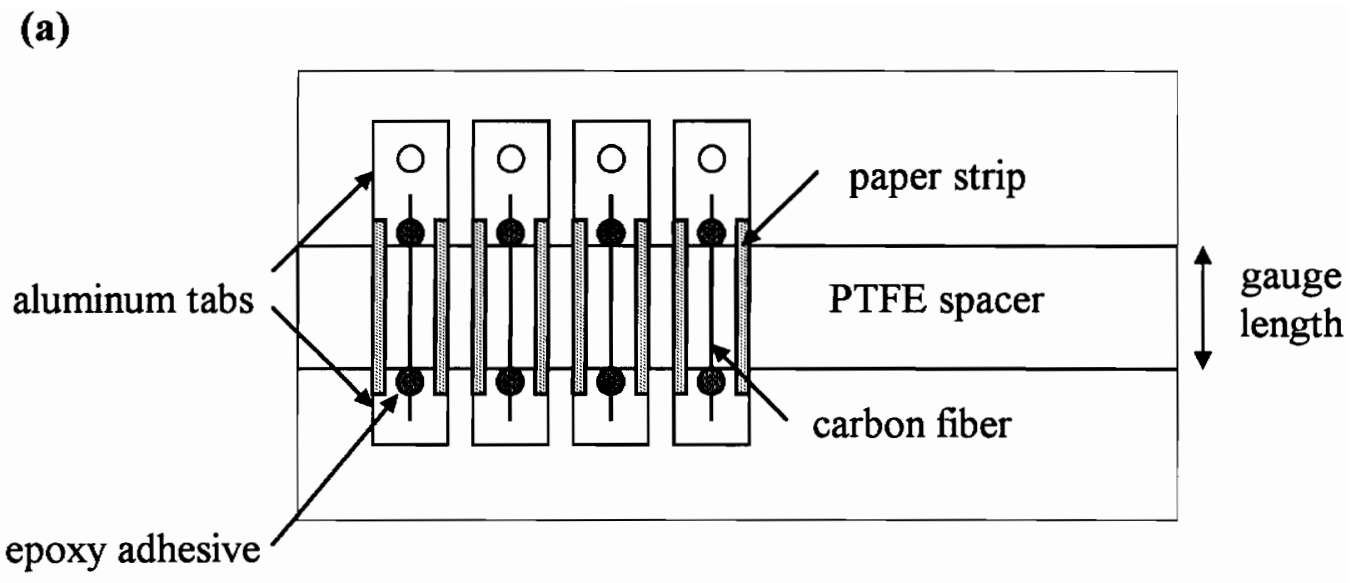

(b)

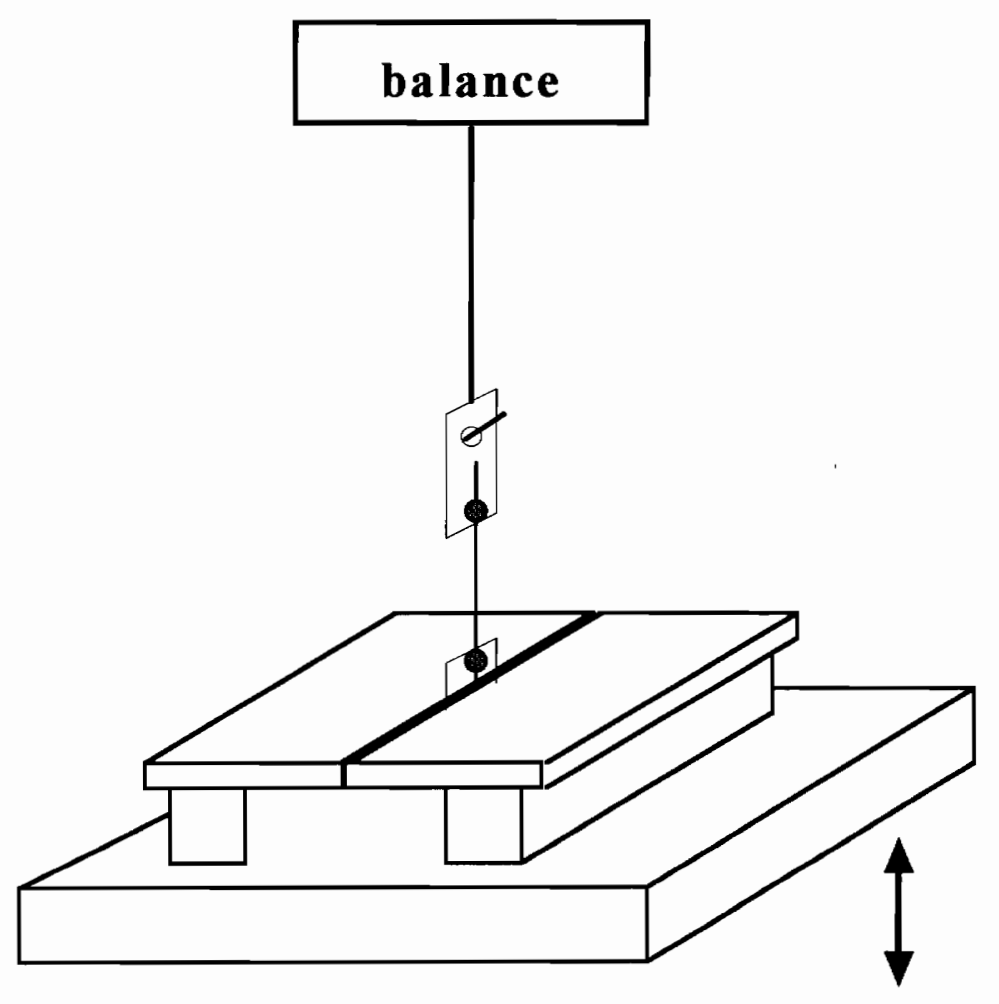

Figure 3.3 Single fiber tensile strength measurement. (a) sample preparation (b) measurement. 


\subsection{Matrix Characterization}

\subsubsection{X-ray Photoelectron Spectroscopy (XPS)}

Cured matrix resin surface chemistry was analyzed by XPS using the same conditions described in Section 3.2.1 except that the sample was attached to the aluminum mount by a piece of Scotch ${ }^{\mathrm{TM}}$ double stick tape.

\subsubsection{Fourier Transform Infrared Spectroscopy (FTIR)}

To investigate possible structural changes in the epoxy resin by humidity and humidity/temperature, the outer layer of the resin from the humidity and humidity/temperature exposed dog-bone samples was analyzed by FTIR using $\mathrm{KBr}$ pellets. The spectra were obtained using a Nicolet 5DXB Fourier transform infrared spectrometer with a resolution of $2 \mathrm{~cm}^{-1}$. The spectrometer was purged with dry nitrogen prior to and during the measurement.

\subsubsection{Surface Energy Analysis}

Surface energy analysis of the cured epoxy resins used was done by measuring the contact angle with a series of wetting liquids having known dispersive and polar surface free energy components.

This method for polymer surface energy measurement was proposed by Owens and Wendt. ${ }^{113}$ By combining equation 3.3 with the Young equation, the following equation can be derived:

$$
\frac{\gamma_{L}(1+\cos \theta)}{2 \sqrt{\gamma_{L}^{d}}}=\sqrt{\gamma_{S}^{d}}+\sqrt{\gamma_{S}^{p}} \sqrt{\frac{\gamma_{L}^{p}}{\gamma_{L}^{d}}}
$$

The values of the solid surface free energy dispersive component, $\gamma_{\mathrm{s}}{ }^{\mathrm{d}}$, and polar component, $\gamma_{\mathrm{s}}^{\mathrm{p}}$, can be determined by contact angles of two or more liquids against the solid. 
Table 3.4 lists the four wetting liquids used for measurement and their surface energies. The contact angle of each liquid against the resin surface was measured by the sessile drop method with a Rame-Hart 100-00 115 NRL contact angle goniometer. Five microliter drops of liquid were carefully placed on the substrate using a microliter syringe without touching the seated drops. The contact angles on both sides of a drop were measured. Measurements from 6-10 drops were used to obtain an average value of the contact angle. Epoxy surface energies were obtained by linear regression of contact angles plotted against liquid surface free energies according to equation 3.12 .

\subsubsection{Differential Scanning Calorimetry (DSC)}

Differential scanning calorimetry measurements were conducted with a Perkin Elmer DSC7 to obtain the glass transition temperature (Tg) of the epoxies. Samples of 6-9 $\mathrm{mg}$ and the reference were heated at a rate of $10^{\circ} \mathrm{C} / \mathrm{min}$ under dry nitrogen. The midpoint of the endothermic change was taken as the glass transition temperature.

\subsection{Fiber/Matrix Adhesion Measurement}

A review of publications on methods for measuring fiber/matrix adhesion led to selection of the single fiber fragmentation test for this study because it is less sensitive to fiber local variations, straightforward in experimental procedure, and the result agrees well with other methods. ${ }^{116}$

\subsubsection{Preparation of Single Fiber Composite}

Five cavity rubber molds were made from a room temperature cure Dow Corning ${ }^{\circledR} 3120$ RTV silicone rubber for preparation of the single fiber fragmentation samples. The shape and dimension of the dog-bone cavity are shown in Figure 3.4. Two slots were cut at the center edges of the cavity to facilitate the fiber placement. 
Table 3.4 Liquids used for epoxy resin surface energy measurement and their surface free energies. ${ }^{58}$

\begin{tabular}{lccc}
\hline & \multicolumn{3}{c}{ Surface free energy $\left(\mathrm{mJ} / \mathrm{m}^{2}\right)$} \\
\cline { 2 - 4 } Liquid & $\gamma_{\mathrm{L}}{ }^{\mathrm{d}}$ & $\gamma_{\mathrm{L}}{ }^{\mathrm{p}}$ & $\gamma_{\mathrm{L}}$ \\
\hline Water (double deionized) & 22.0 & 50.2 & 72.2 \\
Formamide & 32.3 & 26.0 & 58.3 \\
Di-iodomethane & 48.5 & 2.3 & 50.8 \\
1-Bromonaphthalene & 44.6 & 0.0 & 44.6 \\
\hline
\end{tabular}


depth of the cavity is $1.5 \mathrm{~mm}$

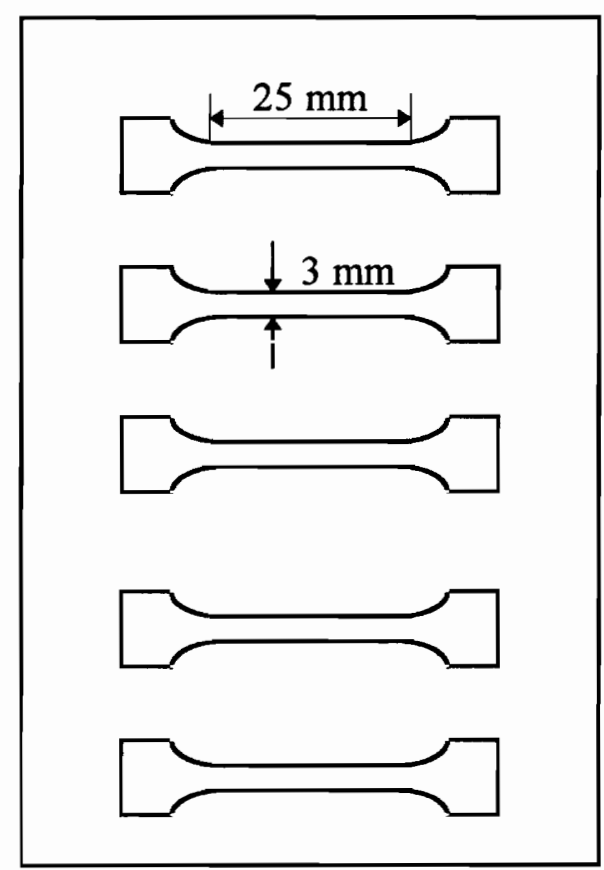

Figure 3.4 Schematic representation of the rubber mold used for preparation of single fiber fragmentation specimens. 
Molds were dried at $175^{\circ} \mathrm{C}$ for 2 hours and cooled in a desiccator before sample preparation. Single fibers were removed from a fiber tow and placed into the cavities. The ends of the fiber were fixed by Scotch ${ }^{T M}$ glass cloth electrical tape at the slots. Care was taken to avoid touching of the fibers in the gauge section either by hand or mold.

Epon 828 and Jeffamine DU-700 were mixed at room temperature. mPDA was heated to $65^{\circ} \mathrm{C}$ for melting and mixed with Epon 828 at $50^{\circ} \mathrm{C}$ to prevent solidification during mixing. Both resins were thoroughly degassed in vacuum prior to molding. The resin was carefully poured into the cavities and filled to the level of the mold surface.

The assembly was transferred to an oven. The temperature was raised, at a rate of approximately $40^{\circ} \mathrm{C} / \mathrm{min}$, to $75^{\circ} \mathrm{C}$ for 2 hours and then to $125^{\circ} \mathrm{C}$ for another 2 hours. After cooling overnight in the oven, the specimens were demolded and stored in a desiccator until testing.

\subsubsection{Interfacial Shear Strength by Single Fiber Fragmentation Test}

A single fiber specimen was mounted in a hand operated loading device which was placed on the stage of a transmitted-light polarizing microscope. The whole setup is shown in Figure 3.5. The sample was pulled in tension at a speed of $1 \mathrm{~mm} / \mathrm{min}$ and the fiber breaking process was observed under cross polarizing light. The orientation of the polarizer is perpendicular to the fiber and that of the analyzer parallel fiber. The pulling was stopped when no further breaks were observed. The elongations were $5-6 \%$ for the carbon fiber/mPDA cured Epon 828 system and $20 \%$ for the carbon fiber/Jeffamine DU700 cured Epon 828 system. The fragment lengths were read with the aid of an eyepiece which was calibrated using a Weitzler stage micrometer. 


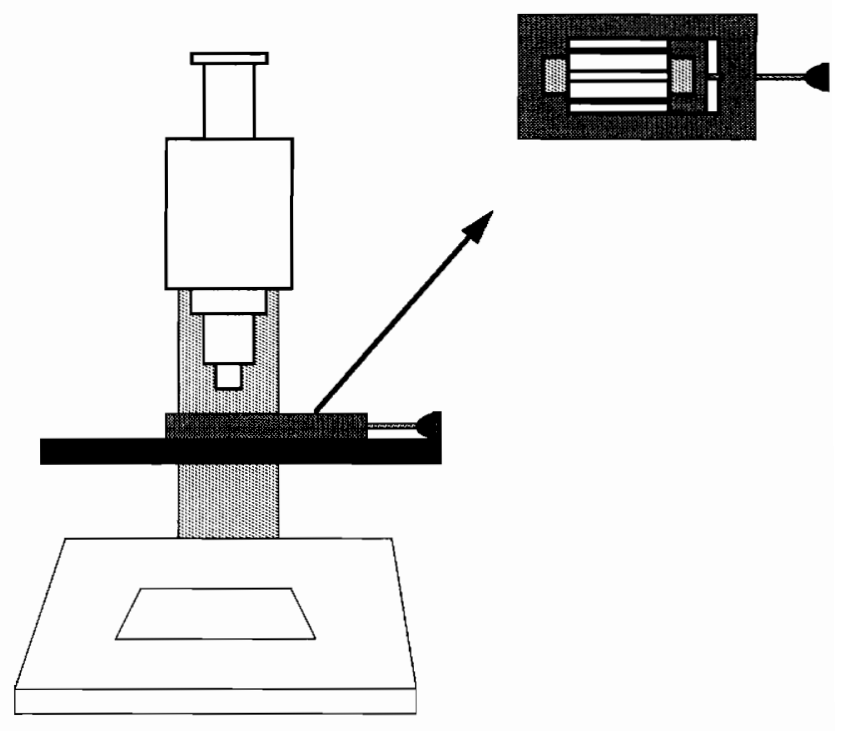

Figure 3.5 Test apparatus for the single fiber fragmentation technique. 
In practical measurement, instead of a single critical length, a distribution of fragments is observed due to fiber defects and heterogeneity. Moreover, as the fiber fracture process approaches to the critical length, some fragments will be slightly longer and some just slightly less than the critical length. The shorter fragments will no longer fracture but those marginally longer will fracture again leading to fragments about one half of the critical length $\left(l_{c}\right)$, and the observed critical lengths are expected to be between $l_{d} / 2$ and $l_{c}$. Therefore, a statistical analysis of the fragment data is needed. The two parameter Weibull distribution was used for this purpose:

$$
f(l)=\frac{\alpha}{\beta}\left(\frac{l}{\beta}\right)^{\alpha-1} \exp \left[-\left(\frac{l}{\beta}\right)^{\alpha}\right]
$$

and the mean value determined by:

$$
l_{c}=\beta \Gamma\left(\frac{\alpha+1}{\alpha}\right)
$$

was used to calculate the interfacial shear strength from:

$$
\tau=\frac{\sigma_{f} d}{2 l_{c}}
$$

Data from six specimens were taken for each carbon fiber/matrix system.

\subsubsection{Interfacial Shear Strength after Humidity Exposure}

It has been found that moisture and temperature are two environments that can have deleterious effects on the performance of advanced graphite-epoxy composites. The purpose of this study is to identify the effect of surface properties on the humidity durability of interfacial adhesion

The embedded single fiber specimens of AU-4, AS-4, Panex 33(S) and AS-4-Na in Epon 828-mPDA system were stored separately in desiccators which were (1) kept dry at $23^{\circ} \mathrm{C}$, (2) saturated with water vapor at $23^{\circ} \mathrm{C} 100 \% \mathrm{RH}$, (3) kept dry at $75^{\circ} \mathrm{C}$ and , (4) 
saturated with water vapor at $75^{\circ} \mathrm{C} 100 \% \mathrm{RH}$. Samples were removed from the desiccator periodically for measurement of interfacial shear strength.

\subsubsection{Interfacial Shear Strength at Elevated Temperature}

The loading device and mounted single fiber specimens were immersed in a thermostated silicone oil bath at elevated temperatures. After allowing 10 minutes to achieve steady state, the temperature was recorded and the sample was pulled in tension to the desired elongation at $1 \mathrm{~mm} / \mathrm{min}$ rate. The specimen was unloaded immediately after the device was retrieved from the hot bath. The sample was examined under a transmittedlight polarizing microscope and break lengths were read with the aid of birefringence.

\subsection{Plasma Treatment of Carbon Fibers}

AU-4 and Panex 33(U) fibers were oxygen plasma treated to investigate the effects of plasma on carbon fiber surface characteristics and interfacial adhesion. Plasma treatments were carried out in a March Instruments Plasmod unit at $13.56 \mathrm{MHz}$ and 50 watts. The operating pressure was 1 torr. Prior to activating the RF field, the plasma chamber was pumped down to 1 torr and filled to 400 torr with oxygen twice for minimizing the residual air content.

Treated carbon fibers for interfacial shear strength measurments were immersed with mixed resin and hardener immediately after removal from the plasma chamber. Fibers for surface analyses were stored in a desiccator. Surface chemistry analysis by XPS was carried out within 30 minutes, surface energy analysis by the two liquid dynamic contact angle method within 5 days, and surface morphology by SEM within 10 days. 


\section{Chapter 4: Results and Discussion}

\subsection{Surface Characterization}

\subsubsection{Carbon Fiber Surface Topography}

Scanning electron microscopy provides a direct view of the fiber surface topography. The SEM photomicrographs of the fibers used in this study at magnification of 10,000x are shown in Figure 4.1. The Hercules AU-4 and AS-4 fibers are relatively featureless and smooth, whereas the Panex 33(U) and Panex 33(S) fibers showed a rather rough surface topography with striations along the length of the fiber originated from the fiber spinning process. It is interesting to investigate the contribution of this kind of surface roughness to fiber/matrix adhesion.

\subsubsection{Carbon Fiber Surface Chemistry}

Qualitative analysis of carbon fiber surfaces in the XPS survey scan mode identified the existence of carbon, oxygen, nitrogen and sodium. Quantitative analysis results from the multiplex scan peak areas and corresponding photoelectron cross section of the elements are listed in Table 4.1. Carbon is the primary element; oxygen is attributed to the carbon fiber surface oxidation and adsorbed materials; nitrogen is attributed to the PAN source and adsorbed materials; and sodium is attributed to the alkyl sodium thiocynate added to the spinning precursor.

Compared with AU-4 and Panex 33(U), AS-4 and Panex 33(S) both have a higher level of surface oxygen produced by commercial surface pretreatment. Angle dependent XPS results in Figure 4.2 showed that oxygen is more concentrated on the very top surface, i.e., the oxygen content at a $15^{\circ}$ take-off angle is greater than that at $45^{\circ}$ or $90^{\circ}$. 


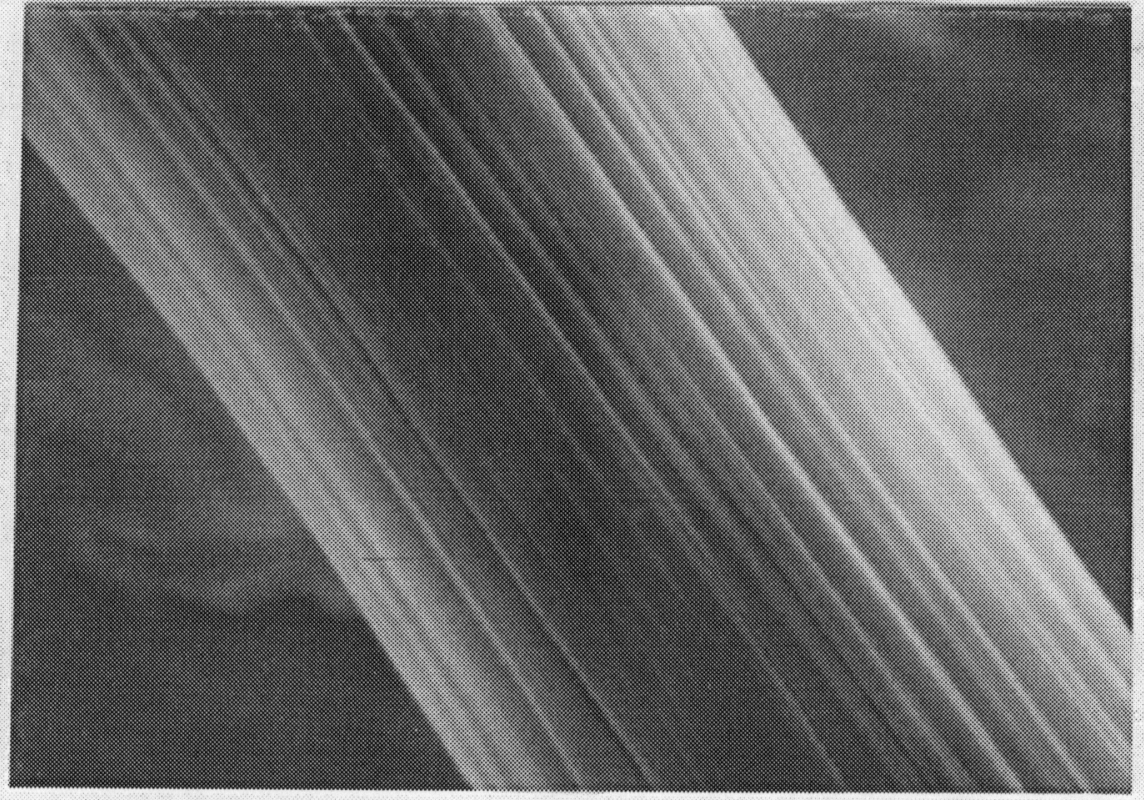

(c)

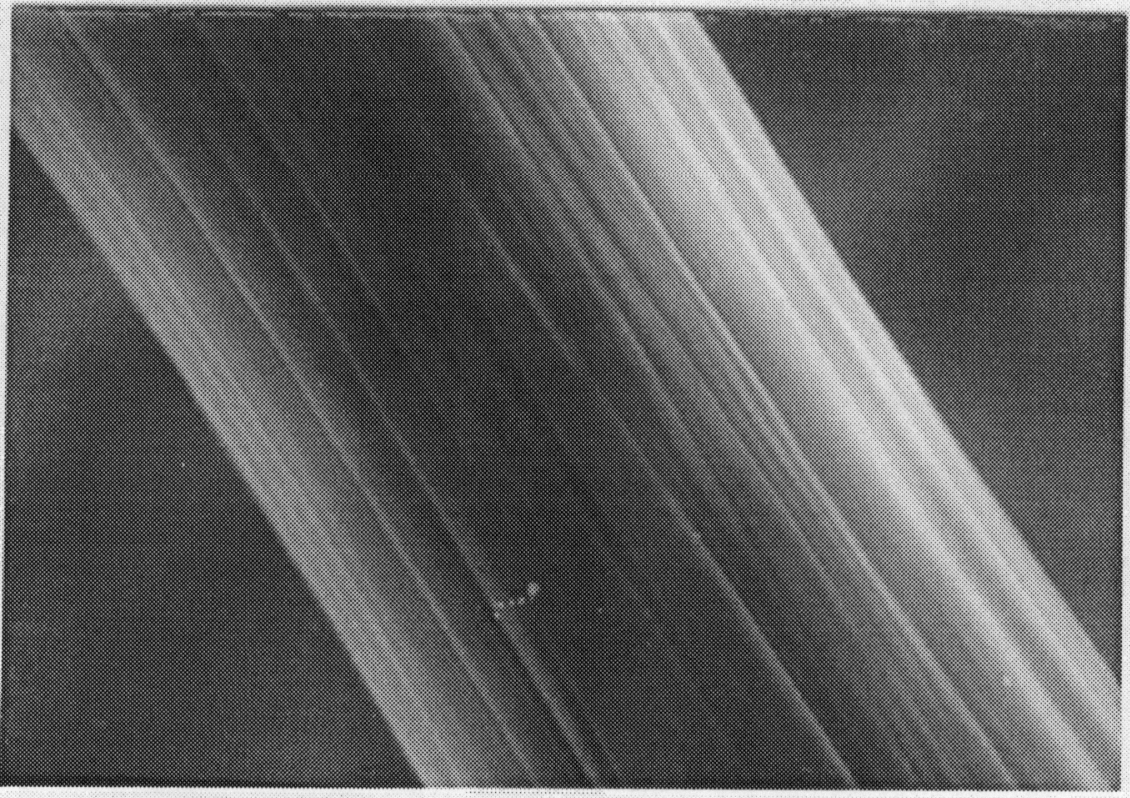

(d)

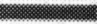

$1 \mu \mathrm{m}$

Figure 4.1 SEM photomicrographs of carbon fibers. (a) Hercules AU-4, (b) Hercules AS-4 


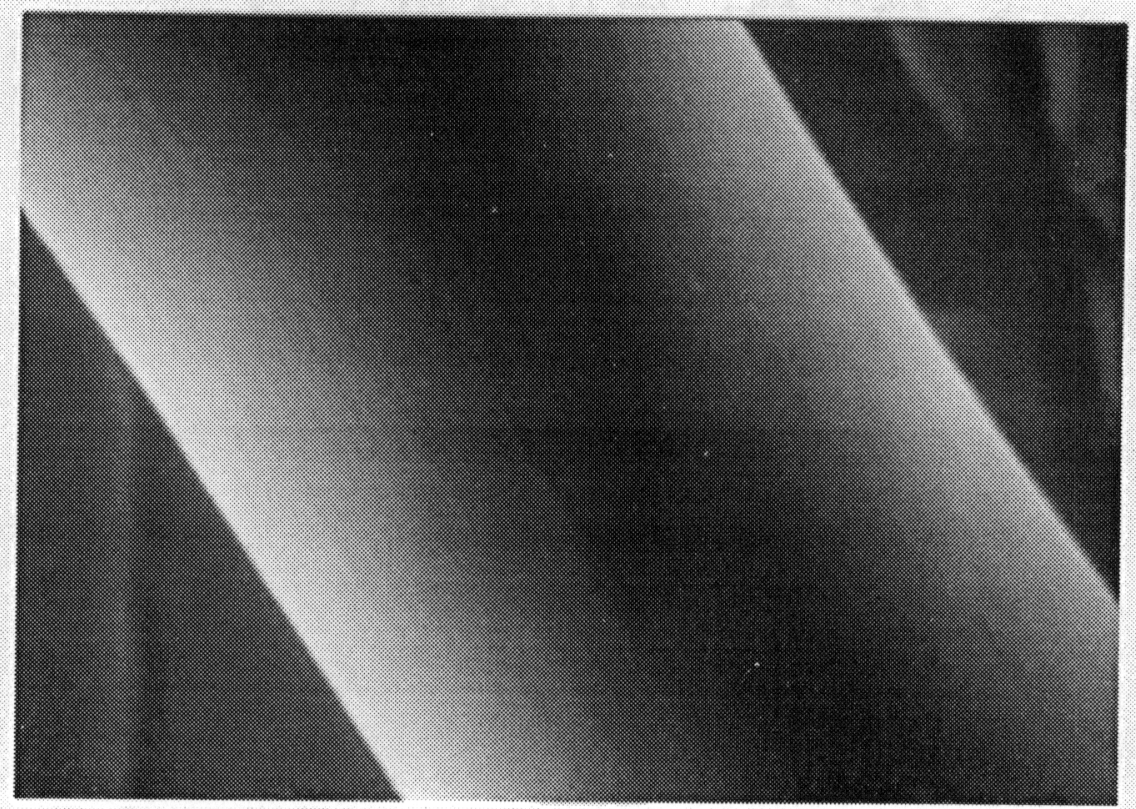

(a)

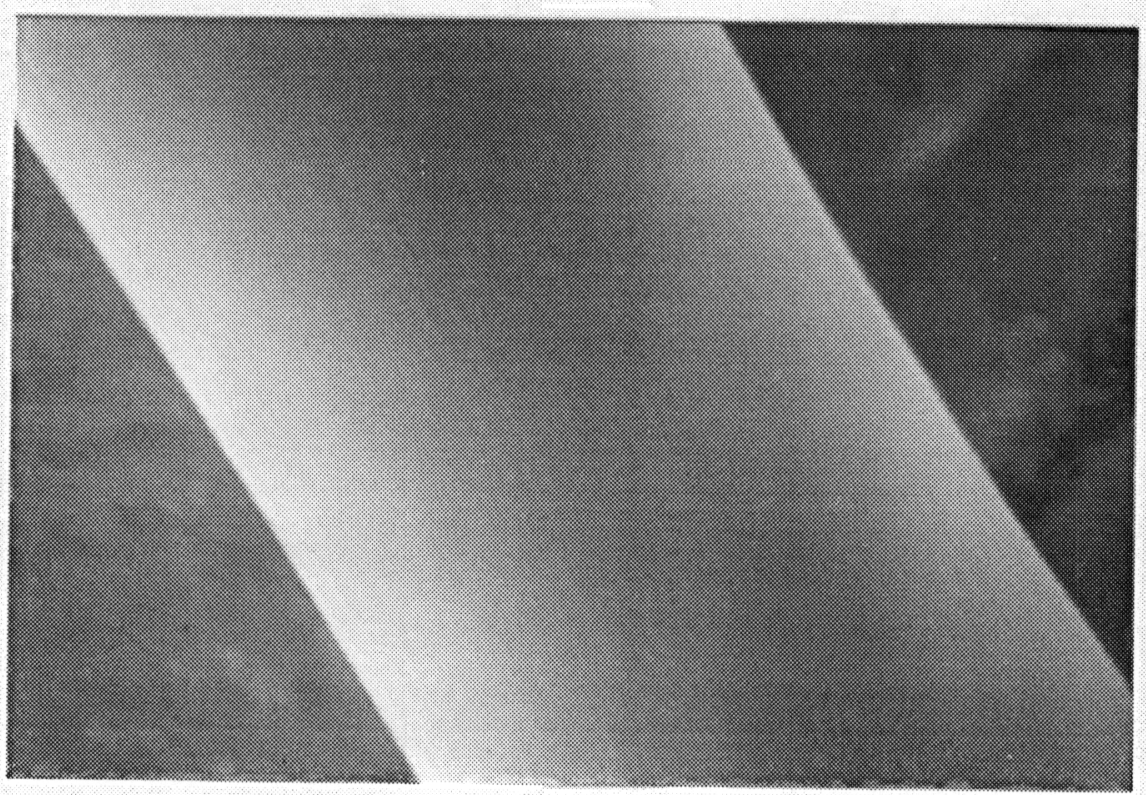

(b)

$1 \mu \mathrm{m}$

Figure 4.1 SEM photomicrographs of carbon fibers. (c) Zoltek Panex 33(U) and, (d) Zoltek Panex 33(S). 
Table 4.1 XPS atomic concentrations of carbon fibers.

\begin{tabular}{|c|c|c|c|c|}
\hline \multirow{2}{*}{ Fiber } & \multicolumn{4}{|c|}{ Atomic Concentration ( $\%)$} \\
\hline & Carbon & Oxygen & Nitrogen & Sodium \\
\hline AU-4 & $94 \pm 1.2$ & $3.1 \pm 0.9$ & $2.5 \pm 0.2$ & $0.04 \pm 0.03$ \\
\hline AS-4 & $85 \pm 1.3$ & $12 \pm 0.7$ & $3.6 \pm 0.3$ & $0.34 \pm 0.15$ \\
\hline Panex 33(U) & $93 \pm 1.2$ & $4.7 \pm 1.0$ & $1.8 \pm 0.4$ & $0.43 \pm 0.10$ \\
\hline Panex 33(S) & $80 \pm 1.5$ & $9.1 \pm 1.2$ & $7.6 \pm 0.4$ & $3.0 \pm 0.5$ \\
\hline AS-4-Na & $85 \pm 0.9$ & $10 \pm 0.5$ & $3.2 \pm 0.2$ & $2.3 \pm 0.4$ \\
\hline
\end{tabular}



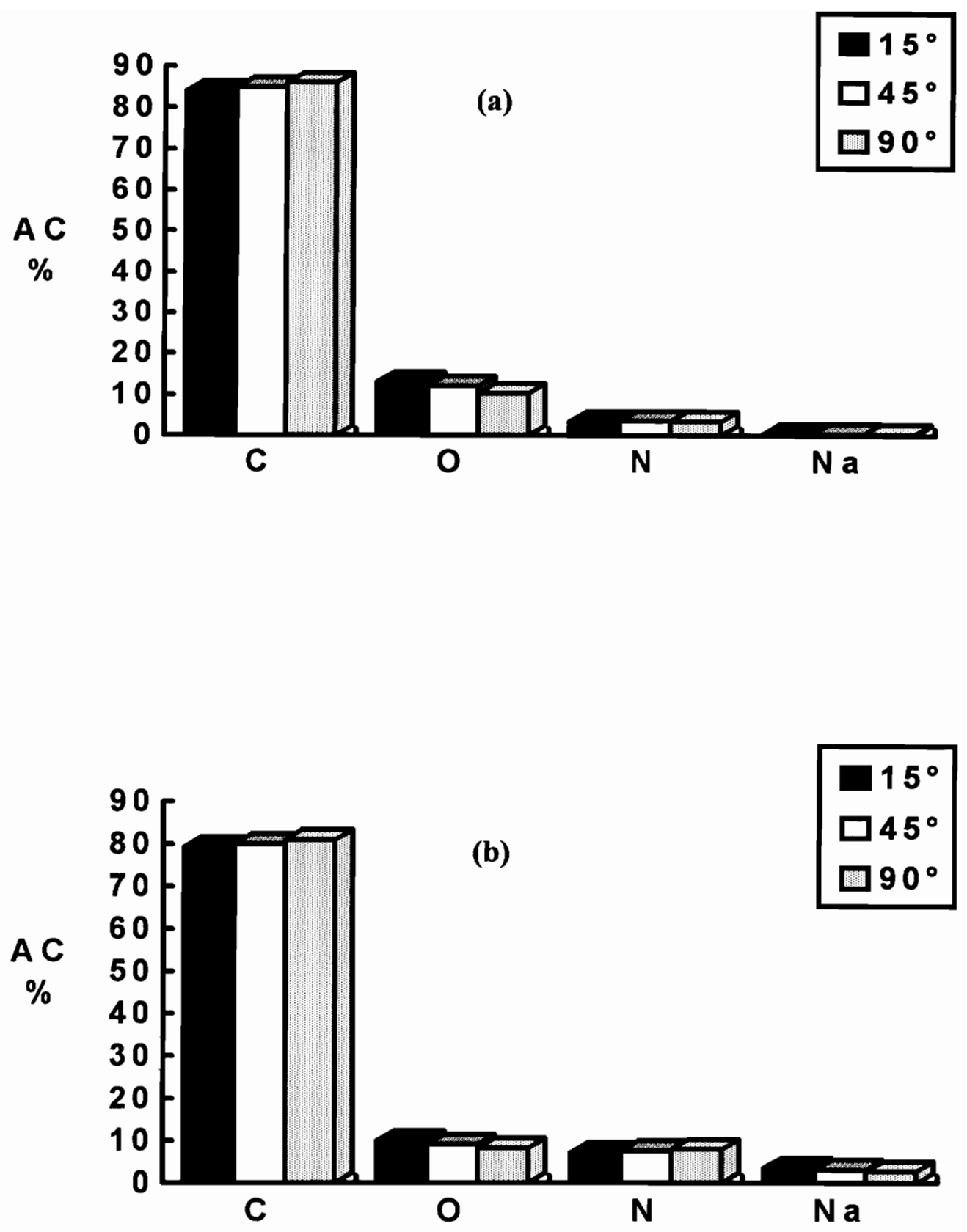

Figure 4.2 Atomic concentrations of (a) AS-4 and (b) Panex 33(S) carbon fibers at different take-off angles. 
A considerable amount of sodium was observed on the Panex 33(S) fiber. It has been assumed that the presence of sodium on carbon fiber surface is harmful because it induces both the degradation of the matrix resin and the oxidization of the carbon fiber. To study the effect of surface sodium and isolate this effect from other variations, AS-4$\mathrm{Na}$ fiber was prepared from AS-4 fiber. A surface sodium concentration of $2.3 \%$ was determined by XPS.

XPS photoelectron peak shape analysis by curve fitting gives another level of surface chemistry information about chemical states. For instance, the carbon 1s graphite peak at $284.6 \mathrm{eV}$ exhibits an asymmetric tailing toward high binding energy. This tail is caused partly by the main graphite peak intrinsic asymmetry and also by the chemical shift of photoelectron peaks associated with functionalized carbons. Ideally, the type of functionality can be determined by the extent of this chemical shift.

The fiber surface carbon 1s photopeaks were curve fitted into six peaks as shown in Figure 4.3. Table 4.2 lists the peak positions, percentage areas and peak assignments. The peak assignment was based on reference works. ${ }^{31,117-119}$ The curve fitting results indicate that the fiber surface carbon was functionalized by oxygen and nitrogen in several bonding states. The commercial fiber surface pretreatment increased fiber surface oxygen in all bonding states.

The corresponding $\mathrm{O} 1 \mathrm{~s}$ peak shifts were not as easy to resolve as the $\mathrm{C} 1 \mathrm{~s}$ shifts mainly because the widths of the $\mathrm{O} 1 \mathrm{~s}$ signals are generally greater than that of the $\mathrm{C} 1 \mathrm{~s}$ signal, leading to less peak resolution. Nonetheless, the results and assignments of curve fitting the oxygen 1s photopeaks are shown in Figure 4.4 and Table 4.3. 

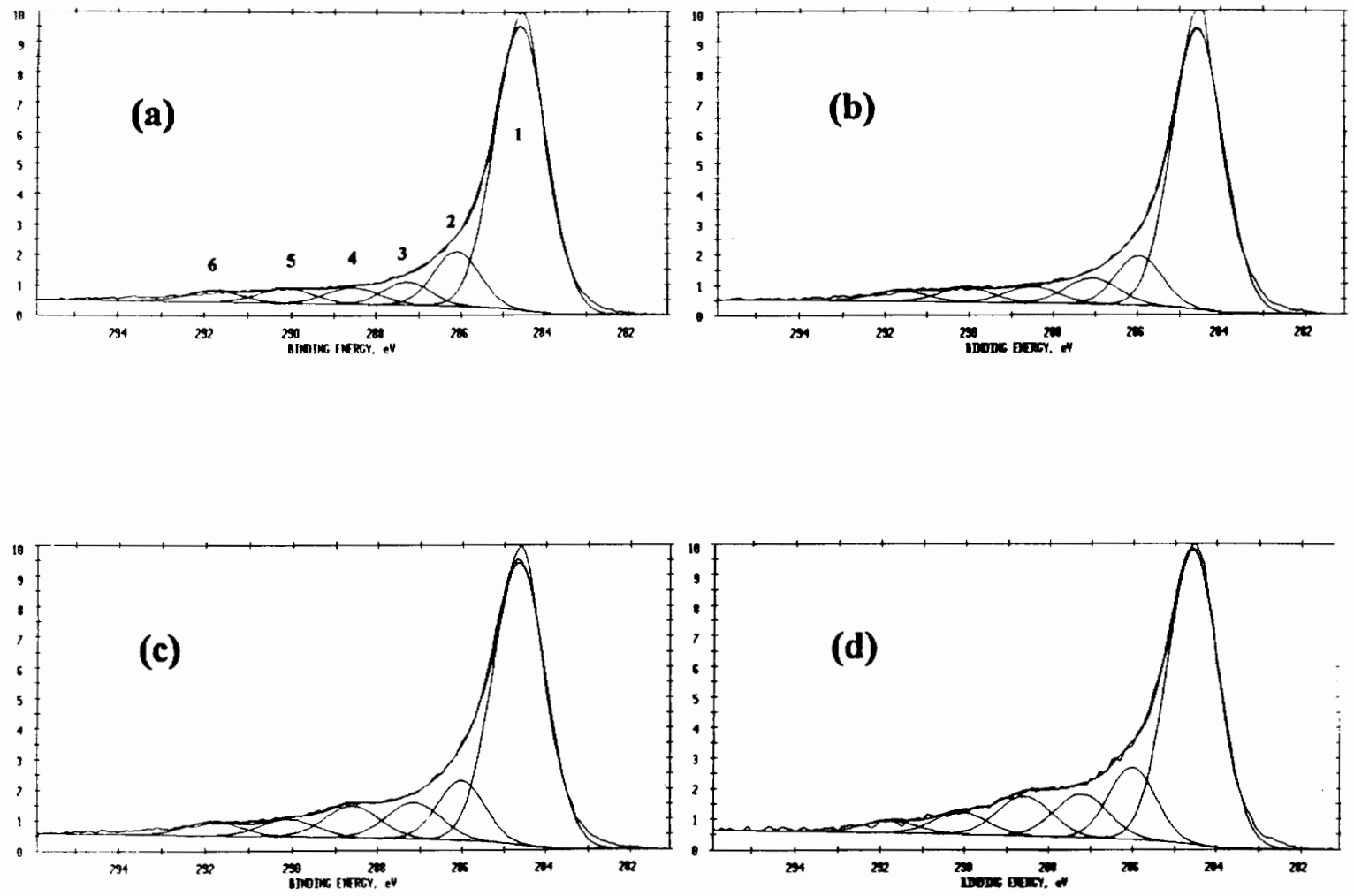

Figure 4.3 Curve fit carbon 1s XPS photoelectron peaks of (a) AU-4, (b) AS-4, (c) Panex 33(U), and (d) Panex 33(S) carbon fibers. 
Table 4.2 Carbon 1s photopeak curve fit results of carbon fibers.

\begin{tabular}{|c|c|c|c|c|c|c|}
\hline \multirow{2}{*}{ Fiber } & \multicolumn{6}{|c|}{ Binding Energy $(\mathrm{eV})^{*}$} \\
\hline & 284.6 & 285.9 & 287.2 & 288.6 & 290.0 & 291.7 \\
\hline AU-4 & 70.2 & 11.7 & 7.0 & 4.2 & 3.8 & 3.1 \\
\hline AS-4 & 64.7 & 12.4 & 8.1 & 7.0 & 4.4 & 3.4 \\
\hline Panex 33(U) & 71.4 & 11.2 & 6.7 & 4.2 & 3.7 & 2.8 \\
\hline Panex 33(S) & 61.1 & 13.6 & 9.4 & 8.5 & 4.7 & 2.66 \\
\hline \multirow{5}{*}{ Assignment } & $\underline{\mathrm{C}}-\mathrm{H}$ & $\underline{\mathrm{C}}-\mathrm{OH}$ & $\underline{C}=0$ & $\mathrm{O}=\underline{\mathrm{C}}-\mathrm{OH}$ & $\mathrm{O}-\underline{\mathrm{CO}} \mathrm{O}-\mathrm{O}$ & plasmon \\
\hline & (graphite, & $\underline{\mathrm{C}}-\mathrm{O}-\mathrm{C}$ & $\mathrm{N}-\underline{\mathrm{C}}=\mathrm{O}$ & $\mathrm{O}=\underline{\mathrm{C}}-\mathrm{OR}$ & $\mathrm{O}=\underline{\mathrm{C}}-\mathrm{O}^{-}$ & \\
\hline & aromatics, & $\underline{\mathrm{C}}-\mathrm{N}$ & & & $\mathrm{O}=\underline{\mathrm{C}}=\mathrm{O}$ & \\
\hline & aliphatics) & $\underline{C}=\mathrm{N}$ & & & & \\
\hline & & $\underline{\mathrm{C}}=\mathrm{N}$ & & & & \\
\hline Peak No. & 1 & 2 & 3 & 4 & 5 & 6 \\
\hline
\end{tabular}

${ }^{*}$ Gaussian function curve fit. Uncertainty in peak position is $\pm 0.1 \mathrm{eV}, \mathrm{FWHM}$ are $1.4 \pm 0.1 \mathrm{eV}$. 

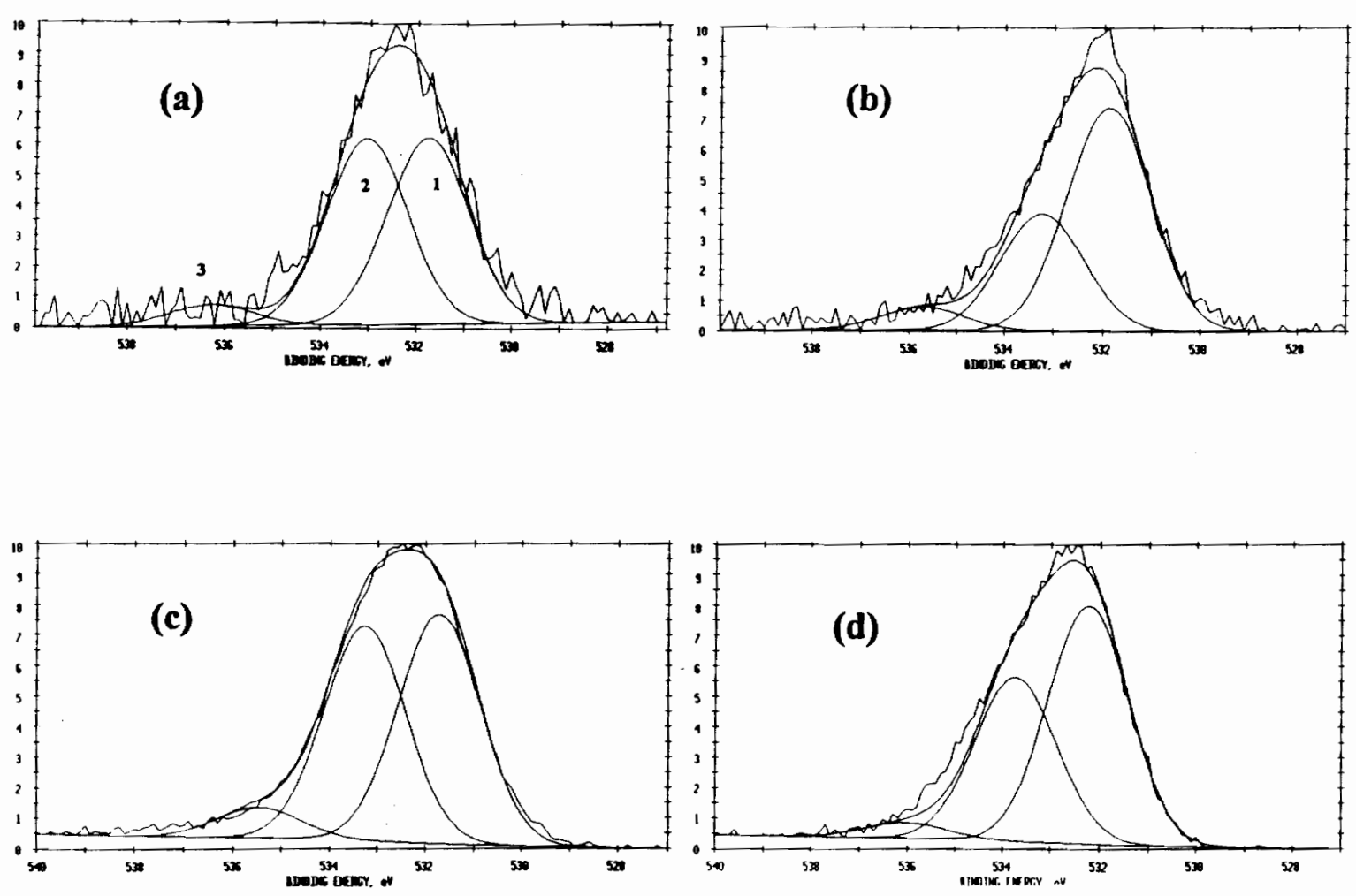

Figure 4.4 Curve fit oxygen is XPS photoelectron peaks of (a) AU-4, (b) AS-4, (c) Panex 33(U), and (d) Panex 33(S) carbon fibers. 
Table 4.3 Oxygen 1s photopeak curve fit results of carbon fibers.

\begin{tabular}{|c|c|c|c|}
\hline \multirow{2}{*}{ Fiber } & \multicolumn{3}{|c|}{ Binding Energy $(\mathrm{eV})^{*}$} \\
\hline & 532.0 & 533.5 & 536.2 \\
\hline AU-4 & 47.4 & 47.3 & 5.3 \\
\hline AS-4 & 48.5 & 45.2 & 6.3 \\
\hline Panex 33(U) & 61.4 & 32.2 & 6.4 \\
\hline Panex 33(S) & 56.4 & 39.9 & 3.7 \\
\hline \multirow[t]{2}{*}{ Assignment } & $\mathrm{C}=\underline{\mathrm{O}}$ & $\mathrm{C}-\underline{\mathrm{O}} \mathrm{H}$ & Adsorbed $\mathrm{H}_{2} \mathrm{O}$ \\
\hline & $\mathrm{C}-\underline{\mathrm{O}}-\mathrm{C}$ & & \\
\hline Peak No. & 1 & 2 & 3 \\
\hline
\end{tabular}

${ }^{*}$ Gaussian function curve fit. Uncertainty in peak position is $\pm 0.3 \mathrm{eV}, \mathrm{FWHM}$ are $1.9 \pm 0.1 \mathrm{eV}$. 


\subsubsection{Carbon Fiber Surface Energy}

The surface free energies of the wetting liquids used for fiber surface energy analysis were measured by the Wilhelmy slide method. The results are listed in Table 4.4. These results are in good agreement with the literature values ${ }^{58}$ indicating that minimal mutual dissolving and impurity have minor influence in this case.

The fiber diameters determined from measured wetting forces in hexane are listed in Table 4.5 and compared with those measured from fiber SEM photomicrographs. Values from hexane wetting were slightly higher because they involved the fiber irregularities, e.g., non-circularity and roughness. These fiber perimeters were used, together with the wetting forces by a series of two liquid systems, to deduce fiber surface energies.

Some typical wetting traces obtained from the two liquid dynamic contact angle analysis are shown in Figure 4.5. The force reading, initially at zero, increased to the wetting force by alkane when the tip of the fiber touched the alkane layer of the two liquid system. This force remained constant as the fiber passed through the alkane layer. The force reading then increased again to value of the sum of wetting forces by the two interfaces as the fiber reached the formamide layer. If the movement was stopped in this stage, the force reading increased to a plateau in advancing and decreased to a plateau in receding as shown in Figure 4.6. The plateau values in advancing were employed for the fiber surface energy calculations.

Using the measured wetting forces, plots were made according to Equation 3.6. The results are shown in Figure 4.7. A best fit linear regression was determined for each fiber and fiber surface energies $\gamma_{\mathrm{s}}{ }^{\mathrm{d}}, \gamma_{\mathrm{S}}{ }^{\mathrm{p}}$ and $\gamma_{\mathrm{S}}{ }^{\text {Total }}$ were determined from the slope and intercept. 
Table 4.4 Liquid surface free energies measured by Wihelmy slide method.

\begin{tabular}{lcc}
\hline Liquid & $\begin{array}{c}\text { Measured Value } \\
\left(\mathrm{mJ} / \mathrm{m}^{2}\right)\end{array}$ & $\begin{array}{c}\text { Literature Value } \\
\left(\mathrm{mJ} / \mathrm{m}^{2}\right)\end{array}$ \\
\hline formamide & 58.0 & 58.3 \\
n-hexane & 18.3 & 18.4 \\
n-octane & 21.4 & 21.8 \\
n-decane & 23.5 & 23.9 \\
n-dodecane & 25.5 & 25.4 \\
n-tetradecane & 26.4 & 26.7 \\
n-hexadecane & 27.3 & 27.6 \\
\hline
\end{tabular}


Table 4.5 Carbon fiber perimeters (p) and diameters (d) measured from hexane wetting force and SEM.

\begin{tabular}{lccc}
\hline Fiber & $\begin{array}{c}\text { p from wetting } \\
(\mu \mathrm{m})\end{array}$ & $\begin{array}{c}\mathrm{d} \text { from wetting } \\
(\mu \mathrm{m})\end{array}$ & $\begin{array}{c}\mathrm{d} \text { from SEM } \\
(\mu \mathrm{m})\end{array}$ \\
\hline AU-4 & $23 \pm 1$ & $7.3 \pm 0.4$ & $6.8 \pm 0.4$ \\
AS-4 & $24 \pm 1$ & $7.7 \pm 0.4$ & $7.1 \pm 0.2$ \\
Panex 33(U) & $28 \pm 3$ & $9.0 \pm 1.0$ & $8.3 \pm 0.6$ \\
Panex 33(S) & $23 \pm 2$ & $7.2 \pm 0.7$ & $6.5 \pm 0.5$ \\
\hline
\end{tabular}



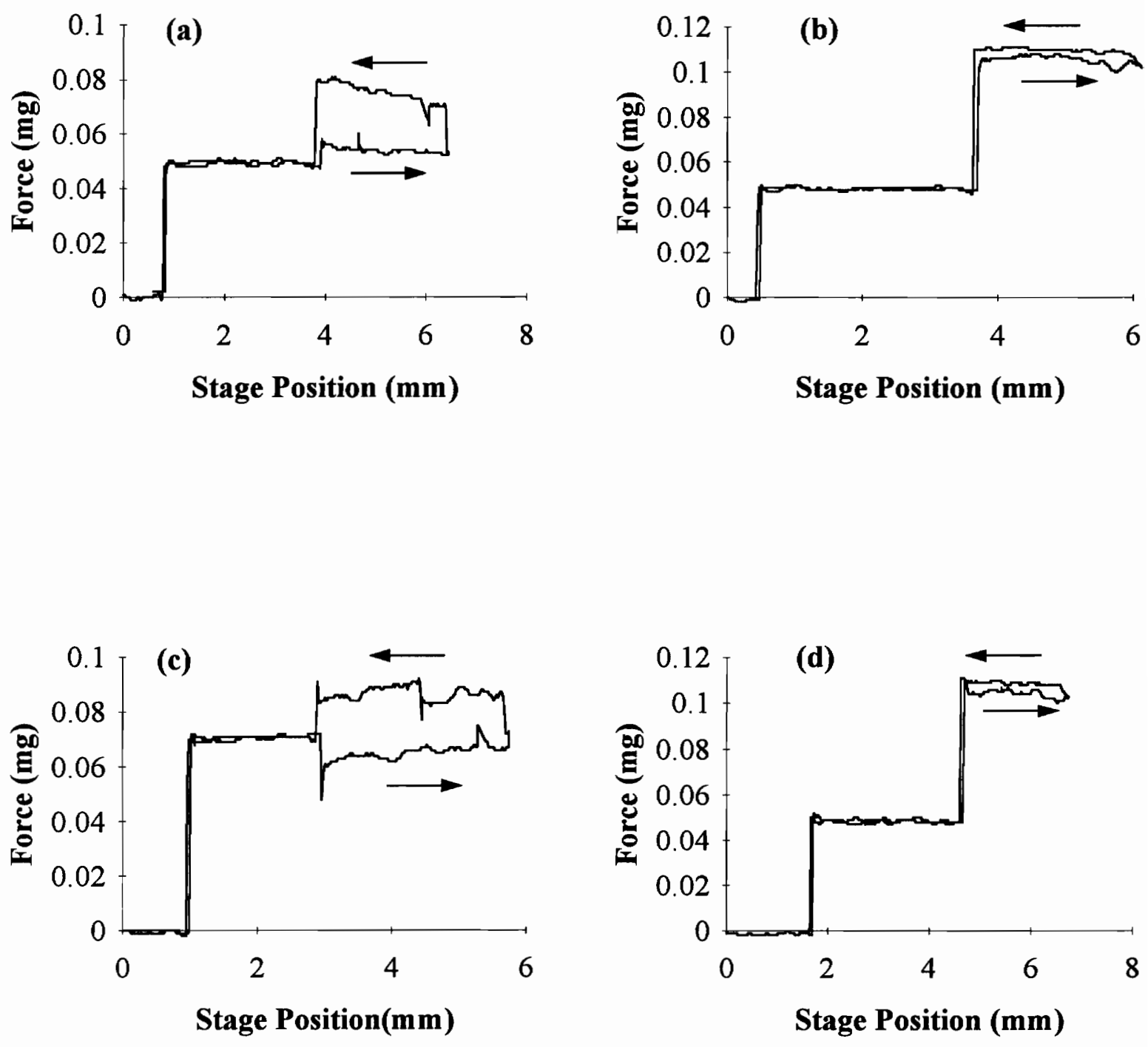

Figure 4.5 Wetting traces obtained from (a) AU-4, (b) AS-4, (c) Panex 33(U) and , (d) Panex 33(S) carbon fibers with immiscible octane/formamide two liquid system. 
(a)

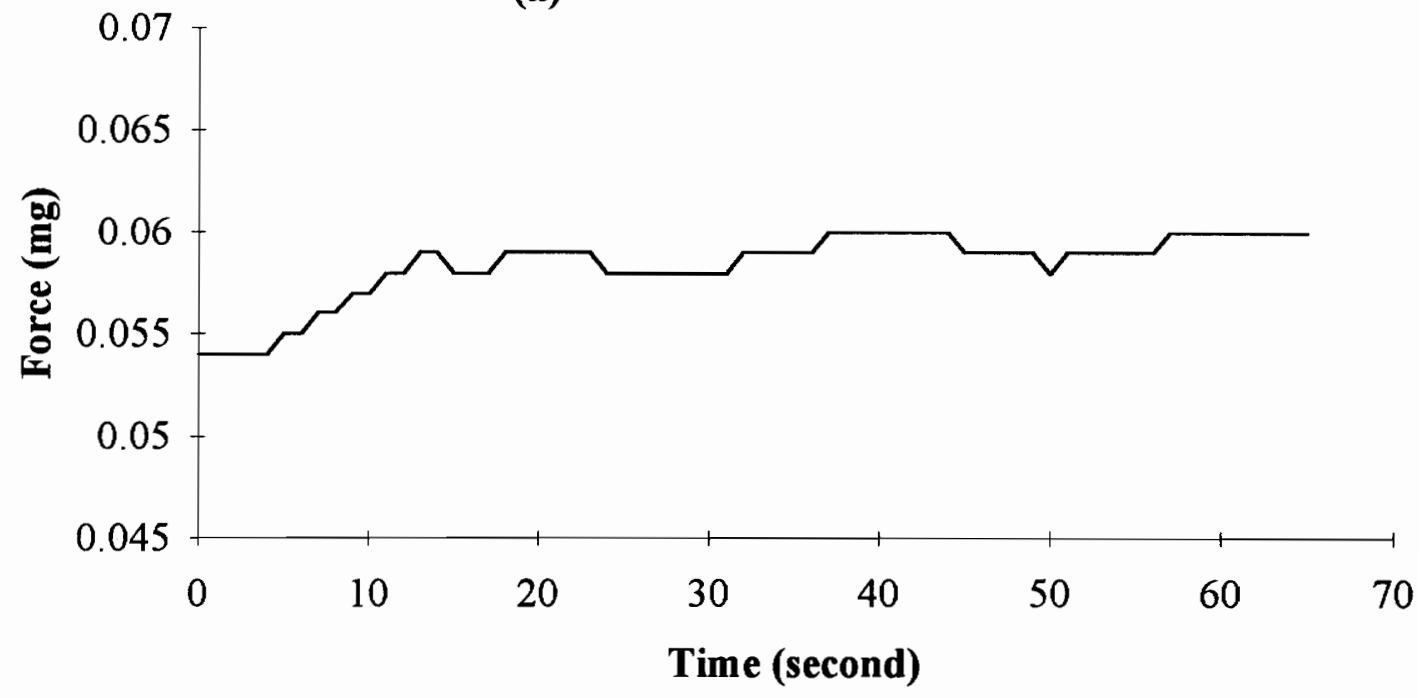

(b)

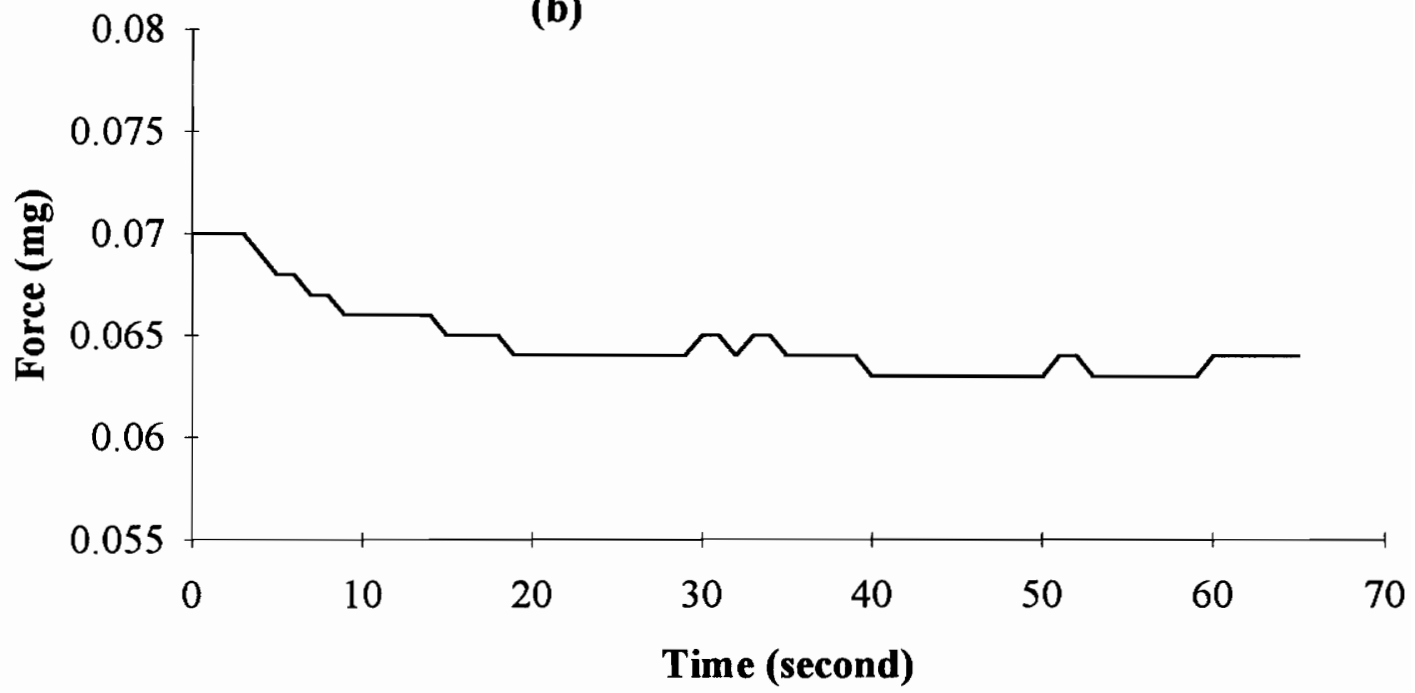

Figure 4.6 The change of wetting forces of AU-4 carbon fiber by octane/formamide in the (a) advancing and $(b)$ receding modes. 

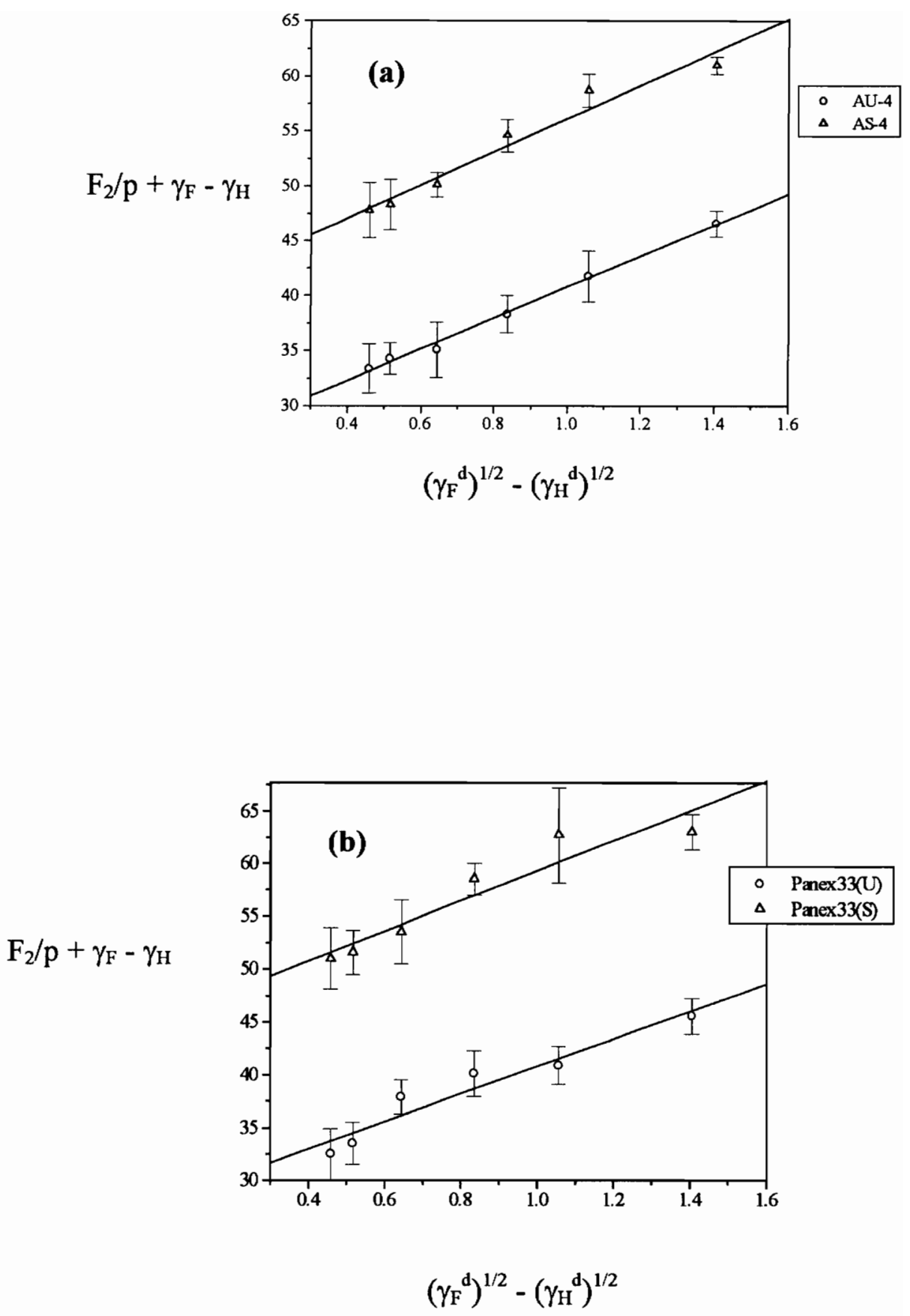

Figure 4.7 Dynamic contact angle analysis plots for (a) AU-4 and AS-4, and (b) Panex 33(U) and Panex 33(S) fibers. 
Values of the polar, dispersive and total surface energies of carbon fibers are listed in Table 4.6. Compared with untreated fibers, the two commercially surface pretreated fibers (AS-4 and Panex 33(S)) exhibited higher surface energies principally due to the polar component. This result paralleled the higher surface oxygen levels in these two fibers determined by XPS analysis (see Table 4.1).

\subsubsection{Epoxy Matrix Surface Chemistry}

The surfaces of the epoxy resins prepared as described in 3.1.2 were analyzed by XPS. The surface atomic concentrations observed are shown in Table 4.7 and compared with the theoretical values calculated from the resin formulation. The results indicate that the surface composition of the two resins is quite close to that of the bulk compositions. It is reasonable to assume that this outer surface resembles the resin surface at the fiber/matrix interface and the surface characteristics measured at this outer surface represent the property of the resin surface in contact with the fiber.

\subsubsection{Epoxy Matrix Surface Energy and Fiber/Matrix Interfacial Work of Adhesion}

Figure 4.8 shows the plots used to calculate the resin surface energy from contact angle measurements. The surface energy dispersive component from the intercept and polar component from the slope are listed in Table 4.8. The total surface energy is the sum of the dispersive and polar components. Epon828-mPDA exhibited a higher surface energy.

Assuming Equation 3.3 is true for this case, the interfacial reversible work of adhesion between the resin and carbon fiber, which is defined by the Dupre equation as:

$$
\mathrm{W}_{\mathrm{a}}=\gamma_{\mathrm{F}}+\gamma_{\mathrm{R}}-\gamma_{\mathrm{FR}}
$$

can be calculated from the resin and fiber surface energies by:

$$
\mathrm{W}_{\mathrm{a}}=\mathrm{W}^{\mathrm{d}}+\mathrm{W}^{\mathrm{p}}=2\left({\gamma_{\mathrm{F}}}^{\mathrm{d}}{\gamma_{\mathrm{R}}}^{\mathrm{d}}\right)^{1 / 2}+2\left(\gamma_{\mathrm{F}}^{\mathrm{P}} \gamma_{\mathrm{R}}^{\mathrm{p}}\right)^{1 / 2}
$$


Table 4.6 Carbon fiber surface energies (in $\mathrm{mJ} / \mathrm{m}^{2}$ ).

\begin{tabular}{lccc}
\hline Fiber & $\gamma_{\mathrm{s}}^{\mathrm{d}}$ & $\gamma_{\mathrm{s}}^{\mathrm{p}}$ & $\gamma_{\mathrm{s}}^{\text {Total }}$ \\
\hline AU-4 & 46.4 & 6.86 & 53.2 \\
AS-4 & 56.9 & 16.3 & 73.2 \\
Panex 33(U) & 44.5 & 7.48 & 51.0 \\
Panex 33(S) & 50.9 & 19.5 & 70.4 \\
\hline
\end{tabular}


Table 4.7 XPS atomic concentrations of epoxy resins.

\begin{tabular}{lccc}
\hline \multirow{2}{*}{ Resin } & \multicolumn{3}{c}{ Atomic Concentration (\%) } \\
\cline { 2 - 4 } & $\mathrm{C}$ & $\mathrm{O}$ & $\mathrm{N}$ \\
\hline Epon828/mPDA & 83.5 & 14.3 & 2.2 \\
Epon828/DU-700 & 77.3 & 20.0 & 2.7 \\
\hline $\begin{array}{l}\text { Theoretical Value for } \\
\text { Epon828/mPDA }\end{array}$ & 83 & 13.8 & 3.1 \\
Theoretical Value for & & & \\
Epon828/DU-700 & 77.8 & 18.6 & 3.6 \\
\hline
\end{tabular}




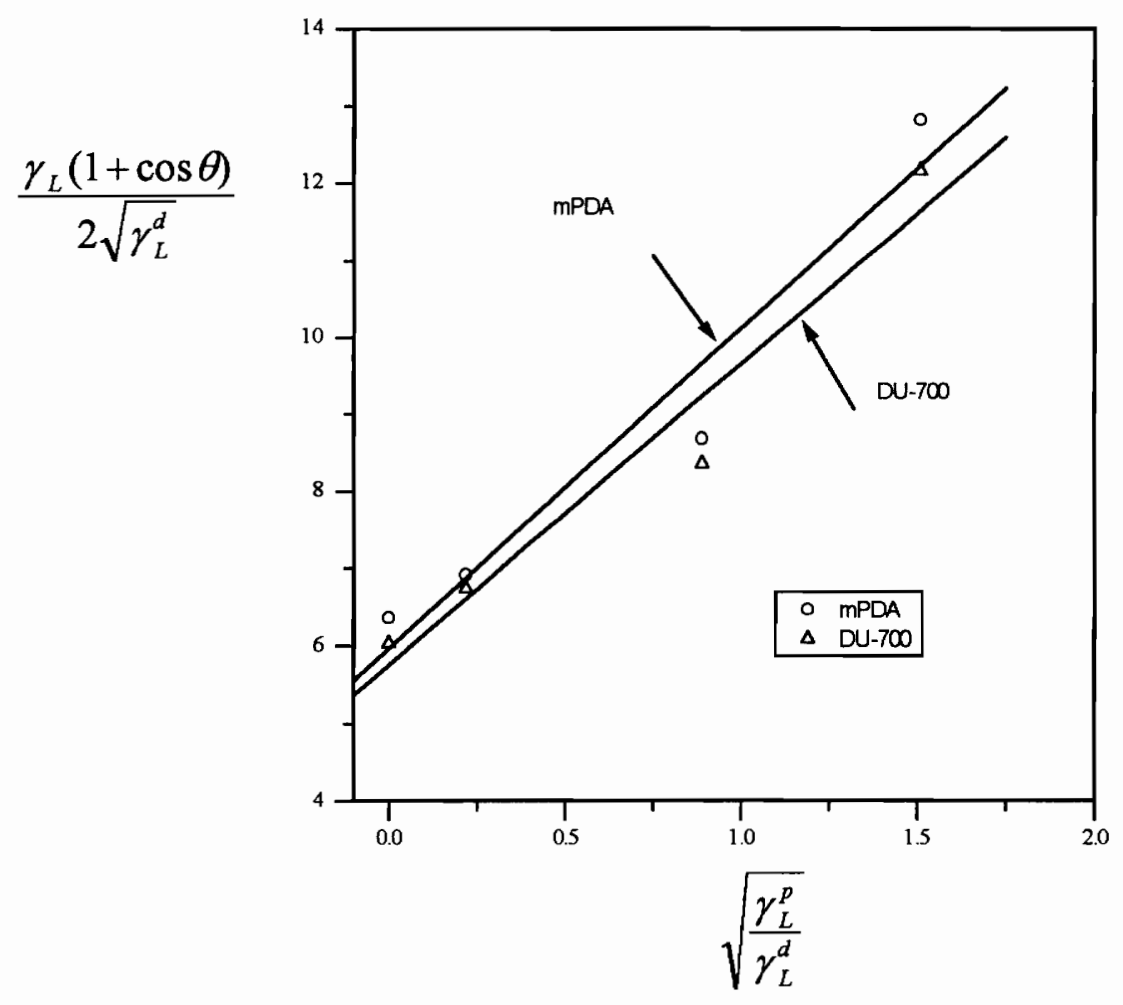

Figure 4.8 Contact angle analysis plots for Epon828/mPDA and Epon828/DU-700 resins. 
Table 4.8 Surface energies of epoxy resins.

\begin{tabular}{lccc}
\hline \multirow{2}{*}{ Resin } & \multicolumn{3}{c}{ Surface Energy $\left(\mathrm{mJ} / \mathrm{m}^{2}\right)$} \\
\cline { 2 - 4 } & $\gamma_{\mathrm{R}}{ }^{\mathrm{d}}$ & $\gamma_{\mathrm{R}}{ }^{\mathrm{p}}$ & $\gamma_{\mathrm{R}}{ }^{\text {Total }}$ \\
\hline Epon828/mPDA & 35.8 & 17.1 & 52.9 \\
Epon828/DU-700 & 33.3 & 15.3 & 48.6 \\
\hline
\end{tabular}


where $\mathrm{W}^{\mathrm{d}}$ and $\mathrm{W}^{\mathrm{p}}$ are the reversible work of adhesion corresponding respectively to dispersive and polar interactions, $\gamma_{\mathrm{F}}{ }^{\mathrm{d}}$ and $\gamma_{\mathrm{F}}{ }^{\mathrm{p}}$ are fiber dispersive and polar surface energies, and, $\gamma_{R}{ }^{d}$ and $\gamma_{R}{ }^{p}$ are resin dispersive and polar surface energies. The calculated reversible works of adhesion between the two materials are shown in Table 4.9.

\subsection{Fiber/Matrix Adhesion}

\subsubsection{Fiber Tensile Strength at Critical Length}

Single fiber tensile fracture strengths were measured at several gauge lengths to estimate the fiber strength at the critical length. Weibull plots of cumulative frequency of failure versus fiber break stress are shown in Figures 4.9 and 4.10 for AS-4 and Panex 33(S) fibers at various gauge lengths. Both types of fibers fit the Weibull distribution quite well.

The mean tensile strengths and standard deviations were obtained by the maximum likelihood approach of the two parameter Weibull distribution. As shown in Figure 4.11, the mean tensile strength increased as the gauge length increased and therefore the probability of fiber surface defects decreased. The measured data approximately fell on a straight line in the log-log plot of fiber tensile strength versus the gauge length as expected by two parameter Weibull model in Equation 3.10. Fiber strengths at the critical length were calculated by extrapolation of the data linear regression down to the critical length which is usually fractions of a millimeter. 
Table 4.9 Reversible work of adhesion (in $\mathrm{mJ} / \mathrm{m}^{2}$ ) between carbon fibers and epoxy resins.

\begin{tabular}{lcc}
\hline Fiber & Epon828/mPDA & Epon828/DU-700 \\
\hline AU-4 & 103 & 99.1 \\
Panex 33(U) & 102 & 98.3 \\
AS-4 & 124 & 119 \\
Panex 33(S) & 122 & 117 \\
\hline
\end{tabular}



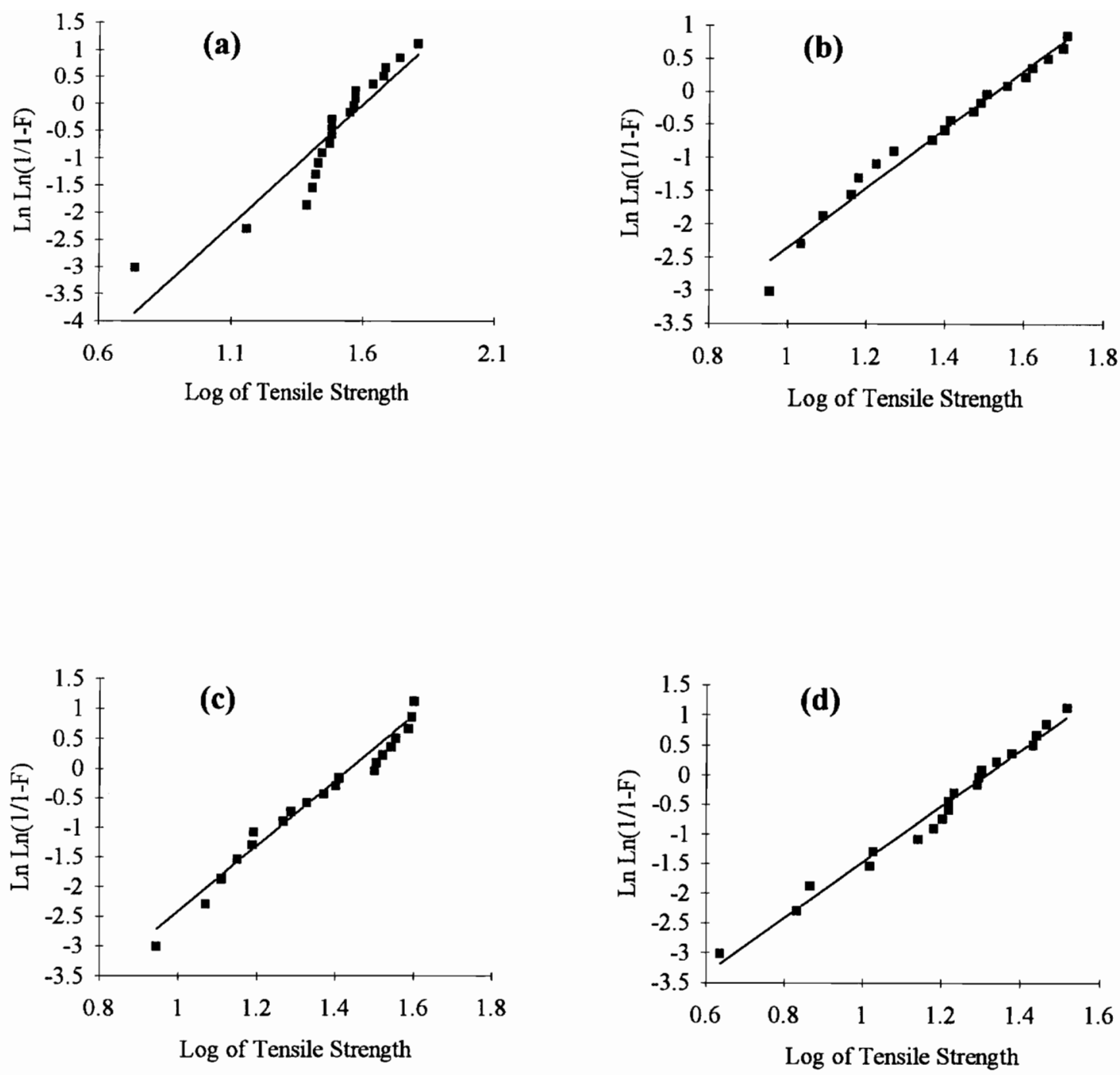

Figure 4.9 Weibull plots of strength distributions for AS-4 fibers at gauge lengths of (a) $1 \mathrm{~mm}$, (b) $12 \mathrm{~mm}$, (c) $20 \mathrm{~mm}$, and (d) $44 \mathrm{~mm}$. 

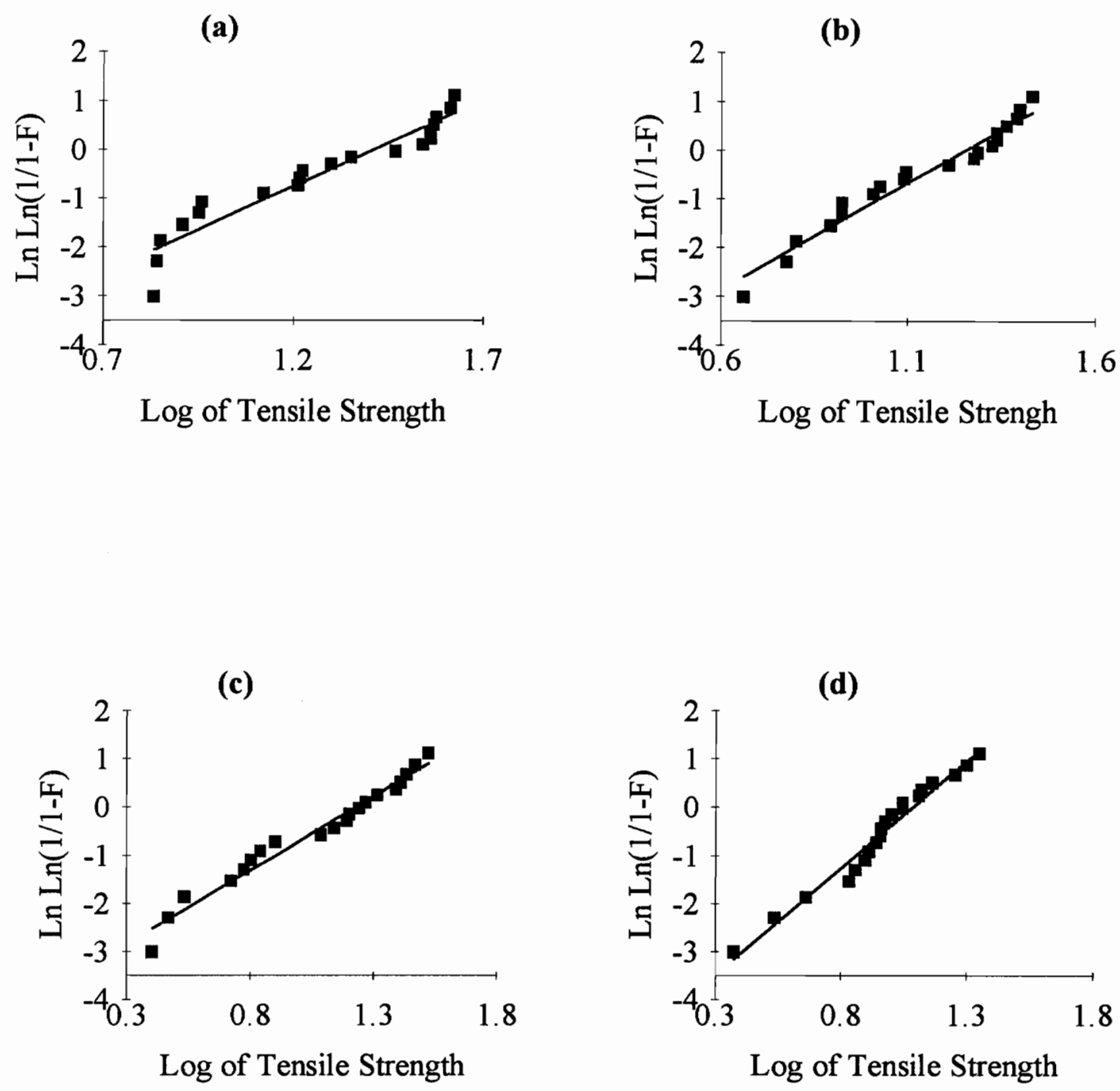

Figure 4.10 Weibull plots of strength distributions for Panex 33(S) fibers at gauge lengths of (a) $1 \mathrm{~mm}$, (b) $12 \mathrm{~mm}$, (c) $20 \mathrm{~mm}$, and (d) $44 \mathrm{~mm}$. 
(a)

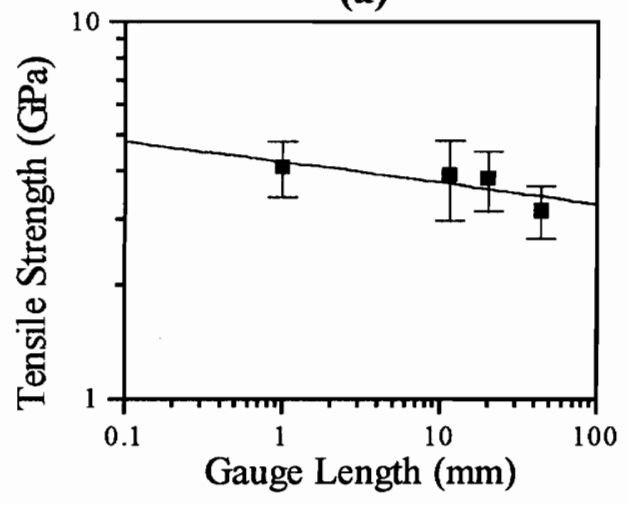

(c)

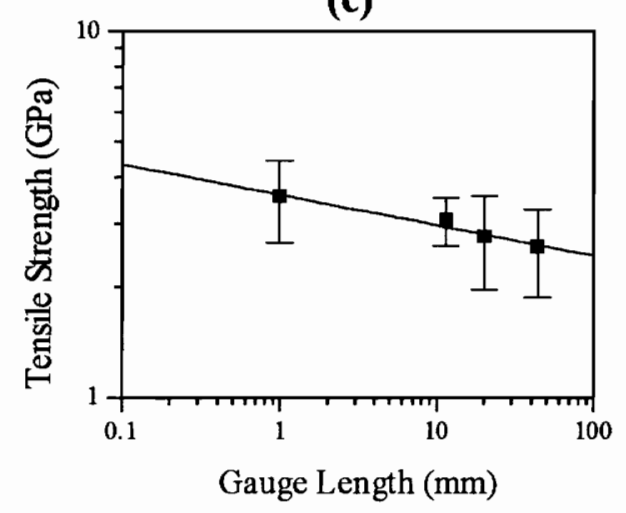

(b)

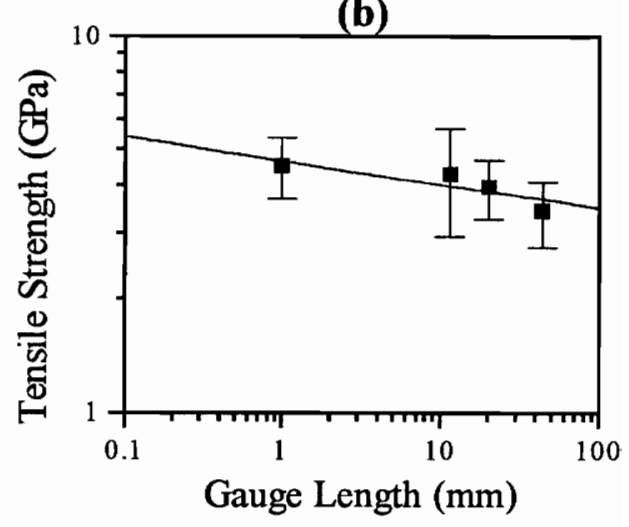

(d)

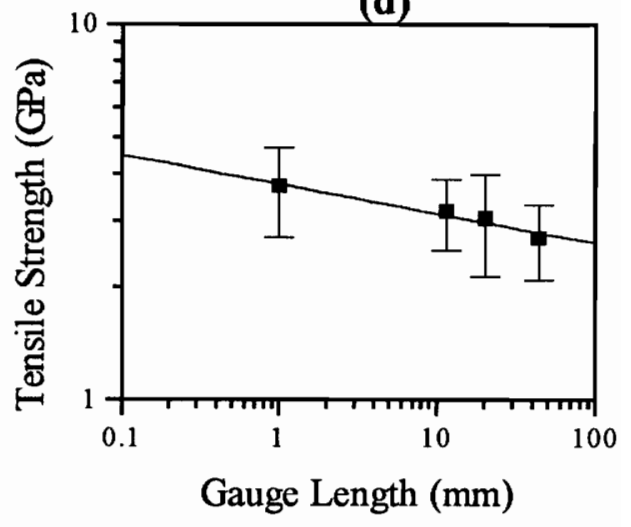

Figure 4.11 Fiber tensile strengths as a function of gauge length. (a) AU-4, (b) AS-4, (c) Panex 33(U), and (d) Panex 33(S). 


\subsubsection{Interfacial Shear Strength}

Carbon fiber/epoxy resin interfacial shear strength was measured using the single fiber fragmentation test. The test was conducted with a hand operated loading device to apply the tensile stress. The loading speed was not precisely $1 \mathrm{~mm} / \mathrm{min}$ but deviated within a range. Results by Sancaktar et al., cited in reference 120 , indicated that the average fiber fragment length decreased from $0.949 \mathrm{~mm}$ to $0.791 \mathrm{~mm}$ when the cross-head rate increased from $3.18 \mathrm{~mm} / \mathrm{min}$ to $25.4 \mathrm{~mm} / \mathrm{min}$. To estimate the effect of a smaller rate change range, tests were conducted under $1 \mathrm{~mm} / \mathrm{min}$ and $2 \mathrm{~mm} / \mathrm{min}$ cross-head speeds for AS-4/Epon 828-mPDA system. The average critical fragment lengths from six specimens were $0.314 \mathrm{~mm}$ and $0.308 \mathrm{~mm}$ respectively, indicating small deviation in the cross-head speed does not affect the fragment length significantly.

The test does not yield a single $l_{c}$ but a distribution because of the fiber surface flaws and fiber geometry. Figures 4.12 and 4.13 show the Weibull plots of fragment lengths obtained from the fragmentation test. The $1_{c}$ values used for calculations in this study were taken as the statistical mean of the two parameter Weibull distribution. Values of the mean critical length $l_{c}$, scale parameter $\beta$, shape parameter $\alpha$, fiber diameter $d$, extrapolated fiber tensile strength at critical length $\sigma_{\mathrm{f}}$, and calculated interfacial shear strength $\tau$, and their standard deviations for six specimens are summarized in Table 4.10. 
(a)

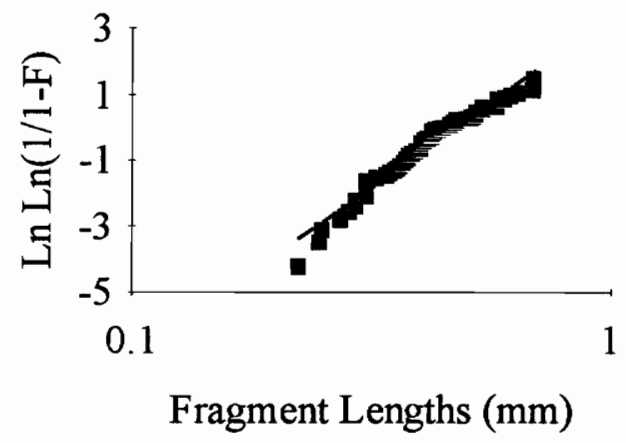

(c)

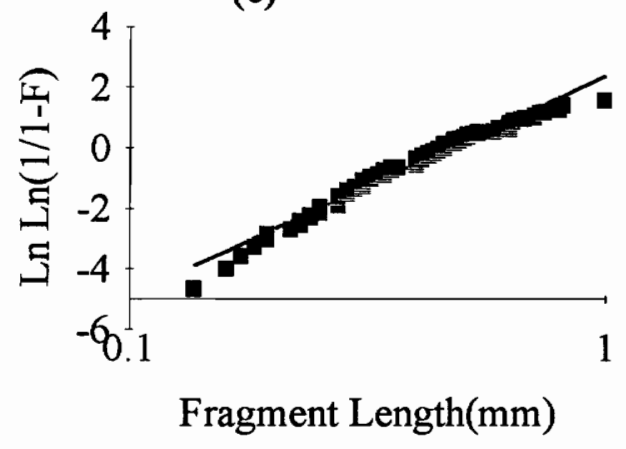

(b)

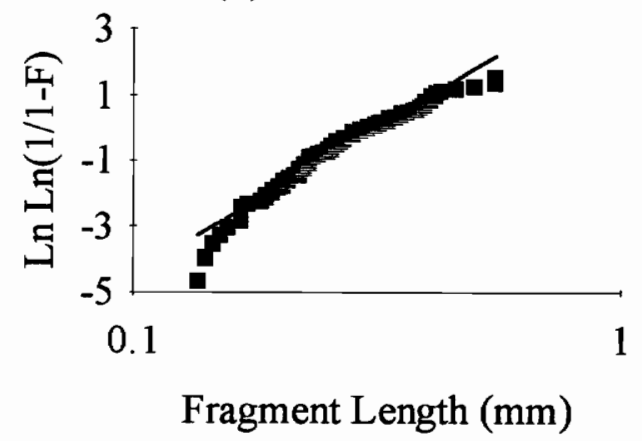

(d)

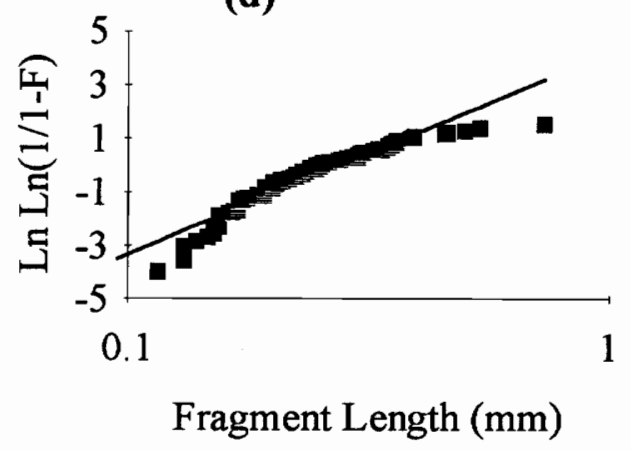

Figure 4.12 Weibull plots of fragment lengths by single fiber fragmentation tests with the fiber/Epon828-mPDA system. (a) AU-4 fiber, (b) AS-4 fiber, (c) Panex 33(U) fiber, and (d) Panex 33(S) fiber. 
(a)

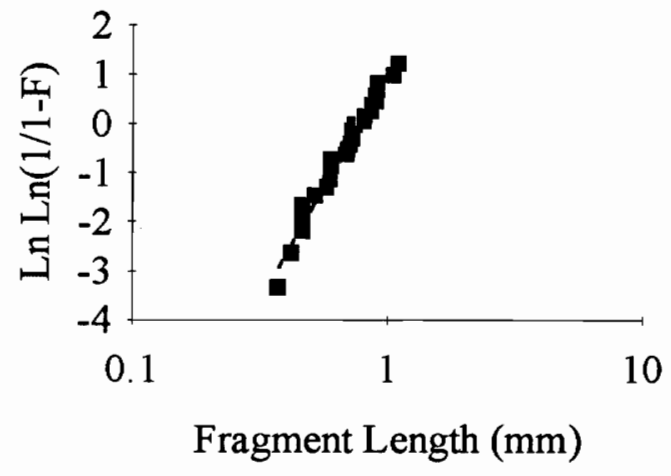

(c)

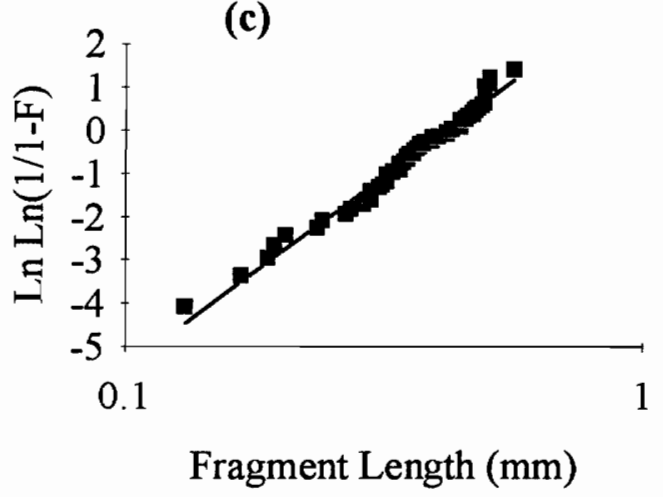

(b)

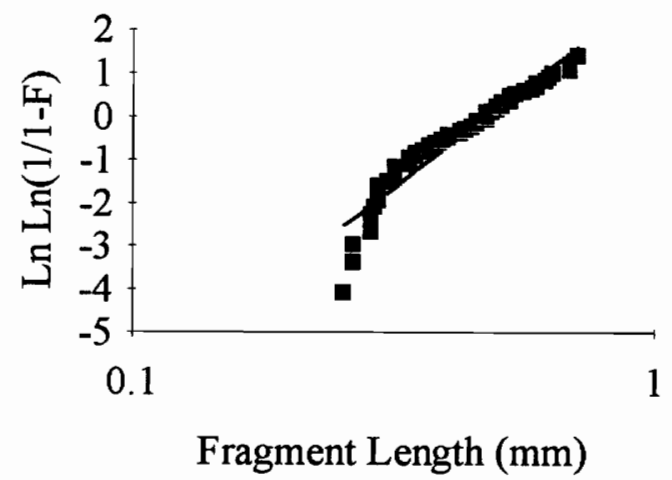

Figure 4.13 Weibull plots of fragment lengths by single fiber fragmentation tests with the fiber/Epon 828-DU700 system. (a) AU-4 fiber, (b) AS-4 fiber, (c) Panex 33(S) fiber. 
Table 4.10 Interfacial shear strength parameters.

\begin{tabular}{|c|c|c|c|c|c|c|}
\hline \multirow[b]{2}{*}{ Fiber/Matrix } & \multicolumn{3}{|c|}{$1_{c}$} & \multirow[b]{2}{*}{$\mathrm{d}(\mu \mathrm{m})$} & \multirow[b]{2}{*}{$\sigma_{\mathrm{f}}(\mathrm{GPa})$} & \multirow[b]{2}{*}{$\tau(\mathrm{MPa})$} \\
\hline & $\mathrm{lc}(\mathrm{mm})$ & $\beta$ & $\alpha$ & & & \\
\hline AU-4/mPDA & $0.44 \pm 0.06$ & $0.48 \pm 0.06$ & $4.4 \pm 1.0$ & $6.8 \pm 0.4$ & 4.4 & $34 \pm 5$ \\
\hline AS-4/mPDA & $0.31 \pm 0.04$ & $0.32 \pm 0.04$ & $3.8 \pm 0.8$ & $7.1 \pm 0.2$ & 5.0 & $57 \pm 7$ \\
\hline $\begin{array}{l}\text { Panex 33(U) } \\
\text { /mPDA }\end{array}$ & $0.51 \pm 0.08$ & $0.55 \pm 0.09$ & $3.8 \pm 1.0$ & $8.3 \pm 0.6$ & 3.8 & $31 \pm 5$ \\
\hline $\begin{array}{l}\text { Panex 33(S) } \\
\text { /mPDA }\end{array}$ & $0.28 \pm 0.06$ & $0.31 \pm 0.07$ & $3.5 \pm 0.9$ & $6.5 \pm 0.5$ & 4.2 & $49 \pm 10$ \\
\hline AU-4/DU-700 & $0.64 \pm 0.07$ & $0.70 \pm 0.07$ & $4.7 \pm 1.4$ & $6.8 \pm 0.4$ & 4.3 & $23 \pm 3$ \\
\hline AS-4/DU-700 & $0.47 \pm 0.05$ & $0.51 \pm 0.05$ & $4.1 \pm 0.5$ & $7.1 \pm 0.2$ & 4.9 & $37 \pm 4$ \\
\hline $\begin{array}{l}\text { Panex 33(S) } \\
\text { /DU-700 }\end{array}$ & $0.41 \pm 0.06$ & $0.44 \pm 0.06$ & $4.8 \pm 1.0$ & $6.5 \pm 0.5$ & 4.0 & $32 \pm 5$ \\
\hline
\end{tabular}


The calculated interfacial shear strengths in Table 4.10 show that the surface treated AS-4 and Panex 33(S) fibers gave substantially higher level of interfacial adhesion with both epoxy matrices compared to untreated fibers. The improved interfacial adhesion may result from the increased fiber surface oxygen content, increased polar component and therefore total fiber surface energy by the surface treatment. Figures 4.14 and 4.15 show the direct correlation between interfacial shear strength and fiber surface $\mathrm{O} / \mathrm{C}$ ratio and fiber surface total energy. Another possible important effect is that surface treatment may remove a weakly bound layer from the original fiber surface leading to a mechanically sound surface to which the resin can form a good bond.

Surface roughness is another factor possibly affecting interfacial adhesion. Two types of surface topography were available in this study. The Panex 33(U) and Panex 33(S) fibers had rough, striated surface whereas the AU-4 and AS-4 had rather smooth surfaces. A general model has been proposed by Nardin et al. ${ }^{121}$ that a linear relationship should exist between the interfacial shear strength and the reversible energy of adhesion $\mathrm{W}_{0}$ :

$$
\tau=\left(\frac{E_{m}}{E_{f}}\right)^{1 / 2} \frac{W_{0}}{\lambda}
$$

where $E_{m}$ and $E_{f}$ are the moduli of matrix and fiber respectively, and $\lambda$ is a constant corresponding to the distance between atoms undergoing physical interaction. Figure 4.16 shows the relationship between the interfacial work of adhesion and interfacial shear strength for the systems in this study. For both systems, Panex fibers deviated to a lower level of adhesion instead of a higher level as expected for a rough surface morphology by a mechanical interlocking type mechanism. This discrepancy was attributed to the difficulties for the matrix resin to completely fill the sunken pit of the fiber surface striations leading to a reduction of interfacial area. When the resin comes in contact with the striated fiber surface, small amounts of residual air could be sealed in the bottom of the pits. The pressure of these isolated air bubbles increased when the temperature was raised 


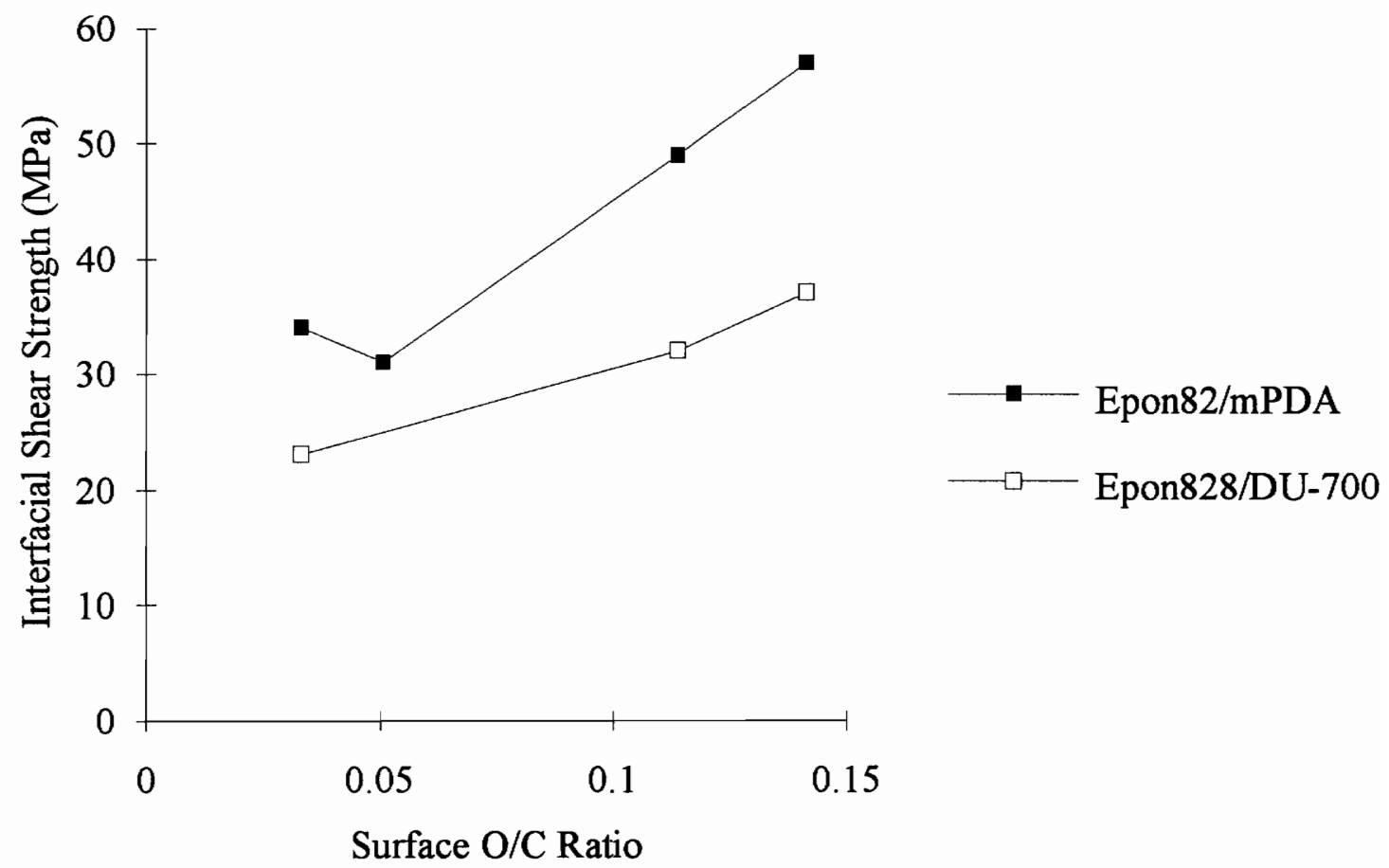

Figure 4.14 Relationship between fiber surface oxygen and interfacial shear strength. 


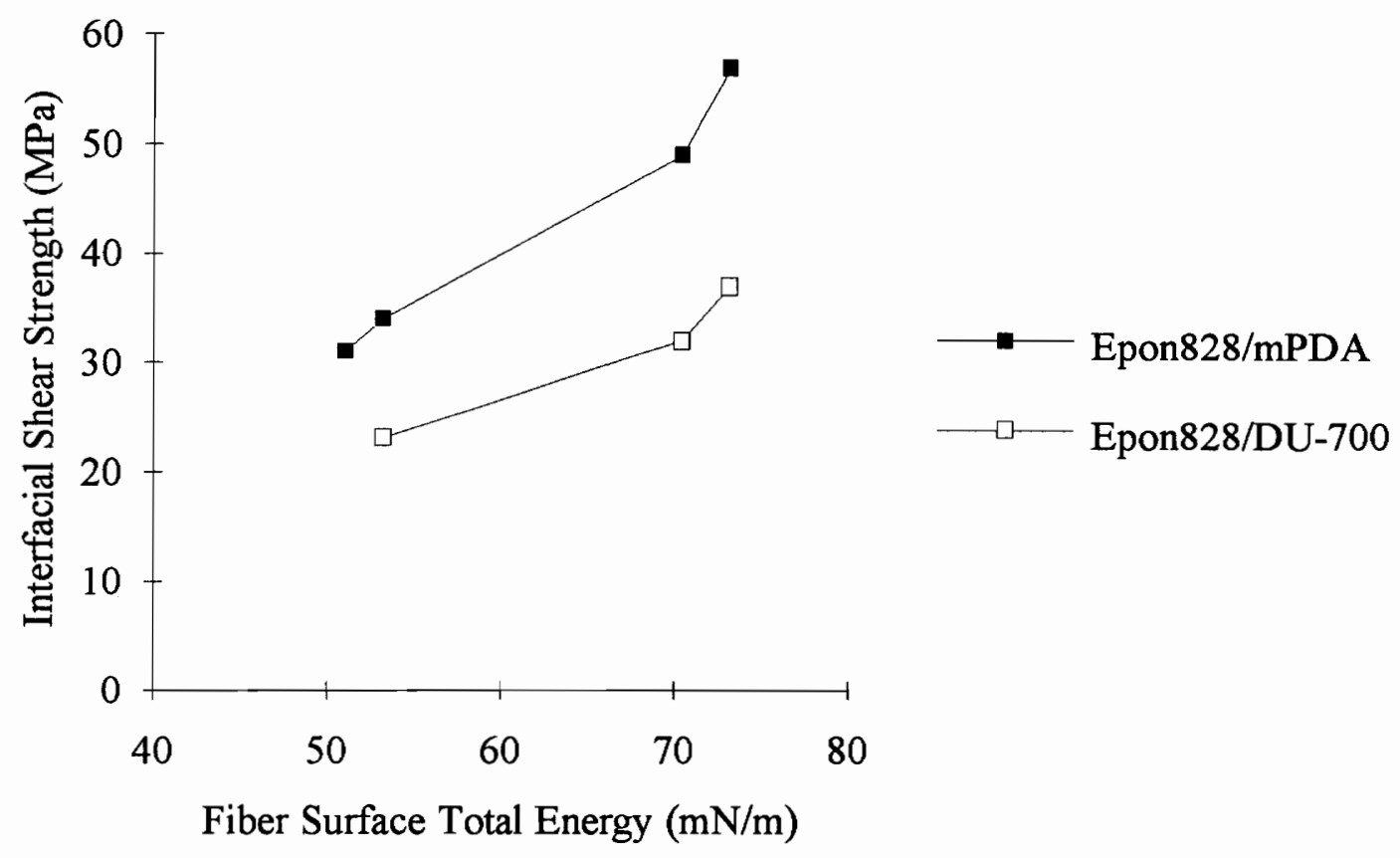

Figure 4.15 Relationship between fiber surface total energy and interfacial shear strength. 


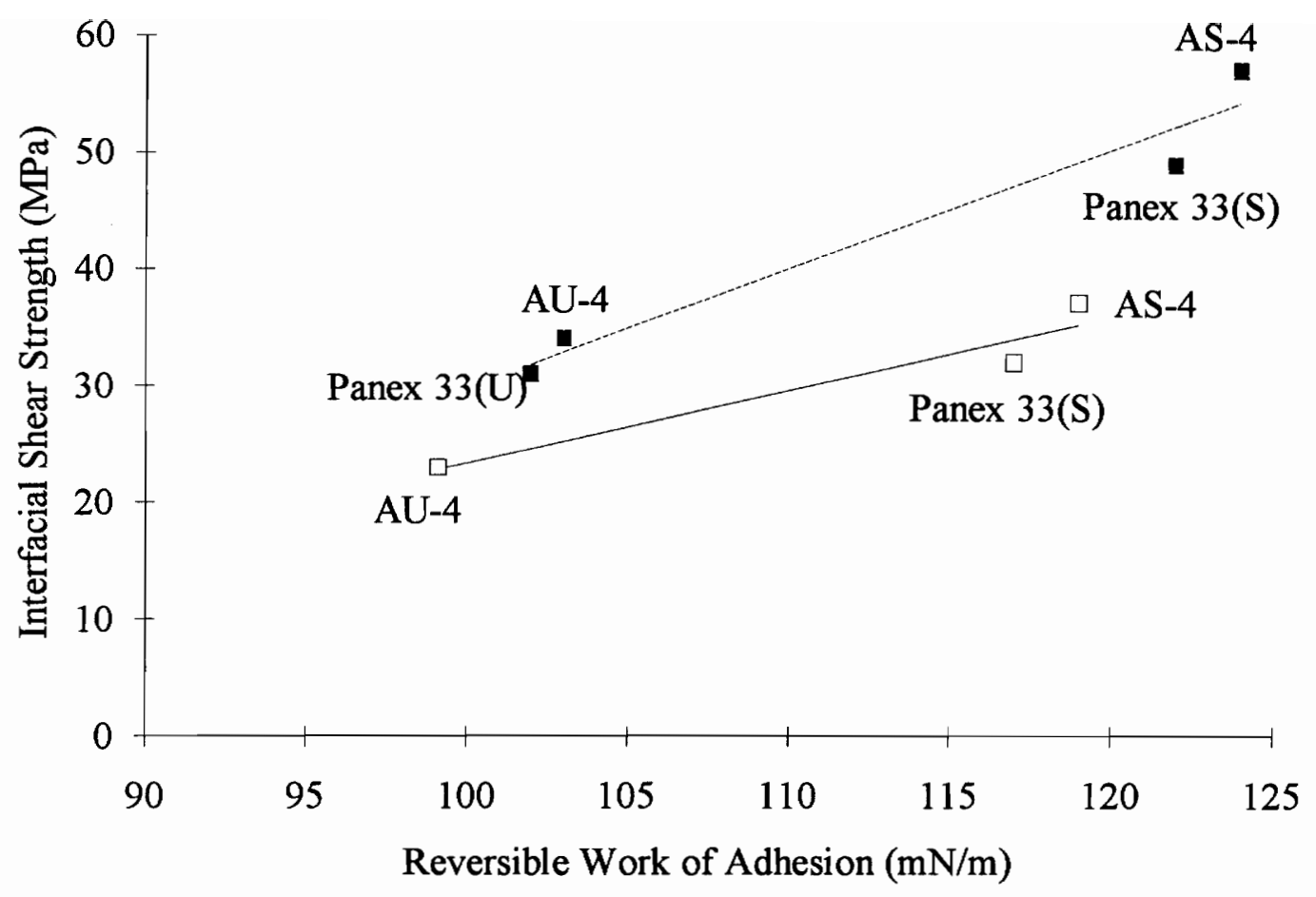

Figure 4.16 Relationship between the reversible work of adhesion and interfacial shear strength. 
for cure leading to more resistance to further filling by the resin. Figure 4.17 shows the SEM photomicrograph of Panex 33(S)/Epon828-DU-700 single fiber composite sample cross section. Some void areas at the bottom of striation between fiber and matrix are visible.

Because of the photoelastic nature of the matrix, more information about stress distribution at the interface was obtained by studying the birefringence produced during the test process. Figure 4.18 are stress birefringence patterns obtained at the moment when multiple fiber breaks just occurred in AU-4, AS-4, and Panex 33(S) with mPDA cured Epon828 systems. Stress induced birefringence built up around the interface with a bulbous region at the fiber end. This bulbous region documented the fact that the interfacial shear stress was most concentrated near the fiber ends. The surface treated fibers behaved differently than the untreated AU-4 fiber. Fiber break was shorter and stress more intense and broader for the surface treated fibers (Figures $18 \mathrm{~b}$ and $18 \mathrm{c}$ ). As shown in Figures 4.19-4.21, with increased strain, the bulbous region moved away from the break end toward the center of the fragment, indicating failure occurred at the end and gradually propagated to the middle. The failed region left a sheath of birefringence. Removing the specimen from the test device and thereby releasing the applied tension, caused the disappearance of the bulbous region but the sheath of birefringence persisted even after a period of relaxation. Figure 4.22 is the polarized transmitted light photograph of samples after the tensile stress was released for 4 hours. The birefringent sheath was still clear. Bascom and Jensen ${ }^{122}$ reported that the same pattern persisted for months. This persistent sheath region was attributed by Bascom and Jensen ${ }^{122}$ to plastic deformation failure of the matrix and was considered as evidence for resin shear yield failure mode. Evidence in this study suggested that all failures occurred by an interfacial stick-slip mechanism. The explanation of the persistence of the sheath is that the friction between interfacial slip failed fiber and matrix preventing the stress from relaxing. Figure 4.22 also showed that the failure region was more extensive in the AU-4 fiber system than in AS-4 and Panex 33 system under the same strain level. 


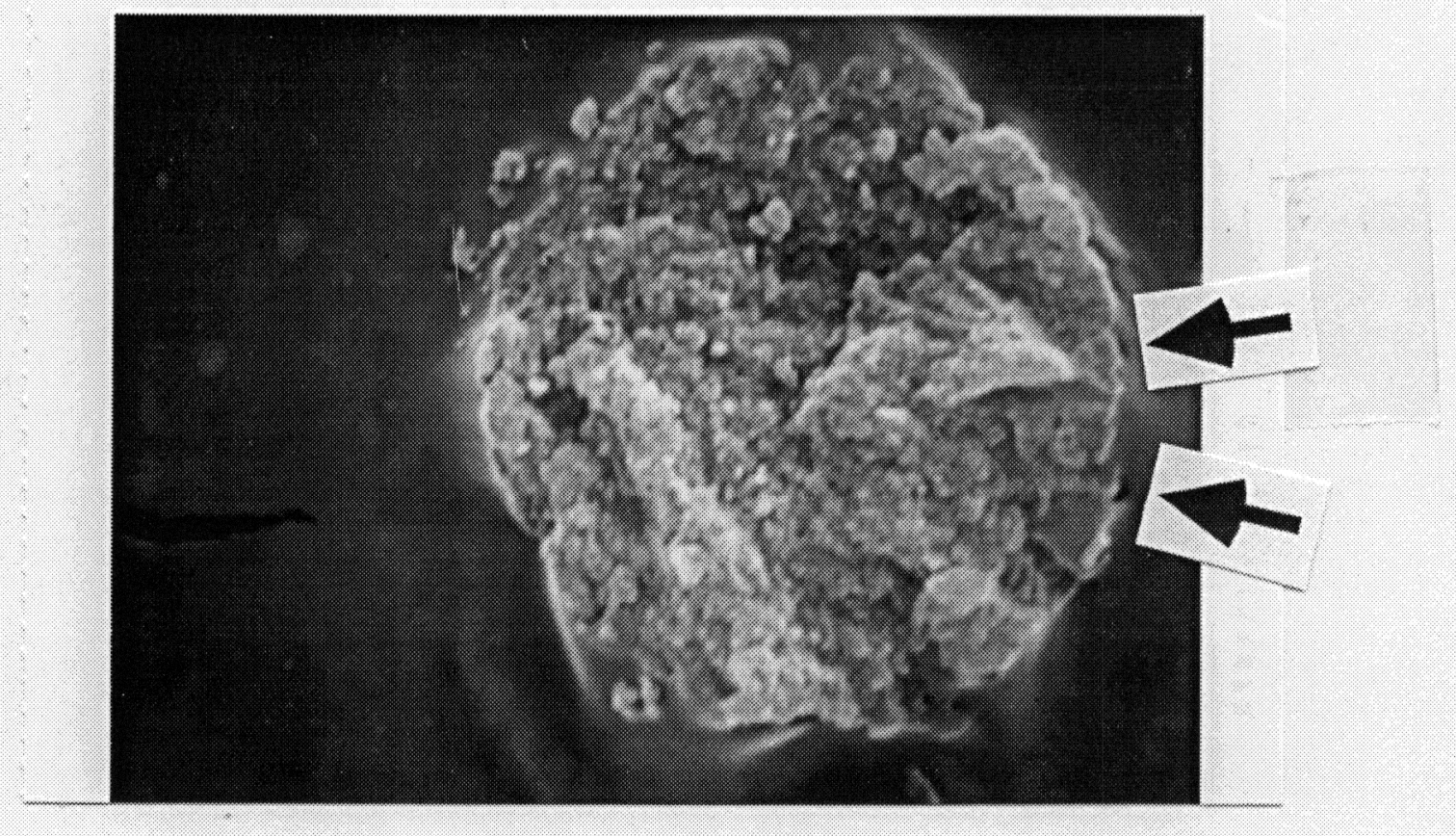

Figure 4.17 SEM photomicrograph of the Panex 33(S)/Epon828-DU700 interface. 


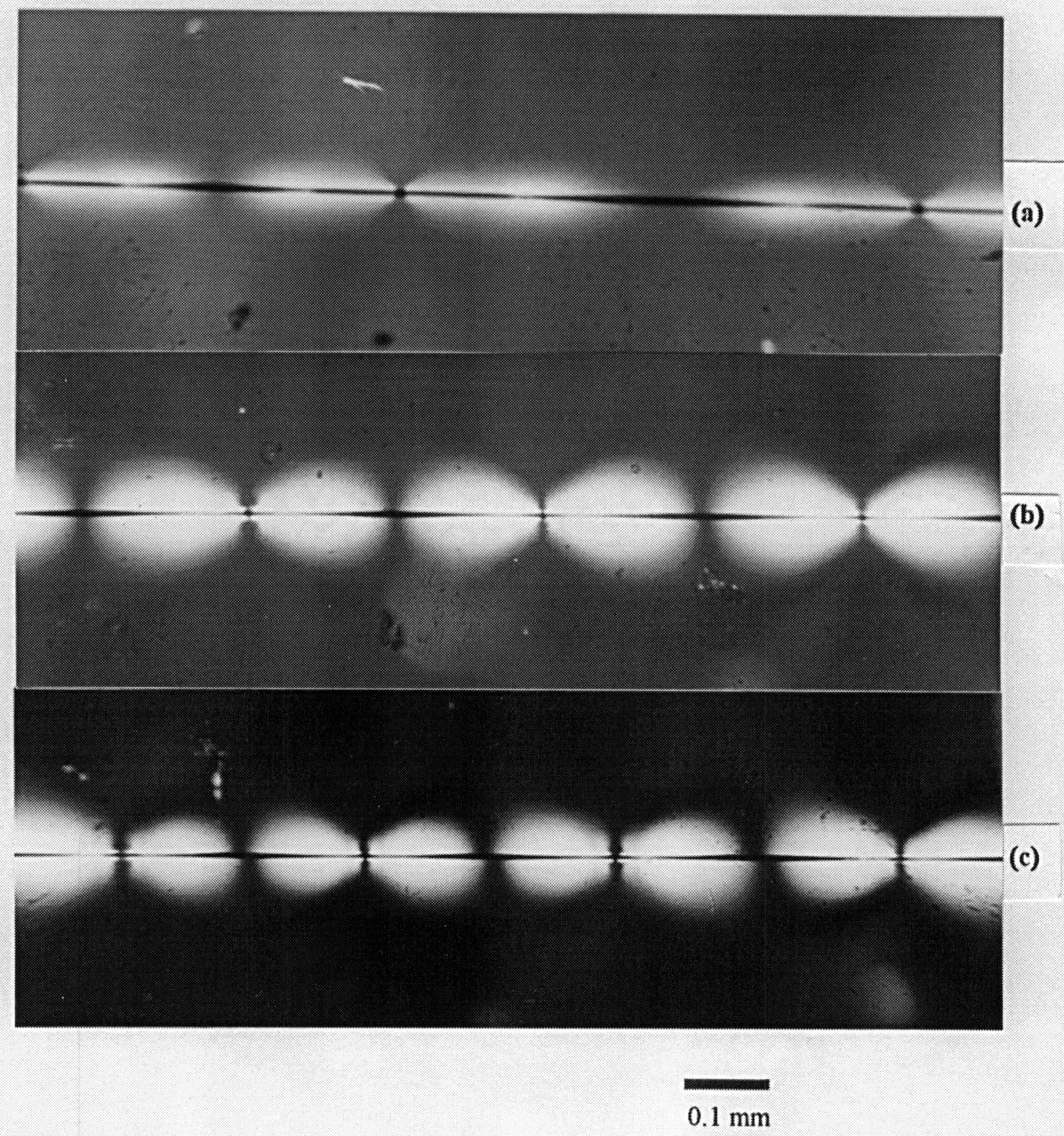

Figure 4.18 Stress birefringence patterns at multiple fiber break occurs. (a) AU-4, (b) AS-4, and (c) Panex 33(S) in Epon828/mPDA. 


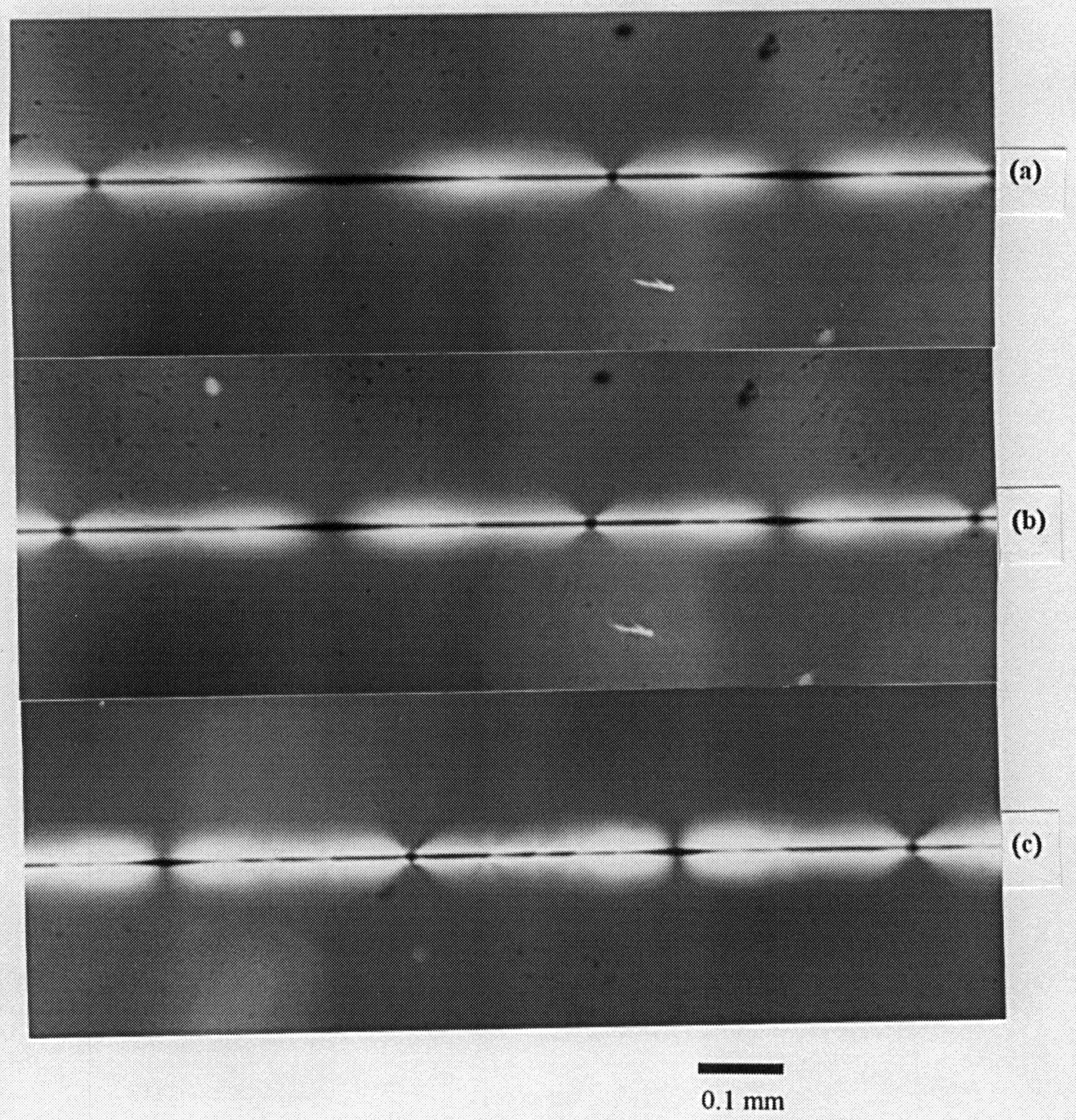

Figure 4.19 The change of birefringence pattern with increasing strain in AU-4/Epon828mPDA system. (a) initial break, (b) $1 \%$ more elongation after initial break, (c) $2 \%$ more elongation after initial break. 


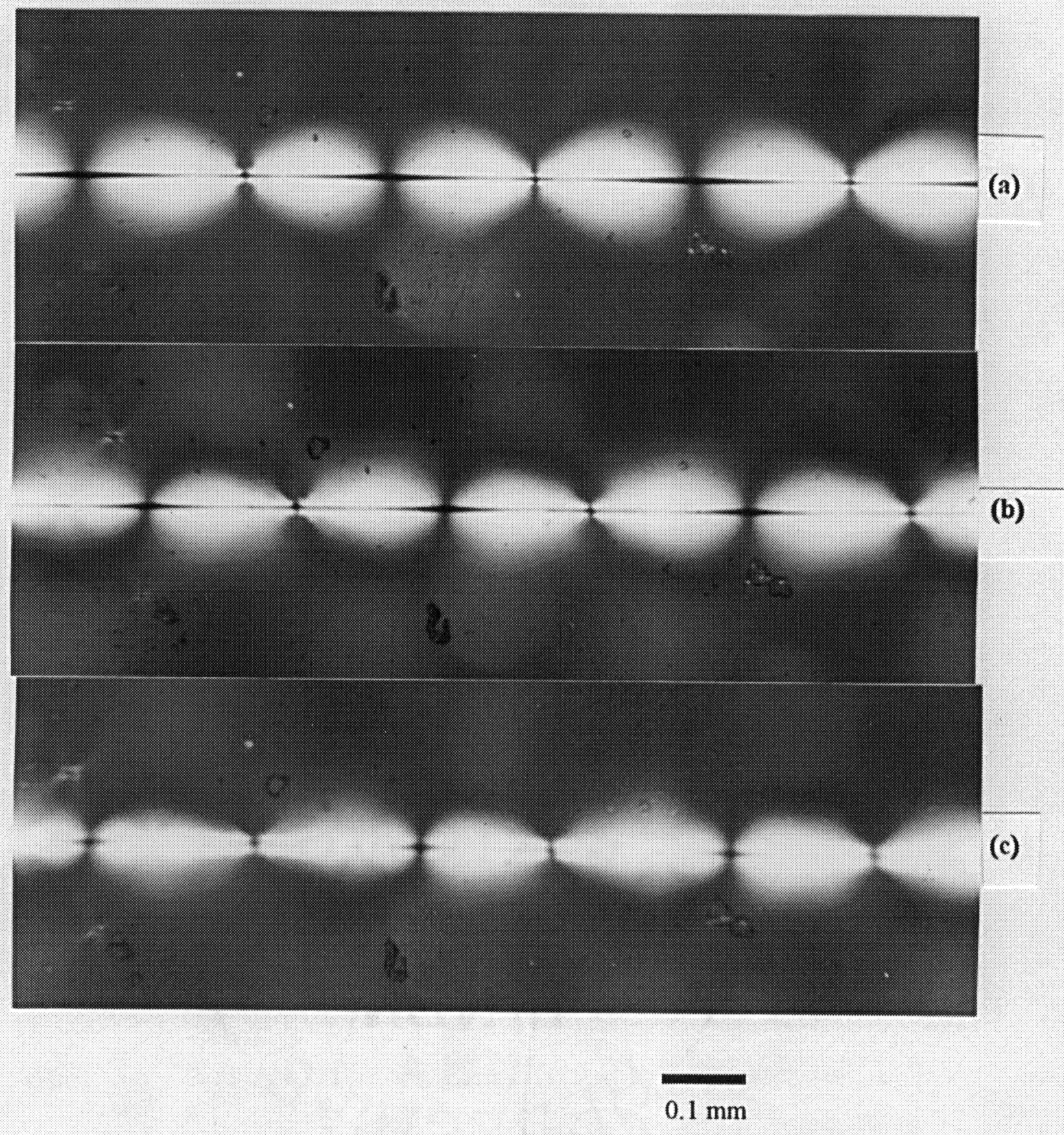

Figure 4.20 The change of birefringence pattern with increasing strain in AS-4/Epon828mPDA system. (a) initial break, (b) $1 \%$ more elongation after initial break, (c) $2 \%$ more elongation after initial break. 


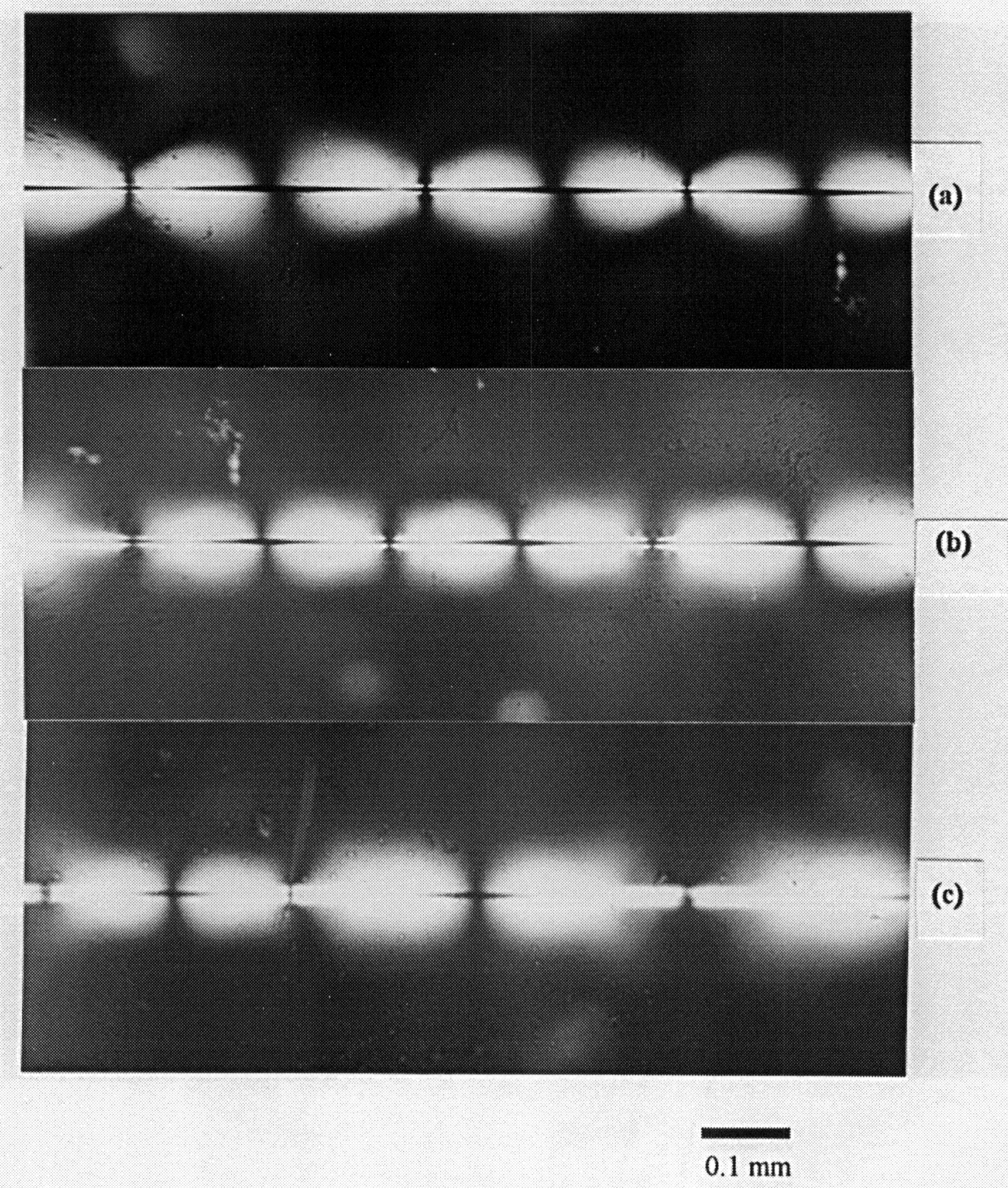

Figure 4.21 The change of birefringence pattern with increasing strain in Panex 33(S) /Epon828-mPDA system. (a) initial break, (b) $1 \%$ more elongation after initial break, (c) $2 \%$ more elongation after initial break. 


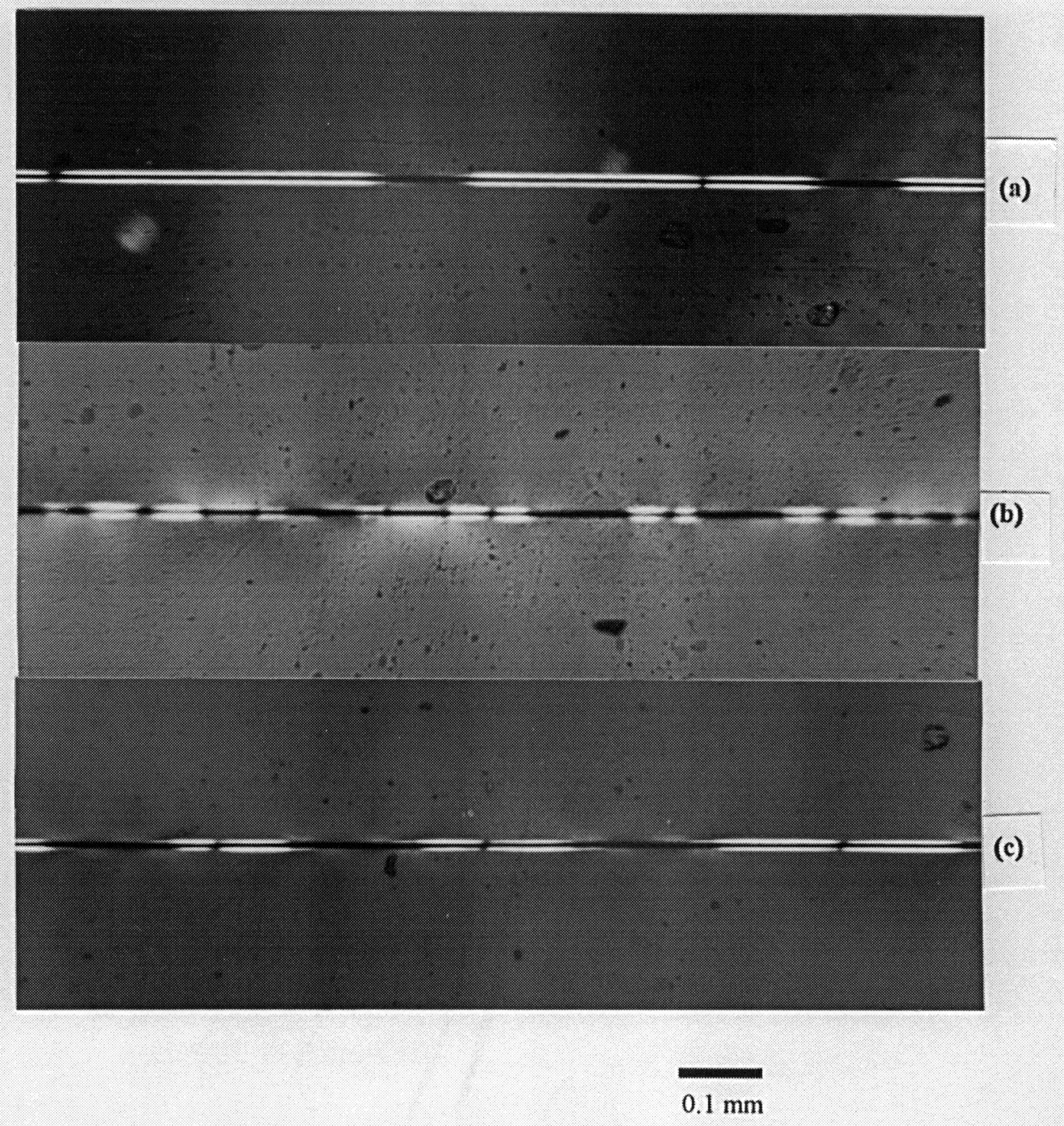

Figure 4.22 Birefringence patterns after tension has been removed for four hours. (a) AU-4, (b) AS-4 and (c) Panex 33(S) in Epon828-mPDA. 


\subsubsection{Effect of Temperature}

The influence of temperature on the interfacial shear strength (IFSS) measured by the single fiber fragmentation test is illustrated in Figures 4.23 and 4.24. The error bars represent the standard deviation of the mean value for each of the six samples tested. The glass transition temperatures measured by DSC were $144^{\circ} \mathrm{C}$ for mPDA cured Epon 828 and $19^{\circ} \mathrm{C}$ for Jeffamine DU-700 cured Epon828.

In the fiber/Epon828-mPDA system, in which all temperatures were below $\mathrm{Tg}$, IFSS generally decreased with increasing temperature. The decrease of matrix modulus with increasing temperature was one cause for IFSS reduction. The predictions of effect of matrix modulus on interfacial adhesion by researchers based on varying assumptions end up with a similar expression: ${ }^{123}$

$$
\frac{l_{c}}{d}=C \sqrt{\frac{E_{f}}{G_{m}}}
$$

where $l_{c}$ is the critical fragment, $d$ is the fiber diameter, $\mathrm{C}$ is a proportionality constant, and $E_{f}$ and $G_{m}$ are the Young's modulus of the fiber and the shear modulus of the matrix, respectively.

The relaxation of thermal residual stress due to increased temperature contribute to the decrease of IFSS too. The presence of residual stresses due to the cooling of the material from the processing temperature to the final temperature (usually room temperature) plays a role in the formation to the fiber-thermosetting matrix adhesion ${ }^{124}$, although maybe less important compared with the case of thermoplastic matrices ${ }^{125}$. The equation which give the stress state at the fiber-matrix interface as a result of the residual stresses is the following ${ }^{126}$ :

$$
\sigma_{r}=\frac{\left(\sigma_{m}-\sigma_{f}\right) \Delta T E_{m}}{1+v_{m}+\left(1-v_{f}\right) \frac{E_{m}}{E_{f}}}
$$




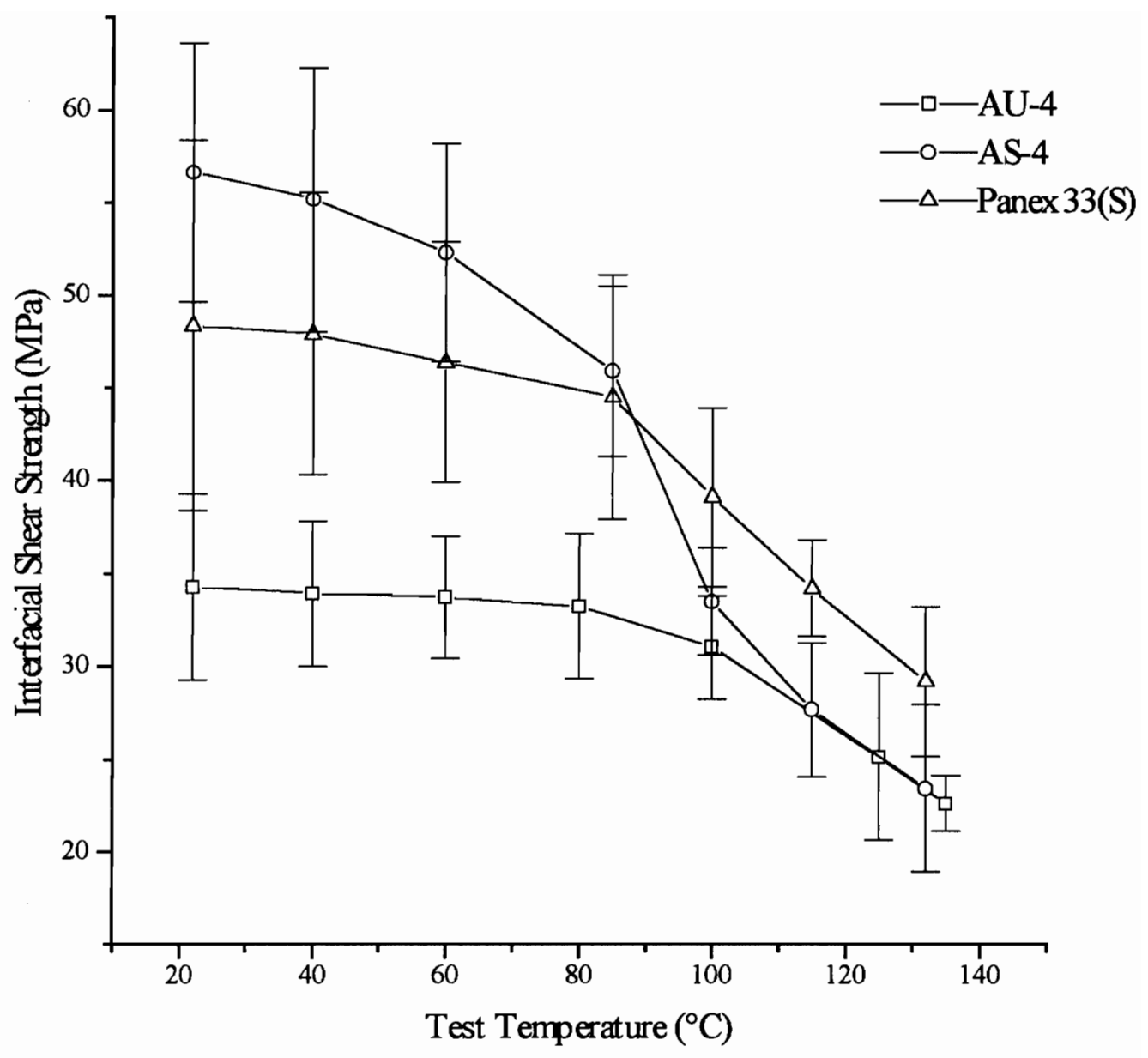

Figure 4.23 Temperature dependence of interfacial shear strength for AU-4, AS-4 and Panex 33(S) fibers in Epon828/mPDA. 


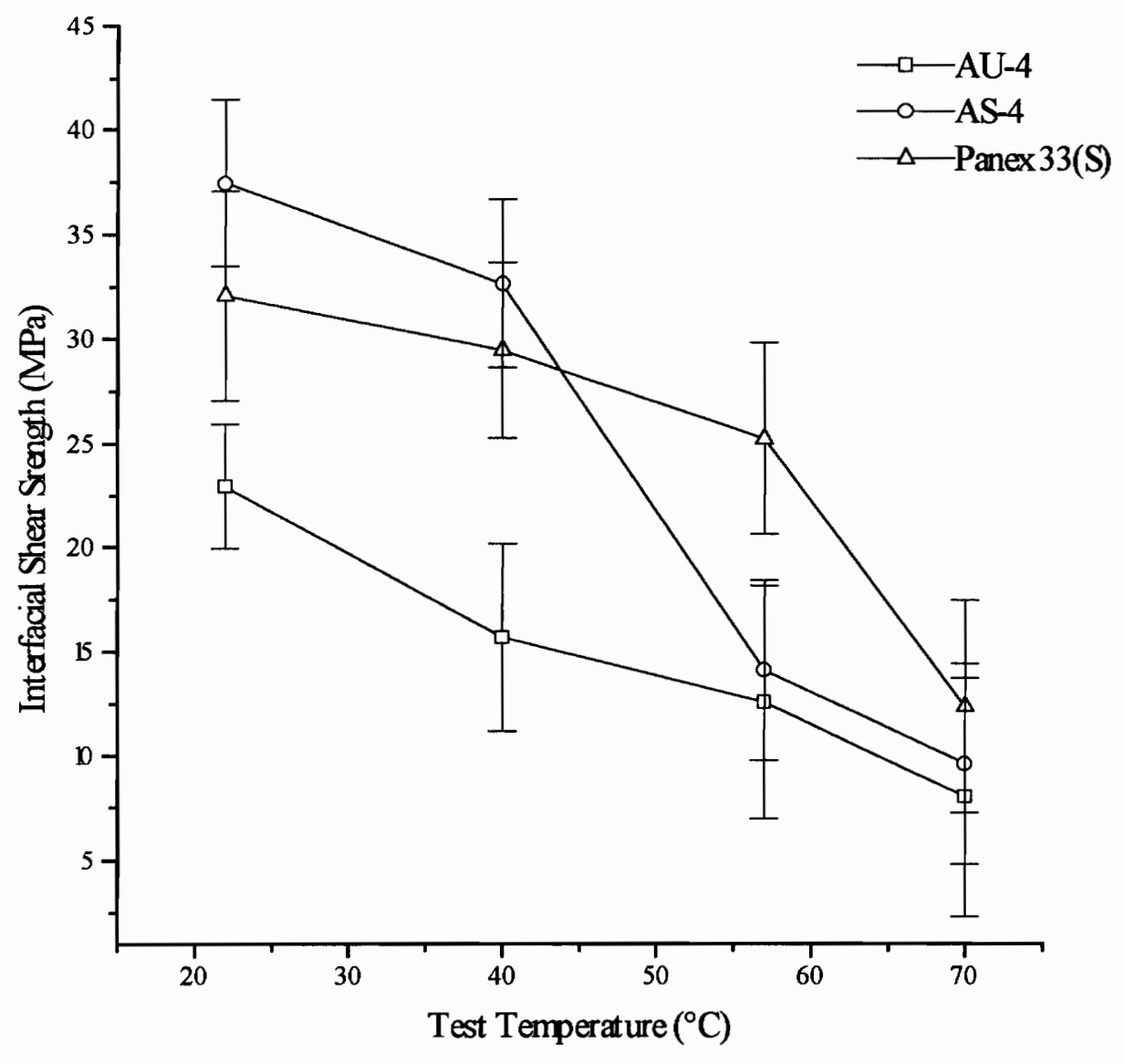

Figure 4.24 Temperature dependence of interfacial shear strength for AU-4, AS-4 and Panex 33(S) fibers in Epon828/Jeffamine DU-700. 
where $\sigma_{\mathrm{r}}$ is the radial stress at the interface, $\alpha$ is the linear expansion coefficient, $\Delta \mathrm{T}$ is the temperature difference between the processing and the test temperatures, $\mathrm{E}$ is the elastic modulus, $v$ is the Poisson coefficient, and subscripts $f$ and $m$ refer to fiber and matrix respectively. By examine this equation we can see that the higher the test temperature the lower the radial stress and therefore the lower the interfacial shear strength.

A dramatic decrease in IFSS especially in the AS-4 fiber system was observed at temperatures about $80^{\circ} \mathrm{C}$ which is much lower than the glass transition temperature of the bulk polymer. The phenomenon has been found by other authors and has been attributed to the existence of an interphase zone of lower glass transition temperature and modulus than the bulk matrix. ${ }^{123,127-128}$ This interphase zone is presumed to be generated by preferential adsorption of the amine on the fiber surface and thus a stoichiometric imbalance between resin and curing agent develops in the vicinity of the fiber.

After this major decrease, the IFSS of the surface treated AS-4 fiber system decreased to essentially the same level as that of untreated AU-4 fiber system. Two reasons were suggested to account for this effect. (1) The interfacial strength is controlled by interfacial interactions at low temperature and systems with different surface properties leading to different levels of adhesion. When the temperature was increased, matrix properties decreased such that the matrix became the weakest linkage in the system. The interface strength was then matrix controlled which was the same for all the fibers. (2) The higher surface energy, more surface functionalized AS-4 fiber established more interatomic/intermolecular actions with the matrix resin at low temperature. With increasing temperature, thermal motion increased and kinetic energy $\left(\frac{3}{2} R T\right)$ overcame the hydrogen and secondary bonding energies so that these forces no longer contributed as much to the interfacial adhesion. The fact that AS-4 and AU-4 fell to the same adhesion level after $100^{\circ} \mathrm{C}$ suggested that surface treated AS-4 fiber had not formed significantly 
more chemical bonding with the matrix resin because much higher temperature would be needed to break chemical bonding.

Although the Panex 33(S) fiber did not give superior initial interfacial adhesion, this system maintained a higher IFSS over a wider temperature range than AS-4. This fact can be attributed to the greater degree of surface roughness of Panex 33(S) fiber compared to the AS-4 fiber. The interfacial interactions predominated at low temperature whereas mechanical interlocking caused by surface roughness enhanced the IFSS when interfacial interactions were diminished at high temperature.

In the Jeffamine DU-700 cured Epon828 systems, in which all temperatures were all above Tg, similar tends were found. IFSS decreased with temperature. The AS-4 and AU-4 systems fell to a similar level of IFSS at high temperature. Panex 33(S) gave higher IFSS over a wider temperature region than the AS-4 fiber. IFSS measurement at high temperature in the Epon 828/DU-700 system was difficult and the data deviation was large because of very low levels of interfacial adhesion and a very soft matrix.

\subsubsection{Effect of Humidity}

The effect of humidity on the durability of the fiber/matrix interface was studied by measuring the interfacial shear strength after specimens were exposed to humidity environments for a period of time. For the effect of humidity to be tested in a reasonable time, the fiber was placed near the surface of the specimen. The depth of the fiber in the matrix was measured by a micrometer with the aid of microscope focusing as $0.2 \mathrm{~mm}$ from the sample surface.

Figures 4.25 and 4.26 show the interfacial shear strength changes in fiber/Epon828-mPDA systems when single fiber specimens were exposed to $100 \%$ relative humidity at $23^{\circ} \mathrm{C}$ and $75^{\circ} \mathrm{C}$ respectively. The IFSS values for the samples stored at dry condition are shown in Figures 4.27 and 4.28. 


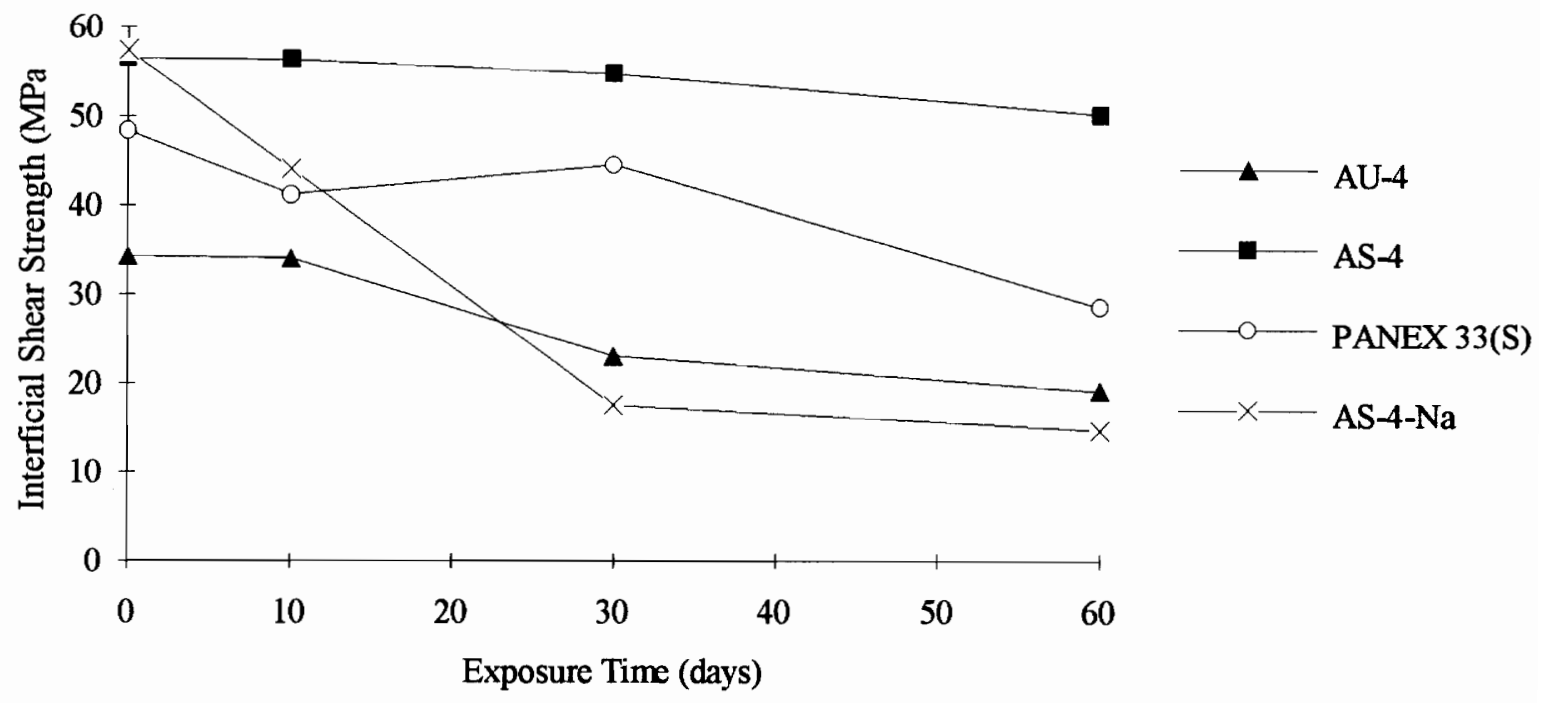

Figure 4.25 The influence of exposure time on interfacial shear strength in fiber/Epon828-mPDA system at $23^{\circ} \mathrm{C} 100 \% \mathrm{RH}$. 


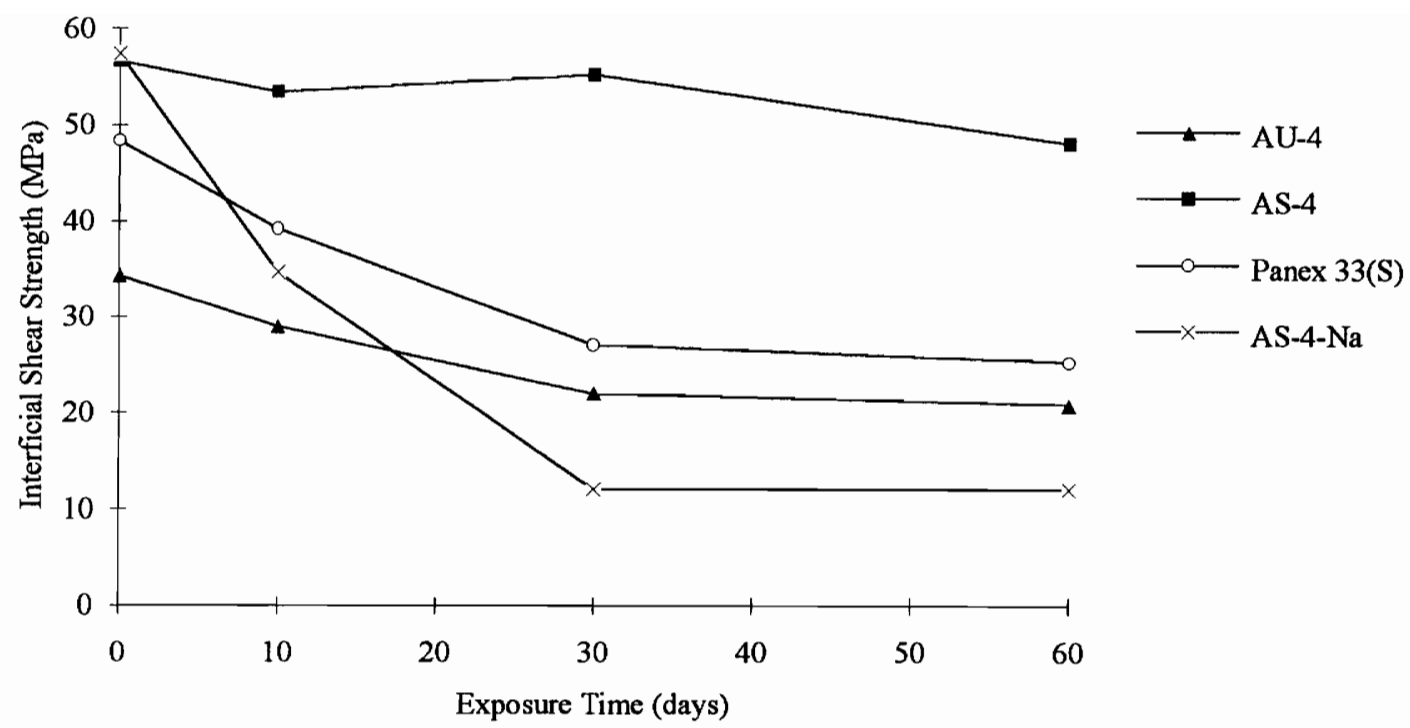

Figure 4.26 The influence of exposure time on interfacial shear strength in fiber/Epon828-mPDA system at $75^{\circ} \mathrm{C} 100 \% \mathrm{RH}$. 


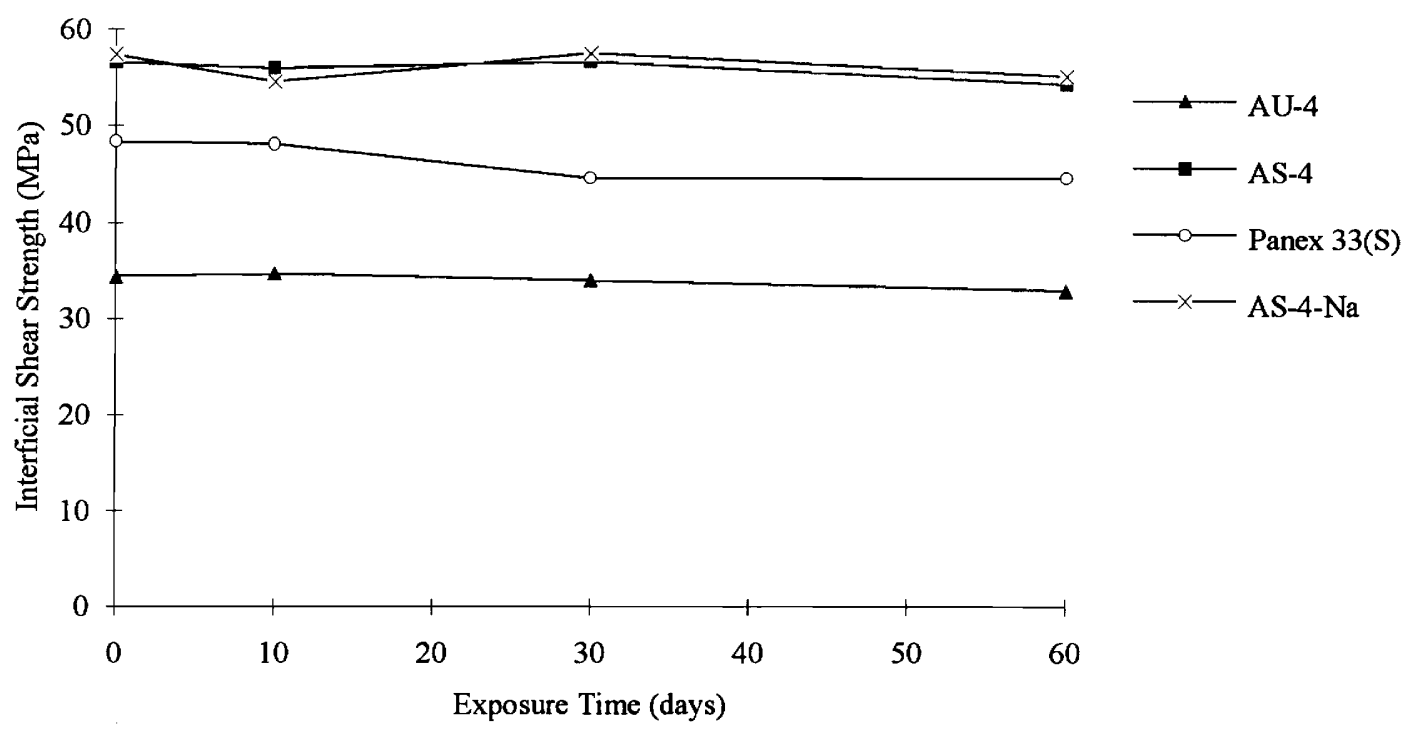

Figure 4.27 The influence of exposure time on interfacial shear strength in fiber/Epon828-mPDA system at $23^{\circ} \mathrm{C} 0 \% \mathrm{RH}$. 


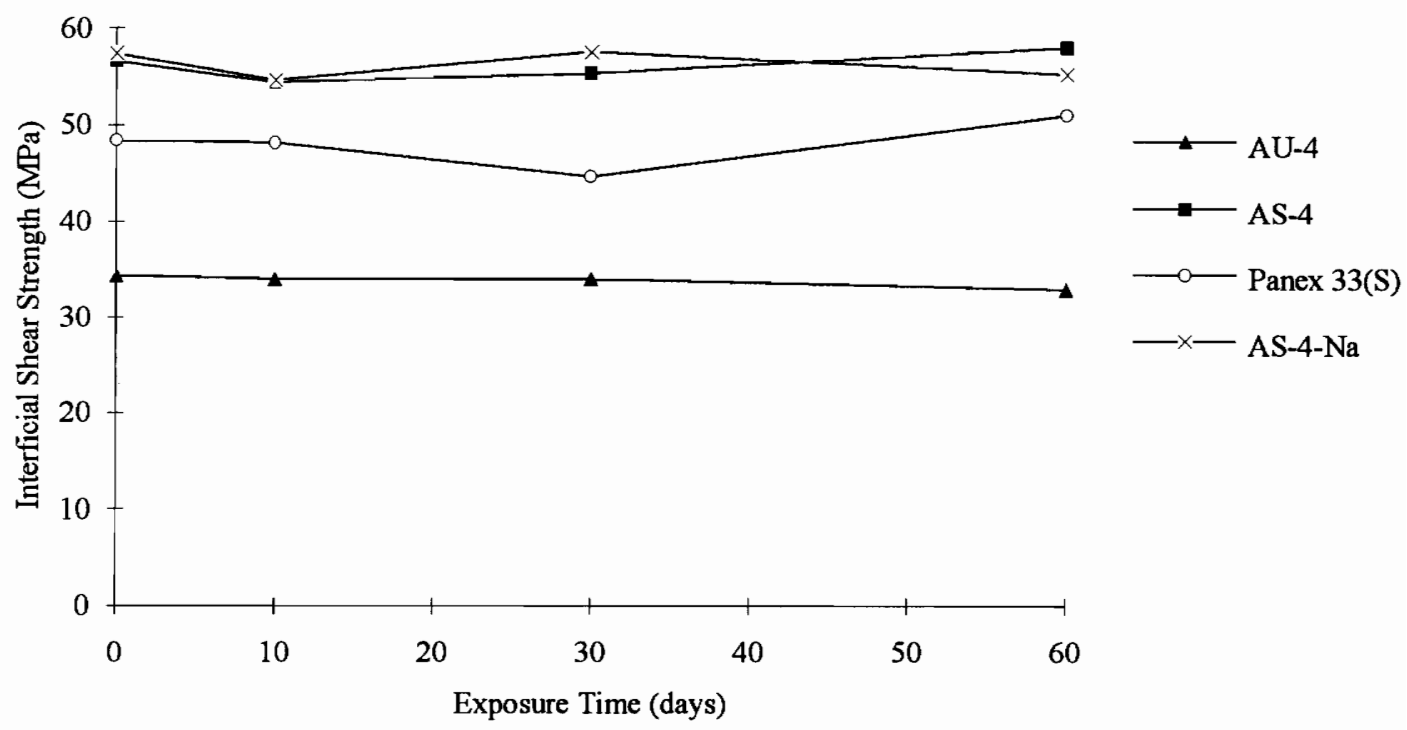

Figure 4.28 The influence of exposure time on interfacial shear strength in fiber/Epon828-mPDA system at $75^{\circ} \mathrm{C} 0 \% \mathrm{RH}$. 
The IFSS of samples stored under dry conditions stayed essentially constant even though the storage temperature was $75^{\circ} \mathrm{C}$. The IFSS of samples exposed to either $23^{\circ} \mathrm{C}$ or $75^{\circ} \mathrm{C}$ water vapor saturated environments decreased with exposure time indicating the degradation of interfacial adhesion by moisture.

The deleterious effect of moisture on interfacial adhesion has been studied by other authors ${ }^{129-132}$ and was attributed mainly to matrix plasticization and a decrease in glass transition temperature by moisture absorption. Epoxy resin systems are especially susceptible to moisture attack because of the hydrophilic nature of the resins.

Generally speaking, the decrease of IFSS at $75^{\circ} \mathrm{C}$ was faster than that at $23^{\circ} \mathrm{C}$ as a result of faster moisture absorption and migration. The rates of moisture uptake of the Epon828/mPDA single fiber specimen at $23^{\circ} \mathrm{C}$ and $75^{\circ} \mathrm{C}$ and $100 \% \mathrm{RH}$ are shown in Figure 4.29.

AS-4-Na fiber initially gave the same IFSS as AS-4 fiber indicating surface sodium did not affect the initial interfacial shear strength. However, upon exposure to humidity, the IFSS of the AS-4-Na system decreased much more dramatically than the other fiber systems documenting that sodium contamination on carbon fiber surface has a very deleterious effect on fiber/matrix durability.

A comparison of AS-4 and AS-4-Na fibers stored in $75^{\circ} \mathrm{C}$ and $100 \% \mathrm{RH}$ for 30 days was made to study the possible function of the sodium on moisture degradation of carbon fibers. Fiber surface atomic concentrations were measured by XPS and fiber tensile strengths were measured with single filament at gauge length of $10 \mathrm{~mm}$. The results are listed in Table 4.11. Fiber surfaces were oxidized to the same extent no matter the content of surface sodium. Fiber tensile strength did not decrease considerably because of sodium induced surface defects. These results indicate that the carbon fiber itself was not significantly degraded by sodium and moisture under the conditions of this study. 


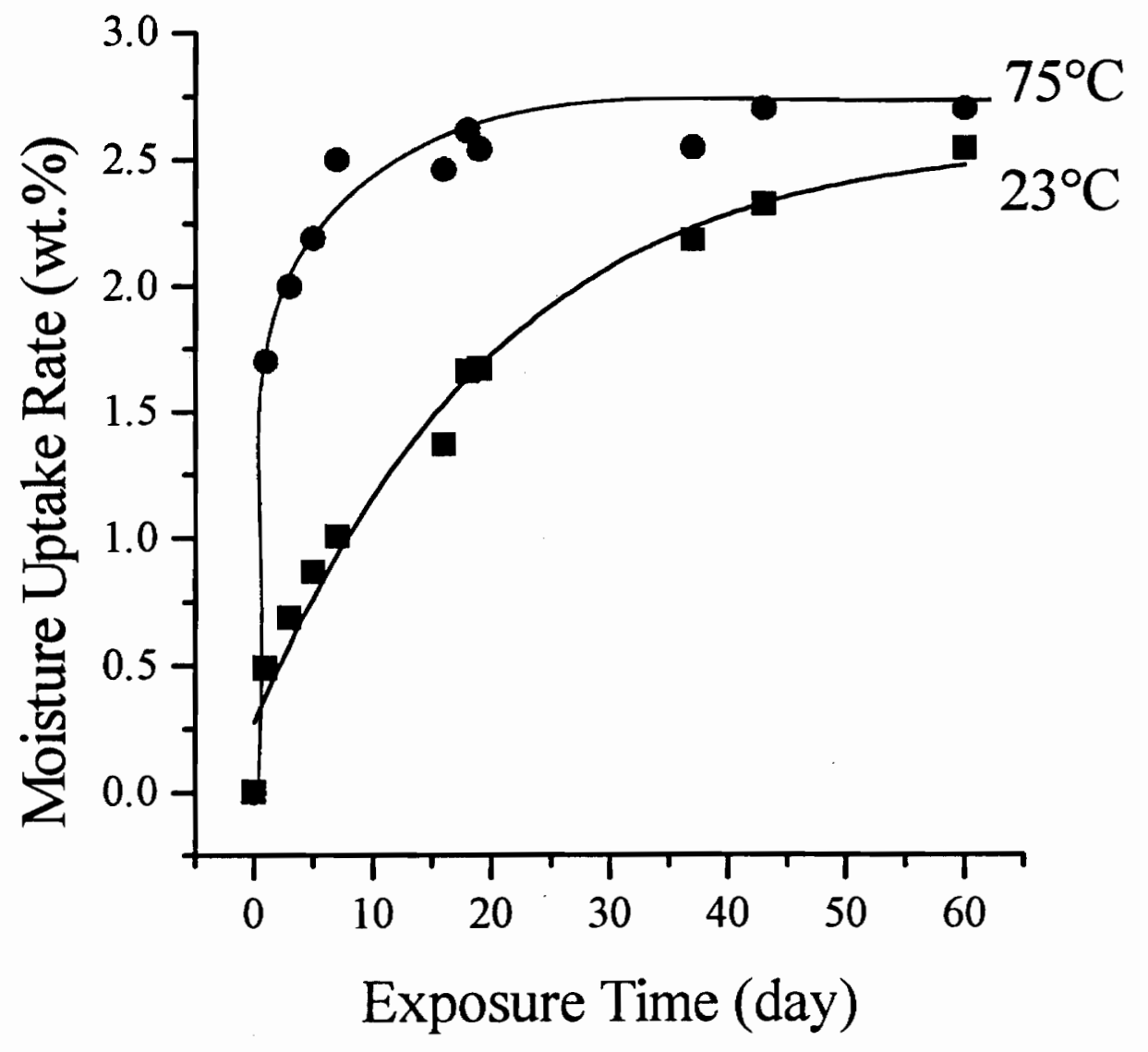

Figure 4.29 Moisture uptake rates of Epon828/mPDA dogbone samples. 
Table 4.11 The effects of sodium and moisture on carbon fiber properties.

\begin{tabular}{|c|c|c|c|c|c|}
\hline \multirow{2}{*}{ Fiber } & \multicolumn{4}{|c|}{ Fiber Surface AC by XPS } & \multirow{2}{*}{$\begin{array}{c}\text { Tensile Strength } \\
\text { (GPa) }\end{array}$} \\
\hline & $\mathrm{C}$ & $\mathrm{O}$ & $\mathrm{N}$ & $\mathrm{Na}$ & \\
\hline AS-4 original & 85 & 12 & 3.6 & 0.34 & $4.3 \pm 1.4$ \\
\hline AS-4-Na original & 85 & 10 & 3.2 & 2.3 & nd* \\
\hline AS- 4 after 30 days & 78 & 17.5 & 3.1 & 1.5 & $4.0 \pm 0.9$ \\
\hline \multicolumn{6}{|l|}{ in $75^{\circ} \mathrm{C} 100 \% \mathrm{RH}$} \\
\hline AS-4-Na after 30 days & 76 & 18 & 3.0 & 3.3 & $4.0 \pm 0.8$ \\
\hline in $75^{\circ} \mathrm{C} 100 \% \mathrm{RH}$ & & & & & \\
\hline
\end{tabular}

* not determined. 
The effects of sodium on the hydrolysis degradation of the epoxy resin were studied by FTIR analysis of resin samples exposed to humidity and aqueous $\mathrm{Na}_{2} \mathrm{CO}_{3}$ solutions. The amine cured epoxy network is usually quite stable to aqueous and alkaline aqueous media. If any degradation occurs, it is expected that elimination of $-\mathrm{OH}$ and formation of olefin, and even further, cleavage of $\mathrm{C}-\mathrm{N}$ bond and formation of aldehyde will occure as shown in Figure 4.30. Neither olefin nor aldehyde were present in the original resin, and thus any degradation could be easily detected in FTIR spectra. The transmission FTIR spectra of samples exposed to humidity and aqueous $\mathrm{Na}_{2} \mathrm{CO}_{3}$ at $23^{\circ} \mathrm{C}$ and $75^{\circ} \mathrm{C}$ are shown in Figure 4.31 and 4.32 respectively. The olefin bond vibration at $1648 \mathrm{~cm}^{-1}$ and aldehyde bond vibration at $1700 \mathrm{~cm}^{-1}$ were only slightly evident (see Figure $4.32 \mathrm{c}$ ) under the most severe condition, that is, when dipped in $10 \% \mathrm{Na}_{2} \mathrm{CO}_{3}$ solution at $75^{\circ} \mathrm{C}$ for 30 days. These results support the conclusion that no significant resin degradation under test conditions.

Thus, it is concluded that the hygroscopic nature of sodium ion must be responsible for the reduction in interfacial bond strength. Once moisture diffuses through the matrix and reaches the interface, it preferentially bonds to sodium and displaces the existing interfacial secondary bonds which provided the original interfacial adhesion.

Panex 33(S) fiber contained a considerable amount of residual sodium on the fiber surface. However, compared with AS-4-Na fiber, this system had a higher level of interfacial adhesion at both room temperature and elevated temperature humidity as shown in Figures 4.25 and 4.26. This result is attributed to the surface roughness of this fiber. Under dry conditions, the secondary forces were stronger than the mechanical interlock contribution and dominated the interfacial bond strength. Under high humidity conditions, secondary force interactions were diminished by moisture interacting, while the relative contribution of mechanical interlocking increased. 

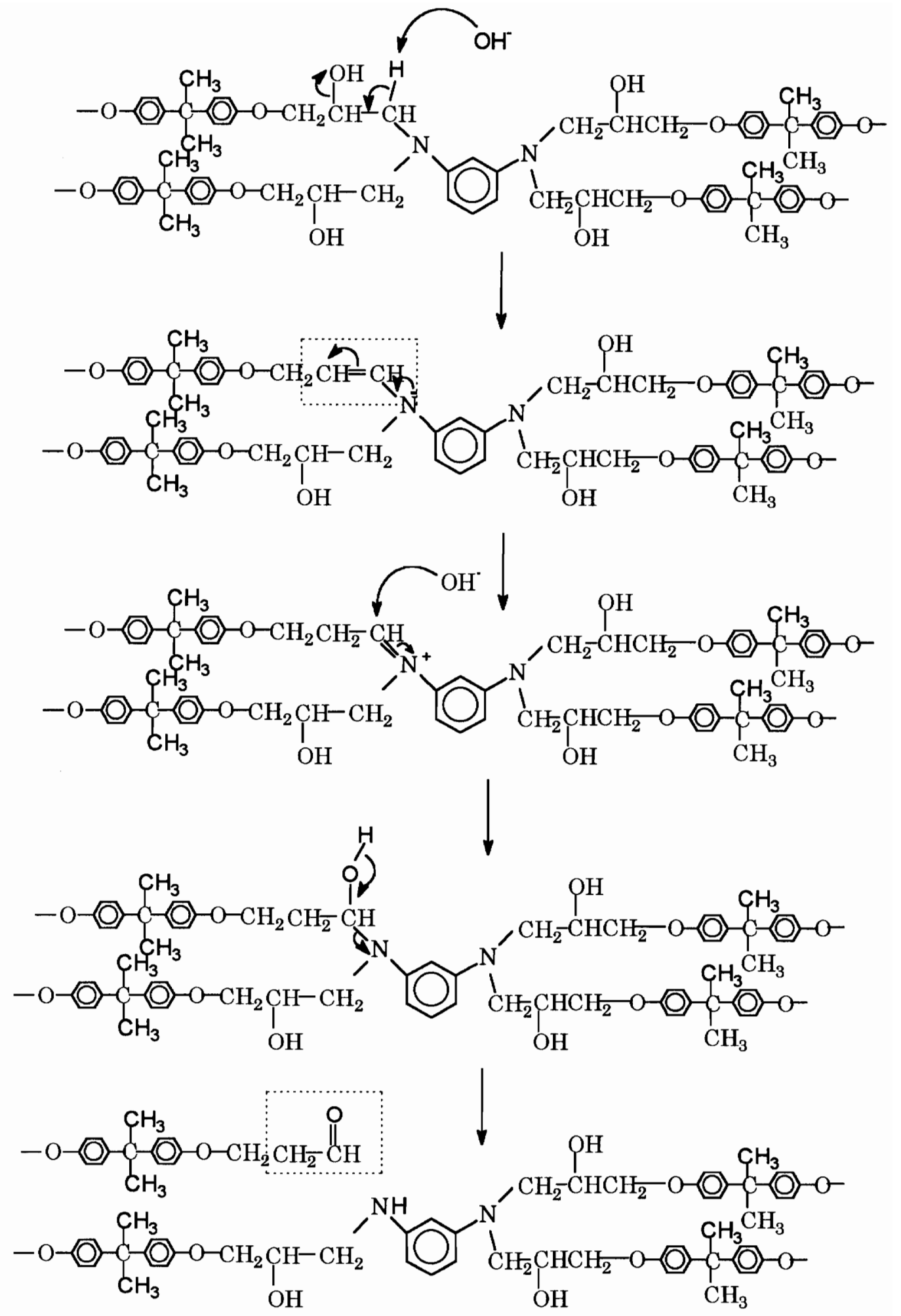

Figure 4.30 Proposed degradation mechanism of mPDA cured Epon828 network. 


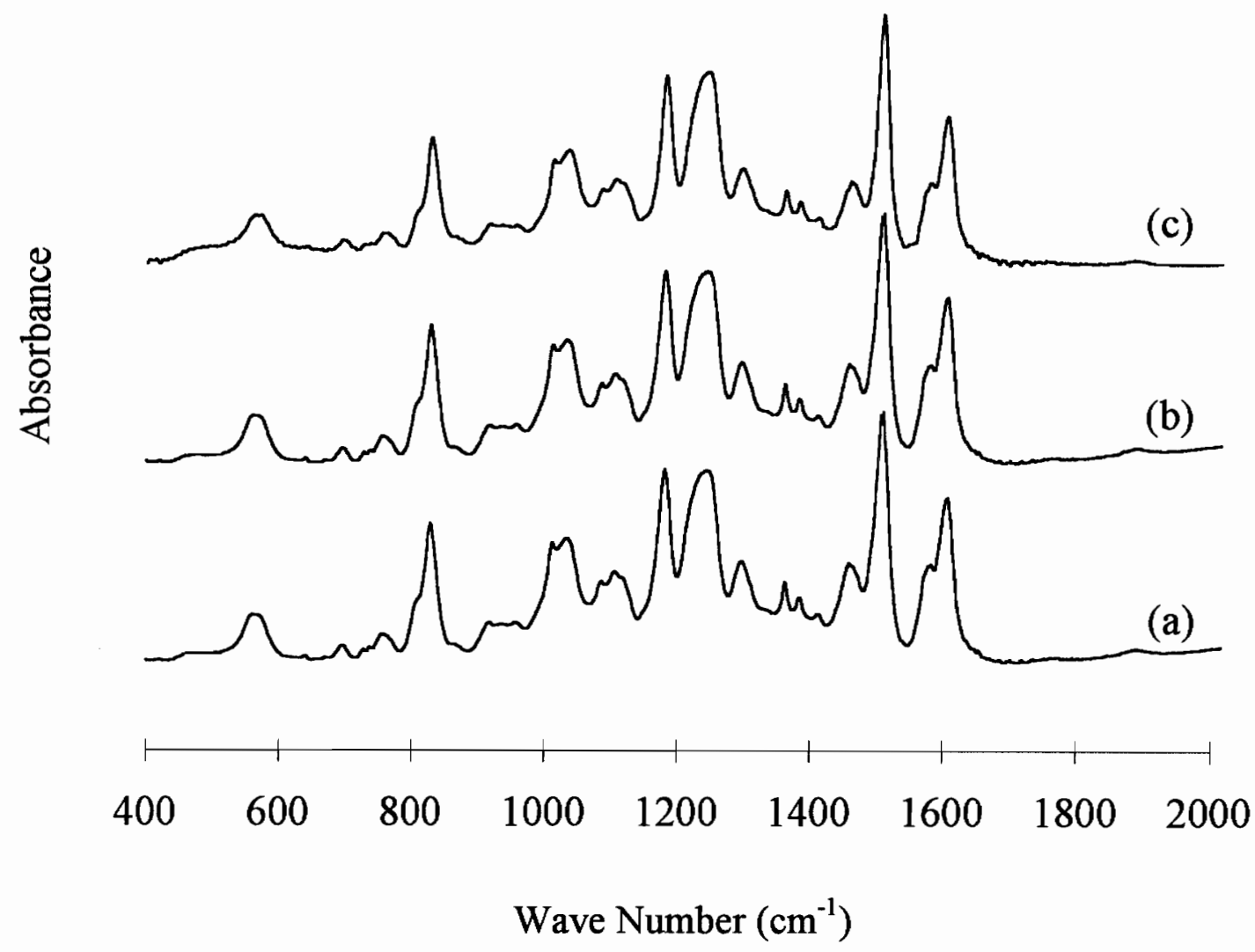

Figure 4.31 FTIR spectra of mPDA cured Epon828 epoxy resin. (a) original, (b) after 30 days in $23^{\circ} \mathrm{C} 100 \% \mathrm{RH}$, and (c) after 30 days in $23^{\circ} \mathrm{C} 10 \% \mathrm{Na}_{2} \mathrm{CO}_{3}$ aqueous solution. 


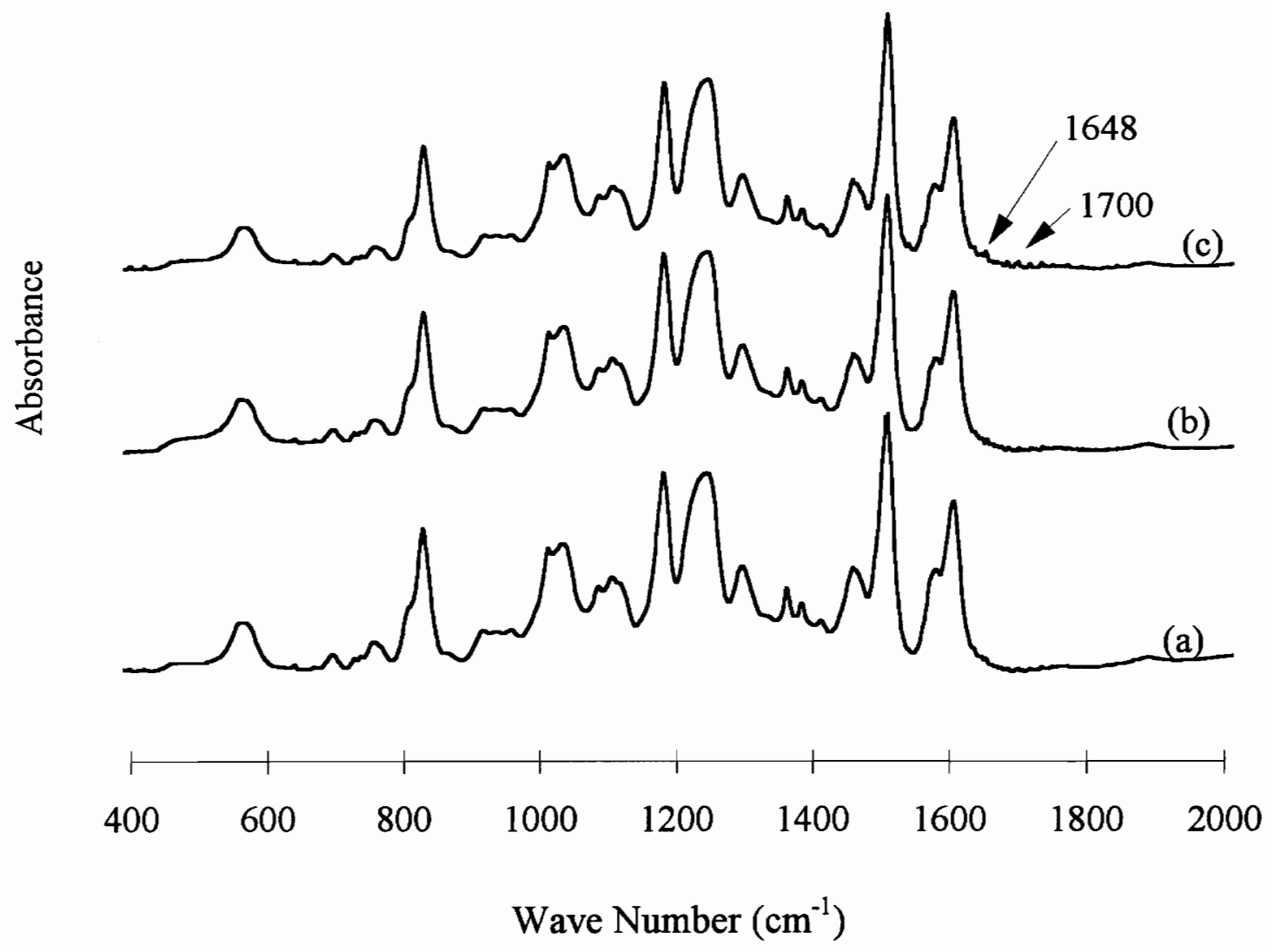

Figure 4.32 FTIR spectra of mPDA cured Epon828 epoxy resin. (a) original, (b) after 30 days in $75^{\circ} \mathrm{C} 100 \% \mathrm{RH}$, and (c) after 30 days in $75^{\circ} \mathrm{C} 10 \% \mathrm{Na}_{2} \mathrm{CO}_{3}$ aqueous solution. 


\subsubsection{Effect of Carbon Fiber Oxygen Plasma Treatment}

It was determined by XPS surface analysis that significant changes in carbon fiber surface composition occurred during oxygen plasma treatment. As shown in Figures 4.33 and 4.34, oxygen plasma significantly increased the surface oxygen content and slightly increased the nitrogen and sodium contents for both AU-4 and Panex 33(U) fibers. The plasma species reacted with the carbon fiber quickly and saturation was reached in about 15 seconds. The saturation is the limit of carbon fiber surface functionalization or the steady state established where the rate of functionalization is the same as that of plasma erosion. The saturation values of the $\mathrm{O} / \mathrm{C}$ ratio for the two fibers were both about 0.30 . Compared with $\mathrm{O}_{2}$ plasma treated AU-4 fiber treated Panex 33(U) had about 10 times more sodium and slightly less nitrogen.

The curve fit $\mathrm{C} 1 \mathrm{~s}$ and $\mathrm{O} 1 \mathrm{~s}$ photoelectron peaks of carbon fibers before and after oxygen plasma treatment are shown in Figures 4.35 and 4.36. Table 4.12 and 4.13 list the peak positions, area percentages and peak assignments for $\mathrm{C} 1 \mathrm{~s}$ and $\mathrm{O} 1 \mathrm{~s}$ respectively. The carbon peak curve fit results indicate that oxygen plasma increased the amount of oxygen functionalized carbon groups on the fiber surface. Based on oxygen peak curve fitting, it is evident that the relative amount of $-\mathrm{OH}$ group was increased by oxygen plasma treatment.

The topographic changes in carbon fiber surface caused by oxygen plasma treatment are shown in the SEM photomicrographs in Figures 4.37 and 4.38. Some evidence of etching and pitting can be seen in $\mathrm{O}_{2}$ plasma treated AU-4 fiber but no so evident in Panex 33(U) fiber at the resolution of the SEM. 

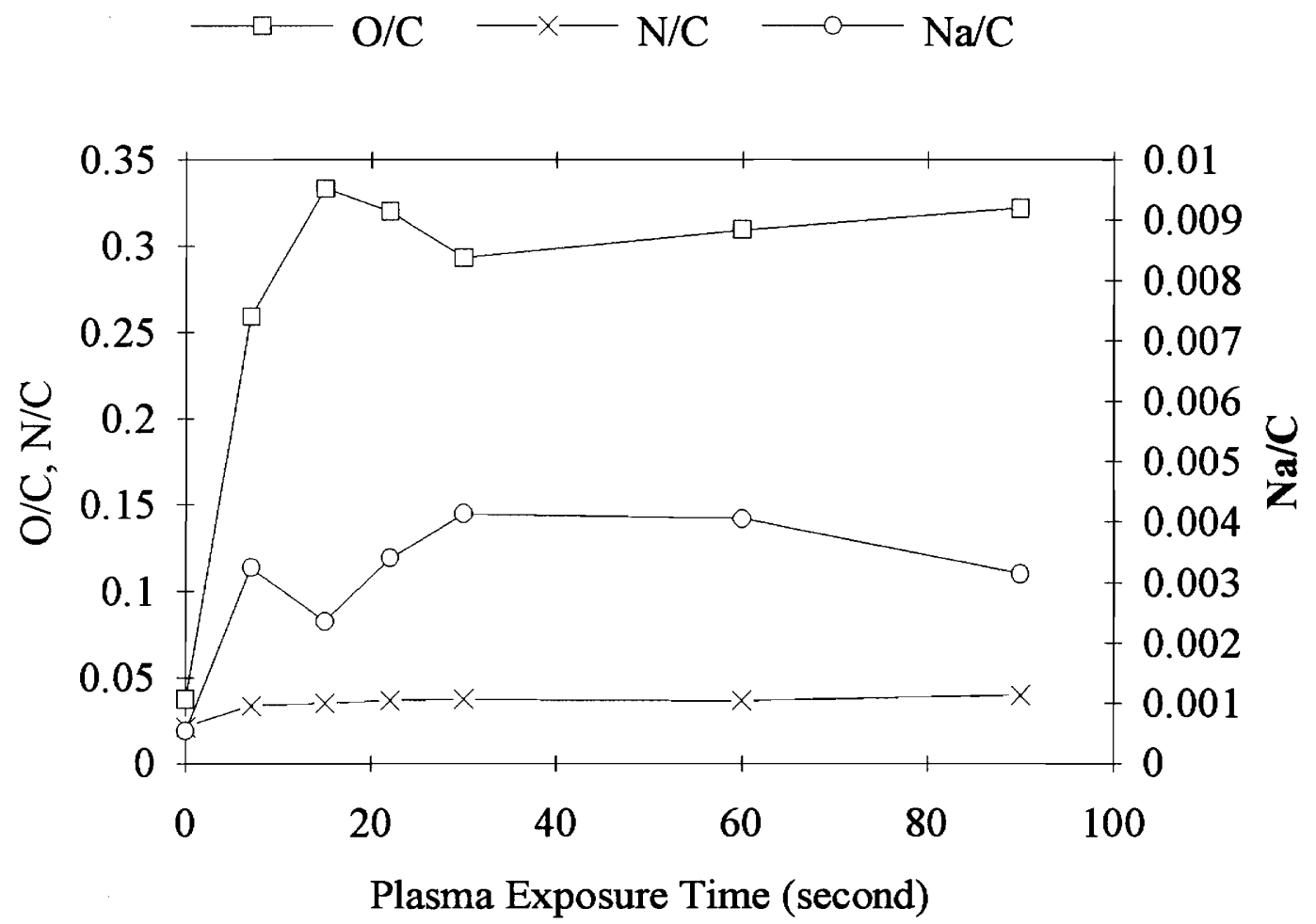

Figure 4.33 AU-4 carbon fiber surface chemistry change as a function of oxygen plasma treatment time. 


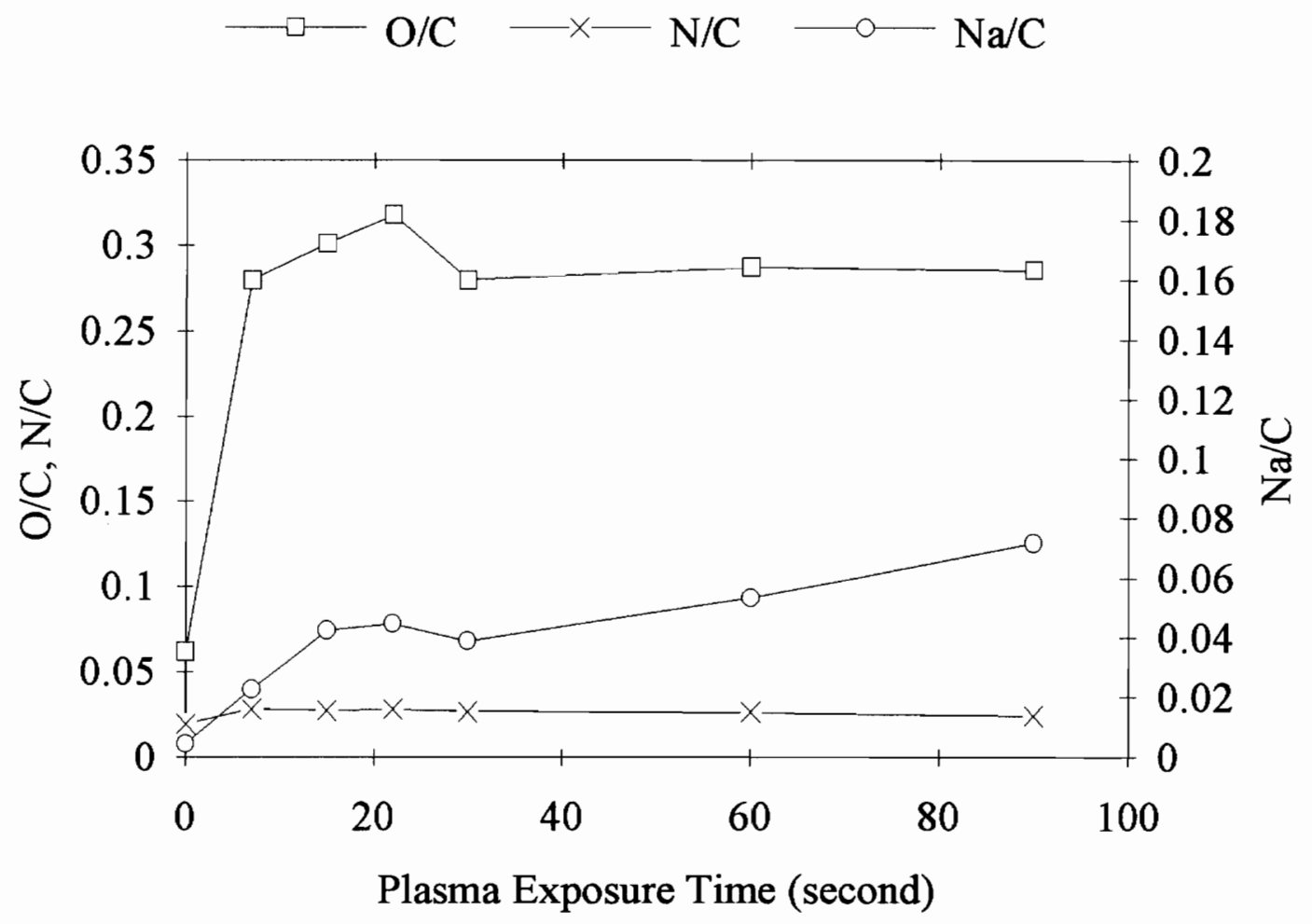

Figure 4.34 Panex 33(U) carbon fiber surface chemistry change as a function of oxygen plasma treatment time. 

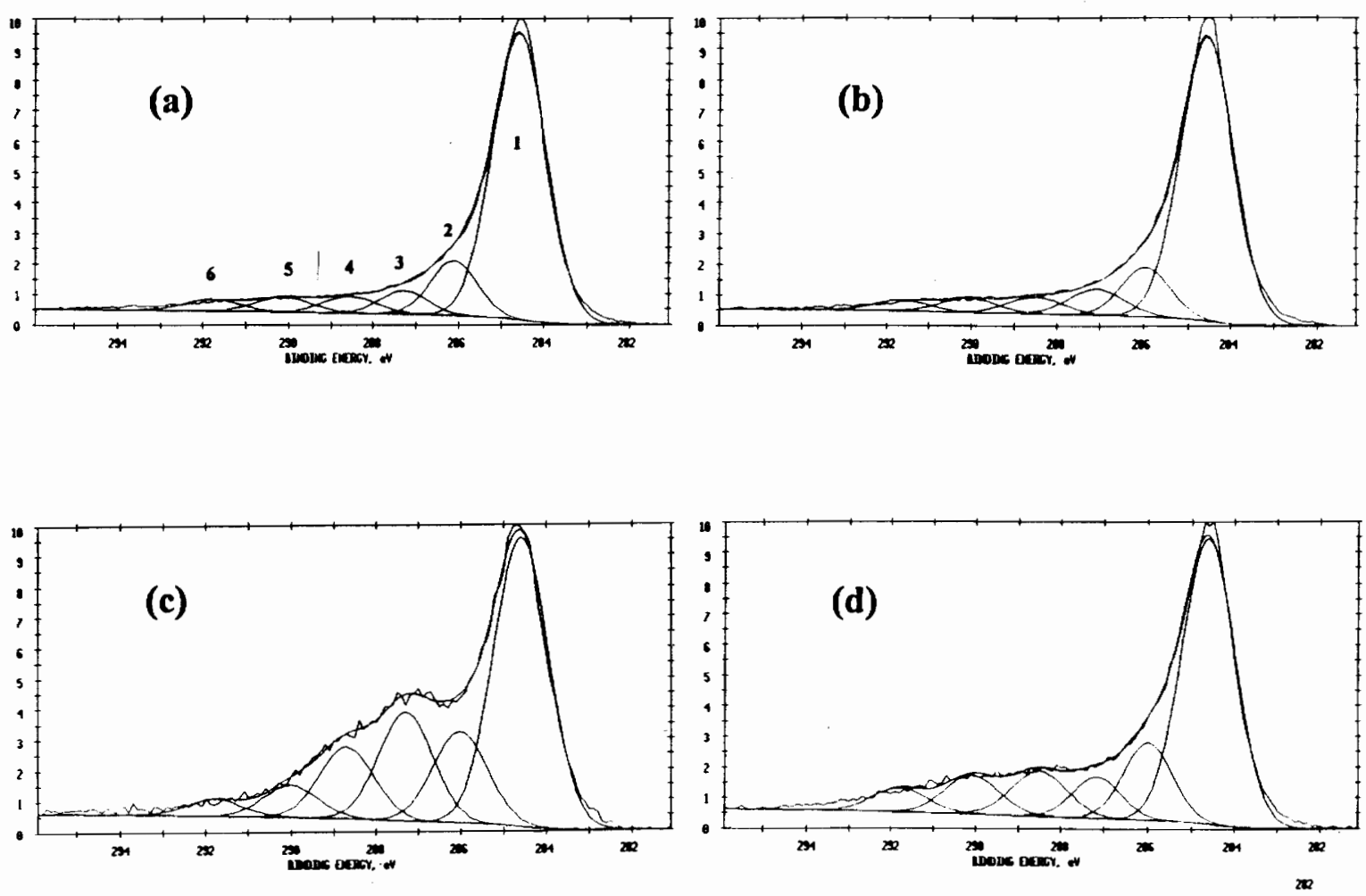

Figure 4.35 Cure resolved carbon 1s XPS photoelectron peaks of (a) AU-4 original, (b) Panex 33(U) original, (c) $90 \mathrm{sec} . \mathrm{O}_{2}$ plasma treated AU-4, and (d) $90 \mathrm{sec} . \mathrm{O}_{2}$ plasma treated Panex 33(U) fibers. 

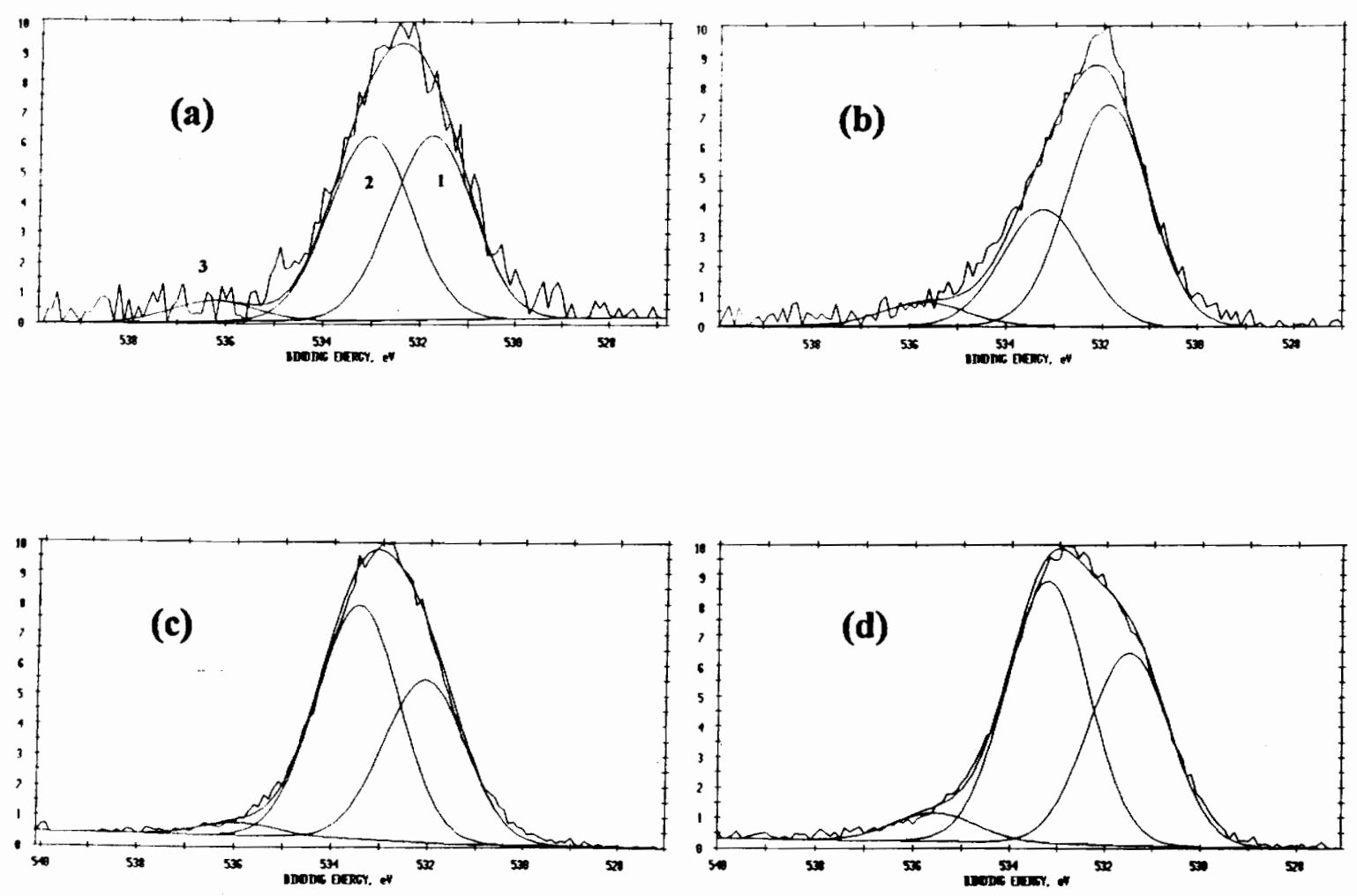

Figure 4.36 Curve fit oxygen 1s XPS photoelectron peaks of (a) AU-4 original, (b) Panex 33(U) original, (c) $90 \mathrm{sec}$. $\mathrm{O}_{2}$ plasma treated AU-4, and (d) $90 \mathrm{sec} . \mathrm{O}_{2}$ plasma treated Panex 33(U) fibers. 
Table 4.12 Carbon 1s photopeak curve fit results of oxygen plasma treated carbon fibers.

\begin{tabular}{|c|c|c|c|c|c|c|}
\hline \multirow{2}{*}{ Fiber } & \multicolumn{6}{|c|}{ Binding Energy $(\mathrm{eV})^{*}$} \\
\hline & 284.6 & 285.9 & 287.2 & 288.6 & 290.0 & 291.7 \\
\hline $\begin{array}{l}\text { AU-4, } \\
\text { original }\end{array}$ & 70.2 & 11.7 & 7.0 & 4.2 & 3.8 & 3.1 \\
\hline $\begin{array}{l}\mathrm{AU}-4,7 \mathrm{sec} \\
\mathrm{O}_{2} \text { plasma }\end{array}$ & 54.2 & 15.8 & 13.9 & 8.6 & 4.5 & 3.0 \\
\hline $\begin{array}{l}\text { AU-4, } 15 \\
\text { sec. } \mathrm{O}_{2} \\
\text { plasma }\end{array}$ & 48.4 & 14.4 & 18.1 & 11.9 & 4.5 & 2.7 \\
\hline $\begin{array}{l}\text { AU-4, } 30 \\
\text { sec. } \mathrm{O}_{2} \\
\text { plasma }\end{array}$ & 53.0 & 14.2 & 14.9 & 10.4 & 4.8 & 2.7 \\
\hline $\begin{array}{l}\mathrm{AU}-4,90 \\
\text { sec. } \mathrm{O}_{2} \\
\text { plasma }\end{array}$ & 46.6 & 14.5 & 18.9 & 11.9 & 5.3 & 2.8 \\
\hline $\begin{array}{l}\text { Panex } \\
33(U), \\
\text { original }\end{array}$ & 71.4 & 11.2 & 6.7 & 4.2 & 3.7 & 2.8 \\
\hline $\begin{array}{l}\text { Panex } \\
33(\mathrm{U}), 7 \\
\text { sec. } \mathrm{O}_{2} \\
\text { plasma }\end{array}$ & 60.5 & 11.6 & 10.6 & 8.2 & 5.3 & 3.8 \\
\hline $\begin{array}{l}\text { Panex } \\
33(\mathrm{U}), 15 \\
\text { sec. } \mathrm{O}_{2} \\
\text { plasma }\end{array}$ & 62.0 & 12.3 & 10.6 & 7.6 & 4.3 & 3.2 \\
\hline
\end{tabular}




\begin{tabular}{|c|c|c|c|c|c|c|}
\hline $\begin{array}{l}\text { Panex } \\
33(\mathrm{U}), 30 \\
\text { sec. } \mathrm{O}_{2} \\
\text { plasma }\end{array}$ & 59.8 & 13.5 & 8.9 & 7.9 & 5.9 & 4.0 \\
\hline $\begin{array}{l}\text { Panex } \\
33(\mathrm{U}), 90 \\
\text { sec. } \mathrm{O}_{2} \\
\text { plasma }\end{array}$ & 57.3 & 13.3 & 7.1 & 9.4 & 7.9 & 5.0 \\
\hline Assignment & $\begin{array}{c}\text { C-H } \\
\text { (graphite, } \\
\text { aromatics, } \\
\text { aliphatics) }\end{array}$ & $\begin{array}{l}\underline{\mathrm{C}}-\mathrm{OH} \\
\underline{\mathrm{C}}-\mathrm{O}-\mathrm{C} \\
\underline{\mathrm{C}}-\mathrm{N} \\
\underline{\mathrm{C}}=\mathrm{N} \\
\underline{\mathrm{C}}=\mathrm{N}\end{array}$ & $\begin{array}{c}\underline{\mathrm{C}}=\mathrm{O} \\
\mathrm{N}-\underline{\mathrm{C}}=\mathrm{O}\end{array}$ & $\begin{array}{l}\mathrm{O}=\underline{\mathrm{C}}-\mathrm{OH} \\
\mathrm{O}=\underline{\mathrm{C}}-\mathrm{OR}\end{array}$ & $\begin{array}{l}\mathrm{O}-\underline{\mathrm{C}} \mathrm{O}-\mathrm{O} \\
\mathrm{O}=\underline{\mathrm{C}}-\mathrm{O}^{-} \\
\mathrm{O}=\underline{\mathrm{C}}=\mathrm{O}\end{array}$ & plasmon \\
\hline Peak No. & 1 & 2 & 3 & 4 & 5 & 6 \\
\hline
\end{tabular}

${ }^{*}$ Gaussian function curve fit, uncertainty in peak position is $\pm 0.1 \mathrm{eV}, \mathrm{FWHM}$ are $1.4 \pm 0.1 \mathrm{eV}$. 
Table 4.13 Oxygen 1s photopeak curve fit results of oxygen plasma treated carbon fibers.

\begin{tabular}{|c|c|c|c|}
\hline \multirow{2}{*}{ Fiber } & \multicolumn{3}{|c|}{ Binding Energy $(\mathrm{eV})^{*}$} \\
\hline & 532.0 & 533.5 & 536.2 \\
\hline AU-4, original & 47.4 & 47.3 & 5.3 \\
\hline AU- 4,7 sec. $\mathrm{O}_{2}$ plasma & 38.9 & 57.2 & 3.9 \\
\hline AU-4, 15 sec. $O_{2}$ plasma & 36.3 & 61.1 & 2.6 \\
\hline $\mathrm{AU}-4,30 \mathrm{sec} . \mathrm{O}_{2}$ plasma & 38.9 & 57.1 & 4.0 \\
\hline AU-4, 90 sec. $\mathrm{O}_{2}$ plasma & 39.9 & 57.3 & 2.8 \\
\hline Panex 33(U), original & 48.5 & 45.2 & 6.3 \\
\hline Panex 33(U), 7 sec. $\mathrm{O}_{2}$ plasma & 48.3 & 47.4 & 4.3 \\
\hline Panex 33(U), 15 sec. $\mathrm{O}_{2}$ plasma & 43.1 & 51.6 & 5.3 \\
\hline Panex $33(\mathrm{U}), 30$ sec. $\mathrm{O}_{2}$ plasma & 41.4 & 53.7 & 4.93 \\
\hline Panex 33(U), 90 sec. $\mathrm{O}_{2}$ plasma & 39.9 & 54.3 & 5.8 \\
\hline Assignment & $\begin{array}{c}\mathrm{C}=\underline{\mathrm{O}} \\
\mathrm{C}-\underline{\mathrm{O}}-\mathrm{C}\end{array}$ & $\mathrm{C}-\underline{\mathrm{O}} \mathrm{H}$ & Adsorbed $\mathrm{H}_{2} \mathrm{O}$ \\
\hline Peak No. & 1 & 2 & 3 \\
\hline
\end{tabular}

* Gaussian function curve fit, uncertainty in peak position is $\pm 0.3 \mathrm{eV}, \mathrm{FWHM}$ are $1.9 \pm 0.1 \mathrm{eV}$. 


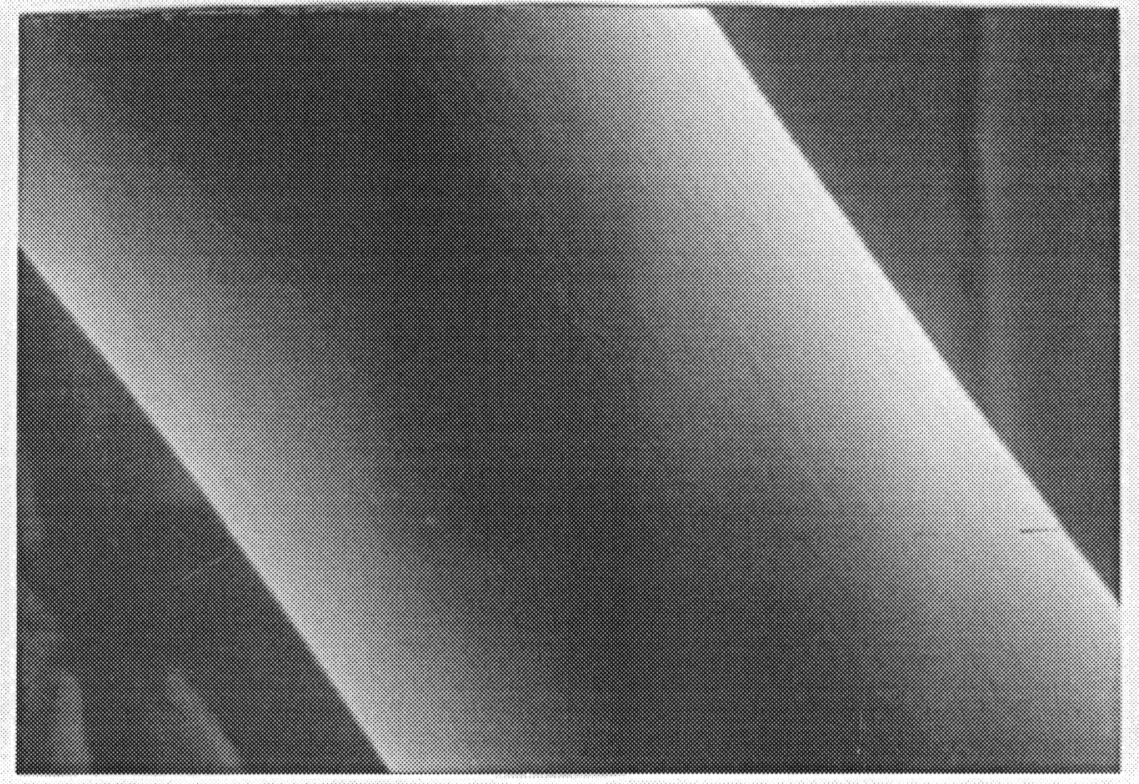

(a)

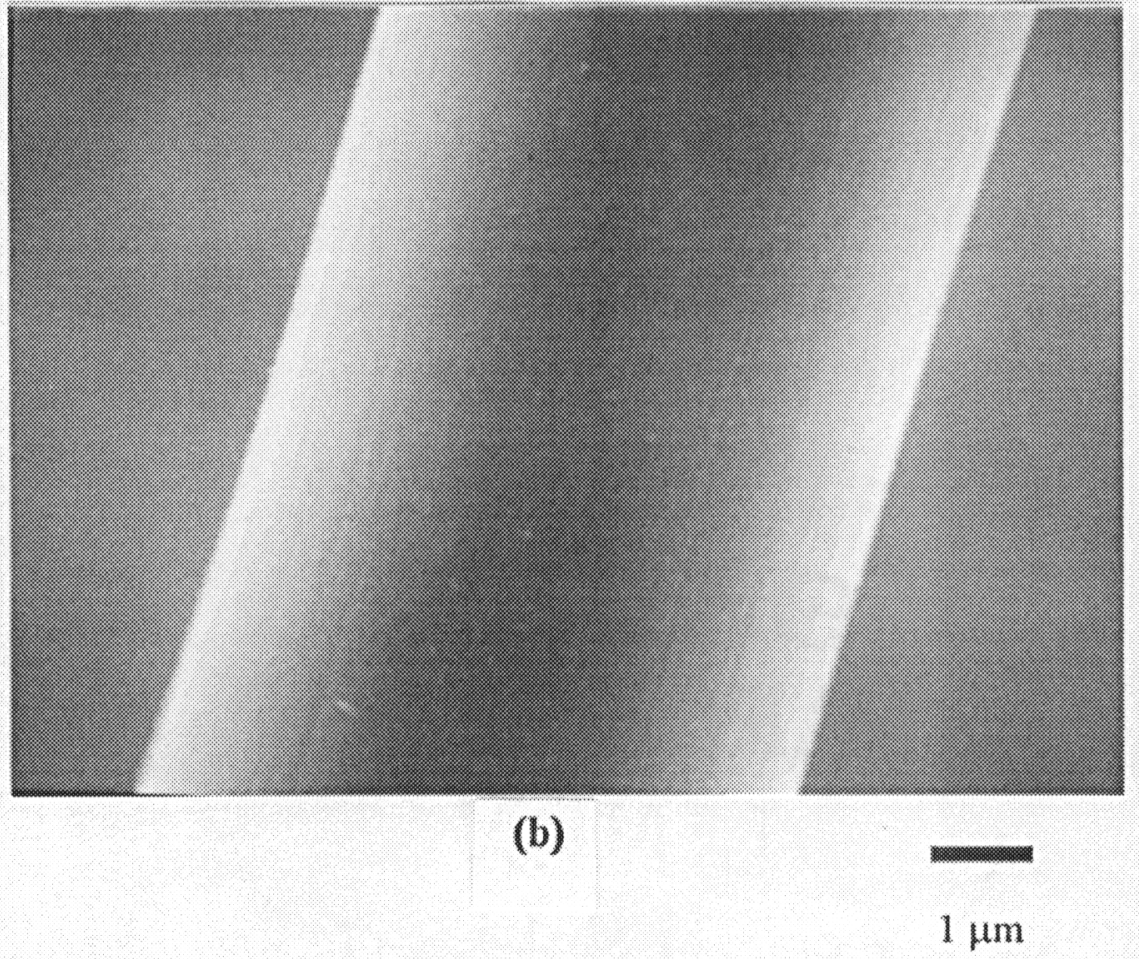

Figure 4.37 Change of fiber topography by oxygen plasma. (a) AU-4 original, and (b) AU-4 90 sec. plasma. 


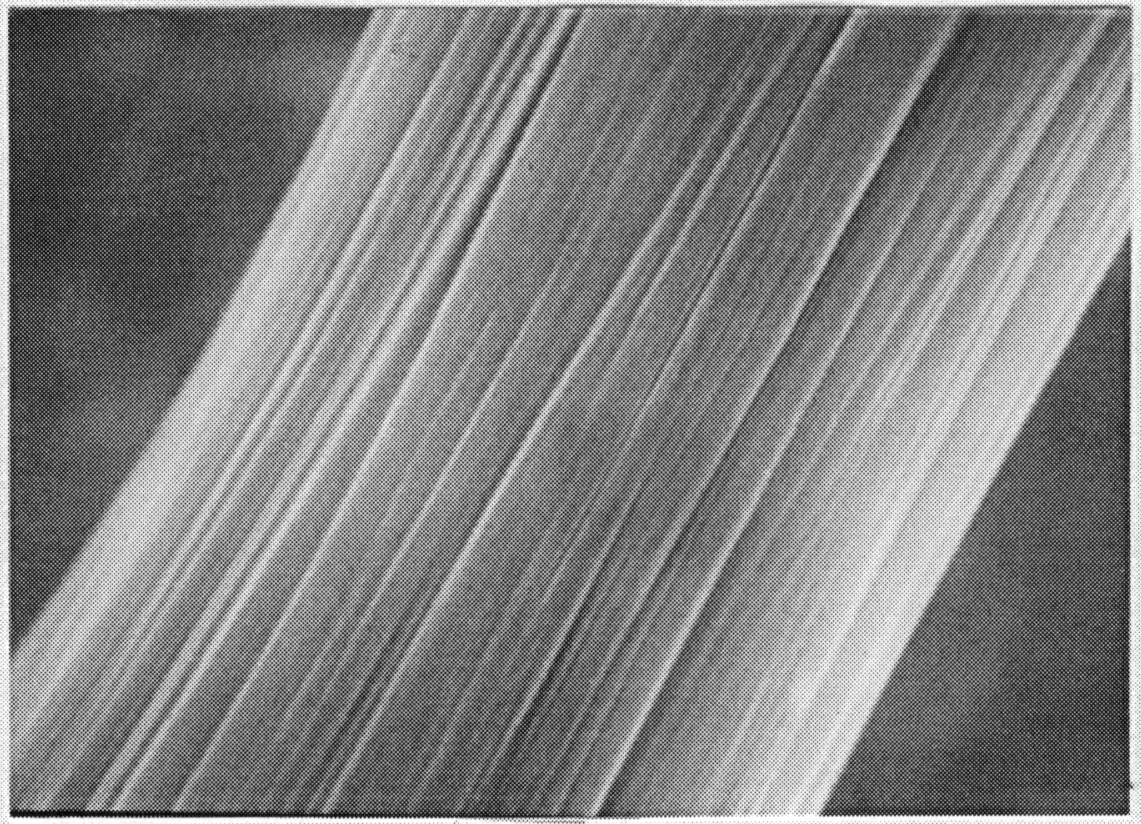

(c)

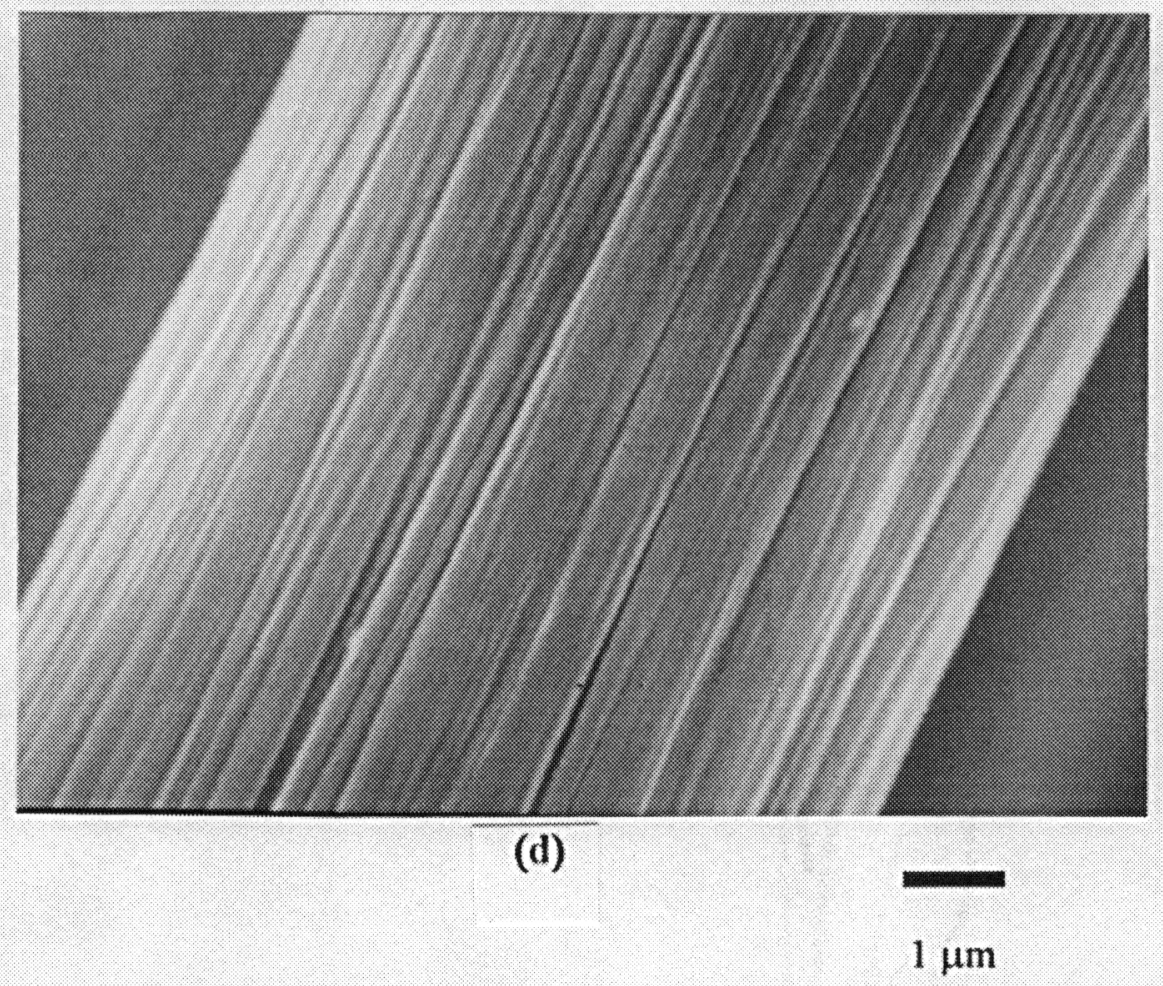

Figure 4.37 Change of fiber topography by oxygen plasma. (c) Panex 33(U) original, and (d) Panex 33(U) 90 sec. Plasma. 
Fiber surface free energy analysis by the two liquid dynamic contact angle test gave reproducible results for the dispersive and polar surface energies of the original fibers and the polar component of plasma treated fibers. However, the dispersive surface energy of oxygen plasma treated fibers was less reproducible due to an uncertainty of about $10 \mathrm{~mJ} / \mathrm{m}^{2}$. The possible reasons for the non-reproducibility are fiber surface inhomogeneities and adsorption because of the very high surface energy. The change of the fiber polar surface energy with plasma treatment time is shown in Figure 4.38. Paralleling the incorporation of surface functional groups into fiber, the polar surface energy increased by a factor of 3 with oxygen plasma treatment. Saturation was reached quickly in about 15 seconds. The values were slightly higher for Panex 33(U) fibers.

The effect of fiber oxygen plasma treatment on the interfacial adhesion was evaluated by interfacial shear strength measurement using the single fiber fragmentation test. Figures 4.39 and Figure 4.40 present the change of IFSS with oxygen plasma treatment of AU-4 and Panex 33(U) fibers in Epon 828/mPDA matrix resin. As a result of oxygen plasma induced surface changes, IFSS increased from about 30 and 31 to 52 and $60 \mathrm{MPa}$, respectively for the AU-4 and Panex 33(U) fibers. The fiber surface oxygen/carbon ratio and surface polar energy are also shown in Figures 39 and 40. Oxygen plasma treatment significantly increased fiber surface oxygen content, surface energy, and fiber/matrix interfacial shear strength. The surface modification by plasma treatment was quite efficient, the steady state for measured properties being reached in about 15 seconds. 


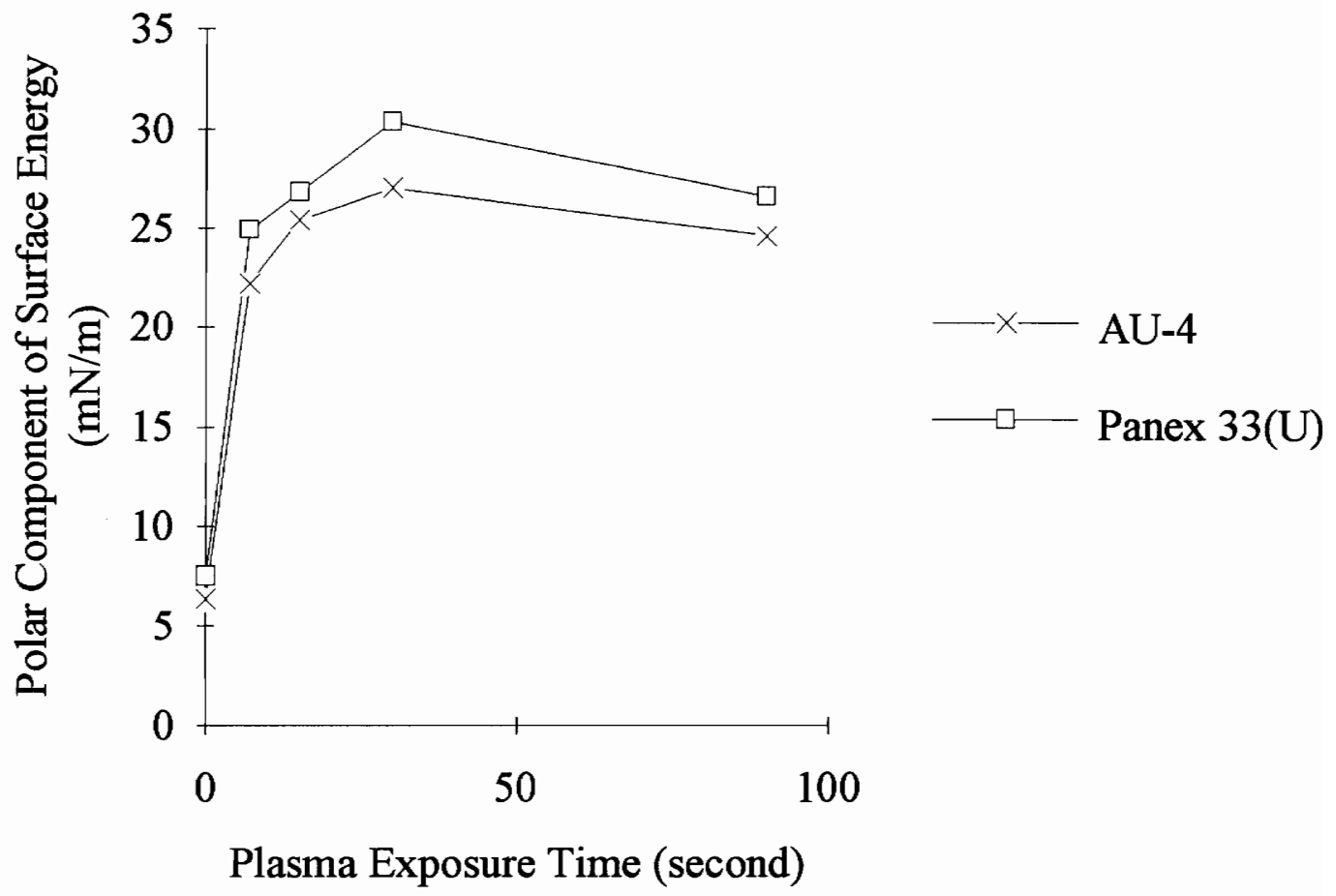

Figure 4.38 Polar component of fiber surface energy as a function of oxygen plasma treatment time. 
- IFSS $\times \gamma^{p} \quad \circ O / C$

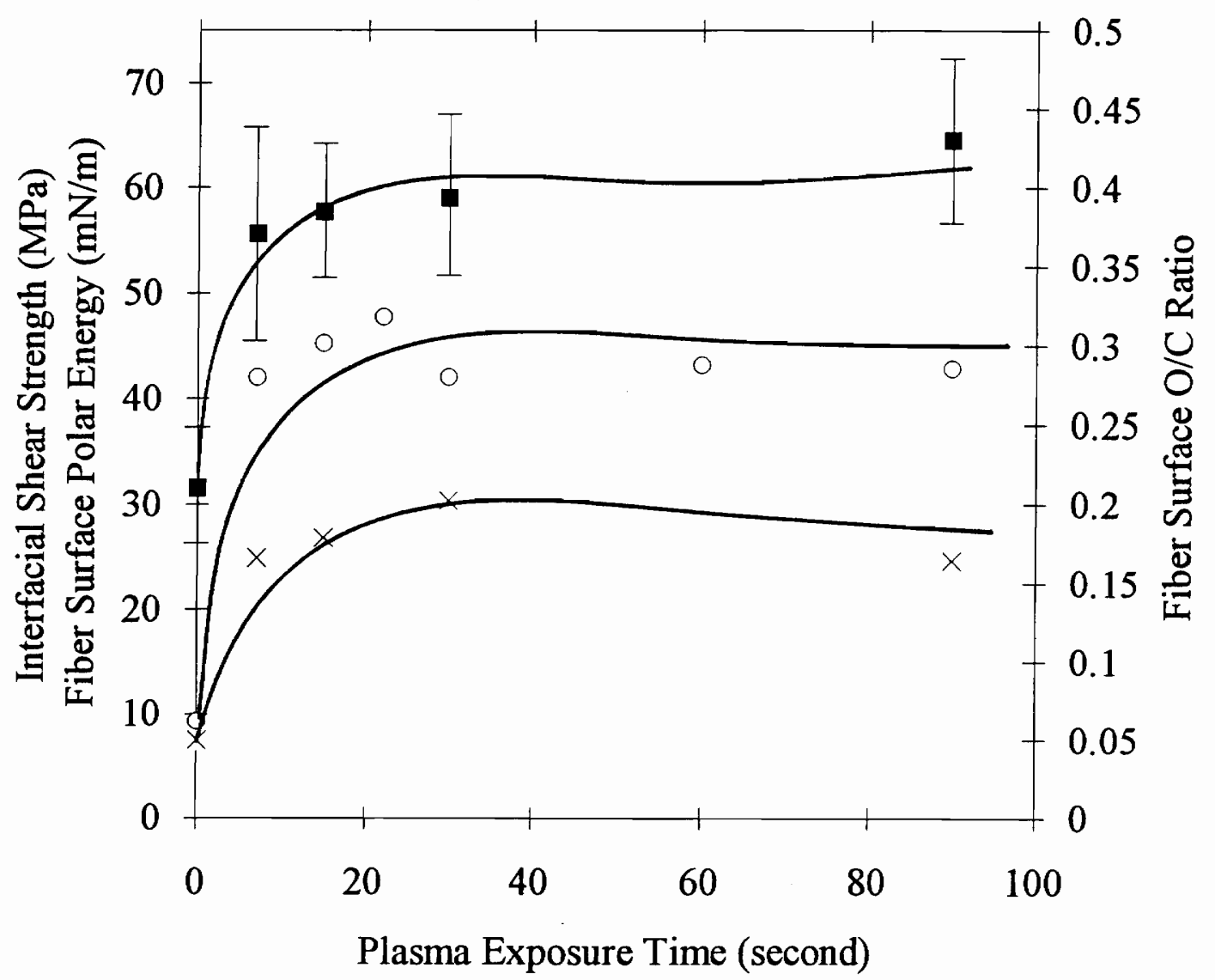

Figure 4.39 Interfacial shear strength as a function of oxygen plasma treatment time in AU-4 fiber and Epon 828/mPDA resin system. 


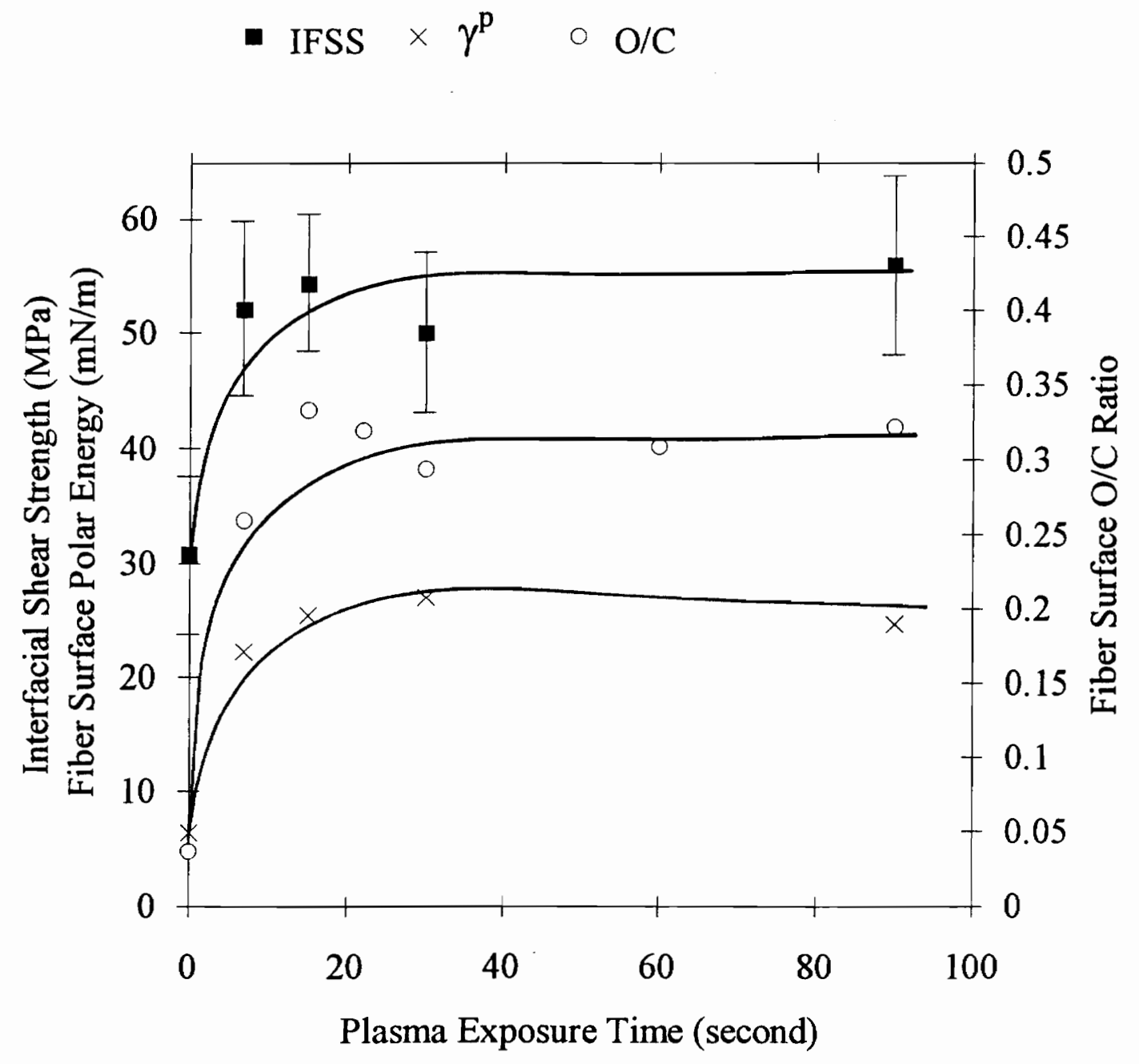

Figure 4.40 Interfacial shear strength as a function of oxygen plasma treatment time in Panex 33(U) fiber and Epon 828/mPDA resin system. 


\section{Chapter 5: Summary}

The surface characterizations were carried out for untreated, commercially surface treated and custom plasma treated carbon fibers. XPS results revealed that commercially surface treated AS-4 and Panex 33(S) carbon fibers gave surface oxygen atomic concentrations of $12 \%$ and $9.1 \%$ respectively, considerably higher than that of untreated AU-4 (3.1\%) and Panex 33(U) (4.7\%) fibers. An even higher surface oxygen content was achieved by oxygen plasma treatment of AU-4 and Panex 33(U) fibers. A steady state oxygen content (about $20 \%$ ) was reached in 15 seconds. To study the effects of surface sodium, AS-4-Na fiber was prepared from AS-4 with similar surface properties except for a $2.3 \%$ of surface sodium content.

Carbon fiber surface energy and the dispersive and polar components were determined by a two-liquid tensiometric method. Compared with untreated fibers, commercial surface treated fibers had a higher surface energy predominantly in polar part. The polar surface energy was increased even further for oxygen plasma treated fibers.

Fiber surface topography was examined by SEM. AU-4 and AS-4 fibers were essentially smooth and featureless whereas Panex 33 fibers had a rather rough surface. The comparison of fibers before and after oxygen plasma treatment indicated that oxygen plasma resulted in etching and pitting of the AU-4 carbon fiber surface.

Carbon fibers with different surface properties were incorporated into two different epoxy matrices. Single fiber fragmentation tests were carried out to evaluate the strength of interfacial adhesion. Commercially treated carbon fibers which had higher surface oxygen contents and higher fiber surface energies clearly produced higher interfacial shear strengths, relative to untreated fibers. An even greater level of adhesion was achieved with oxygen plasma treated fibers. 
Interfacial shear strength (IFSS) decreased with temperature in both the fiber/Epon828-mPDA system where the test temperature was below $\mathrm{Tg}$ of the matrix and the fiber/Epon828-Jeffamine DU-700 system where the test temperature was above Tg. In the fiber/Epon828-mPDA system, a quite dramatic decrease was observed at about $80^{\circ} \mathrm{C}$ which is considerably lower than the matrix $\operatorname{Tg}$ at $144^{\circ} \mathrm{C}$. This decrease was attributed to the existence of a low $\mathrm{Tg}$ interphase region and the loss of secondary forces with increased temperature. Above $80^{\circ} \mathrm{C}$, the IFSS of the commercial surface treated AS-4 fiber system dropped to the same level as that of untreated AU-4 fiber system implying the higher IFSS of AS-4 compared to the AU-4 was essentially non-chemical nature.

The IFSS of the fiber/Epon828-mPDA system decreased when exposed to high humidity environments. The degradation speed was enhanced when the temperature was elevated from room temperature to $75^{\circ} \mathrm{C}$. The presence of surface sodium did not affect the initial interfacial adhesion. However, IFSS decreased dramatically when the fiber/matrix system was exposed to humidity. This phenomenon was attributed to the hygrometric property of sodium which led to water accumulation in the interface.

Fiber surface roughness did not enhance the initial interfacial adhesion strength. However, mechanical interlock appeared to play a role when interfacial strength was lost by elevated humidity or elevated temperature. 


\section{Chapter 6: References}

1. B. Harris, P. W. R. Beaumont and E. M. de Ferran, J. Mater. Sci., 6, 238, 1971.

2. L. T. Drzal in Controlled Interphases in Composite Materials, H. Ishida ed, p.309, Elsevier Science, New York, 1990.

3. B. C. Cope in Handbook of Adhesion, D. E. Packham, ed., p.165, Longman, Essex, 1992.

4. J. B. Donnet and R. C. Bansal in Carbon Fibers, 2nd ed., Marcel Dekker, New York, 1990.

5. D. W. McKee and V. J. Mimeault in Chemistry and Physics of Carbon, Vol. 8, P.

L. Walker, Jr., ed., p.151, Marcel Dekker, New York, 1973.

6. G. E. Hammer and L. T. Drzal, Appl. Surf. Sci, 4, 340, 1980.

7. J. C. Bokros in Chemistry and Physics of Carbon, Vol. 5, P. L. Walker, Jr., ed., p. 10, Marcel Dekker, New York 1969.

8. D. M. Riggs, R. J. Shuford and R. W. Lewis in Handbook of Composites, G. Lubin, ed., p.196, Van Nostrand Reinhold, New York, 1982.

9. D. J. Johnson and C. N. Tyson, J. Physics, Ser. D, 2, 787, 1969.

10. B. Harris in Carbon Fibers in Engineering, M. Langley ed., p. 10, McGraw-Hill New York, 1973.

11. Committee on High-Performance Synthetic Fibers for Composites in HighPerformance Synthetic Fibers for Composites, National Materials Advisory Board, Commission on Engineering and Technical Systems, National Research Council, NMAB-434, National Academy Press, Washington, D.C., 1992.

12. R. Bacon in Chemistry and Physics of Carbon, Vol. 9, P. L. Walker Jr. and P. A. Thrower, eds., p.1, Marcel Dekker, New York, 1973.

13. W. Watt, Proc. Roy. Soc. London., A, 319, 5, 1970.

14. J. W. Johnson, J. R. Marjoram, and P. G. Rose, Nature, 221, 357, 1969.

15. J. G. Dillard, in Engineered Materials Handbook, Vol.3, p.286, ASM International, Metals Park, Ohio, 1990.

16. C. Jones, Composite Sci. Technol., 42, 275, 1991.

17. A. Proctor and P. M. A. Sherwood, J. Electr. Spectra. Rel. Phen., 27, 39, 1982.

18. T. Takagi and A. Ishitani, Carbon, 22, 43, 1984.

19. G. E. Hammer and L. T. Drzal, Appl. Surf. Sci., 4, 340, 1980. 
20. E. Ochiello, F. Garbassi, M. Morra and C. Nicolais, Composite Sci. and Technol., 36(2), 133, 1989.

21. E. Fitzer and R. Weis, Carbon, 25, 455, 1987.

22. D. M. Brewis et al., Fiber Sci. Technol., 12, 41, 1979.

23. T. A. DeVilbiss, Ph.D. dissertation, Virginia Polytechnic Institute and State University, Blacksburg, Virginia, 1987.

24. L. T. Drzal, Carbon, 15,129, 1977.

25. L. T. Drzal, J. A. Mescher and D. Hall, Carbon, 17, 375, 1979.

26. M. Nardin, E. M. Asloun and J. Schultz in Controlled Interphases in Composite Materials, H. Ishida, ed., p.285, Elsevier Science, New York, 1990.

27. J. B. Donnet and G. Guilpain, Composites, 22(1), 59, 1991.

28. T. T. King, D. D. Adams and D. A. Buttry, Composites, 22, 380, 1991.

29. C. Jones, Carbon, 27(3), 487, 1989.

30. G. J. Farrow and C. Jones, J. Adhesion, 45, 29, 1994.

31. C. L. Heisey, Ph.D. dissertation, Virginia Polytechnic Institute and State University, Blacksburg, Virginia, 1993.

32. P. Commercon, Ph.D. dissertation, Virginia Polytechnic Institute and State University, Blacksburg, Virginia, 1992.

33. P. Bourgeois and T. Davidson, J. Adhesion, 45, 73, 1994.

34. C. Jones, Carbon 27(3), 487, 1989.

35. C. Jones and E. Sammann, Carbon, 28, 509 \& 515, 1990.

36. L. Y. Yuan, C. S. Chen, S. S. Shyu and J. Y. Lai, Composite Sci. and Technol., $45,1,1992$.

37. Y. Xie and P. M. A. Sherwood, Appld. Spectr., 43(7), 1153, 1989.

38. J. B. Donnet, M. Brendle, T. L. Dhami and O. P. Bahl, Carbon, 24(6), 7571986.

39. J. B. Donnet, T. L. Dhami, O. P. Bahl and M. Brendle, J. of Physics D: Applied Physics, 20, 269, 1987.

40. P. Bourgeois and T. Davidson, J. Adhesion, 45, 73, 1994.

41. B. Z. Jang, Composite Sci. Technol. 44, 333, 1992.

42. N. Dilsiz, E. Ebert, W. Weiler and G. AKovali, J. Coll. Interf. Sci., 170 (2), 241, 1995.

43. B. Harris, P. W. R. Beaumont and A. Rosin, J. Mater. Sci., 4, 432, 1969. 
44. R. V. Subramanian and A. S. Crasto, Polym. Composites., 7, 201, 1986.

45. L. T. Drzal, M. J. Rich, M. F. Koenig and P. F. Lloyd, J. Adhesion, 16, 133, 1982.

46. S. J. Jenkins, G. T. Emmerson, P. T. McGrail and R. M. Roginson, J. Adhesion, 45, $15,1994$.

47. J. P. Bell, J. Chang, H. W. Rhee and R. Joseph, Polym. Composites., 8(1), 46, 1987.

48. J. J. Lesko, R. E. Swain, J. M. Cartwright, J. W. Chin, K. L. Reifsnider, D. A.

Dillard and J. P. Wightman, J. Adhesion, 45, 43, 1994.

49. L. S. Penn and T. T. Chiao in Handbook of Composites, G. Lubin, ed., p.57, Van Nostrand Reinhold, New York, 1982.

50. J. G. Williams in Composite Materials for Aircraft Structures, B. C. Hodkin and A. A. Baker, eds., p.48, American Institute of Aeronautics and Astronautics, New York, 1986.

51. "Epoxy Resins" in International Encyclopedia of Composites, vol.2, S. M. Lee ed., p.78, VCH Publishers, New York, 1990.

52. H. Lee and K. Neville, Handbook of Epoxy Resins, McGraw-Hill, New York, 1967.

53. L. H. Sharpe, J. Adhesion, 4, 51, 1972.

54. P. J. Herrera-Franco and L. T. Drzal, Composites, 23(1), $2,1992$.

55. W. Janssens, L. Doxsee, I. Verpoest and O. de Meester in Interfacial Phenomena in Composite Materials '89, F. R. Jones, ed., p.147, Butterworths, London, 1989.

56. S. M. Lee and S. Holguin, J. Adhesion, 31, 91, 1990.

57. L. T. Drzal in Advances in Polymer Science, Vol.75, K. Dusek, ed., p. 1, SpringerVerlag, New York, 1986.

58. A. J. Kinloch in Adhesion and Adhesives, Chapman and Hall, London, 1987.

59. J. R. Huntsberger, Adhesives Age 13(11), 43, 1970.

60. I. N. Ermolenko, I. P. Lyubliner and N. V. Gulko, in Chemically Modified Carbon Fibers, VCH Publishers, Weinheim, 1990.

61. E. Fitzer and R. Robinson, Carbon, 25, 455, 1987.

62. L. T. Drzal, M. J. Rich and P. F. Lloyd, J. Adhesion, 16, 1, 1982.

63. J. Harvey, C. Kozlowski and P. M. A. Sherwood, J. Mater. Sci., 22, 1585, 1987.

64. C. Kozlowski and P. M. A. Sherwood, J. C. S. Faraday Trans., 81(11), 2745, 1985.

65. J. R. G. Evans and D. E. Packham, J. Adhesion, 10, 177, 1979. 
66. P. Marshall and J. Price, Composites, 22, 388, 1991.

67. B. Tissington, G. Pollard and I. M. Ward, Composite Sci. Technol., 44, 185, 1992.

68. D. E. Packham in Adhesion Aspects of Polymeric Coatings, K. L. Mittal, ed., Plenum, New York, 1983.

69. L. T. Drzal in Engineered Materials Handbook, 2nd ed., Vol.3, p.391, ASM International, Metals Park, Ohio, 1990.

70. I. Verpoest and M. Desaeger, in Interfacial Phenomena in Comosite Materials '91, I. Verpoest and R. Jones, eds., p.70, Butterworths, Oxford, 1991.

71. M. R. Piggott and S. R. Dai, Polymer Engr Sci., 31(17), 1246, 1991.

72. L. J. Broutman, ASTM STP 452, p.27, ASTM, Philadelphia, 1969.

73. P. Lawrence, J. Mater. Sci. 7, 1, 1972.

74. L. B. Greszczuk, ASTM STP 452, p.42, ASTM, Philadelphia, 1969.

75. M. R. Piggott, Composite Sci. Tech., 30, 295, 1987.

76. M. R. Piggott, Composite Sci. Tech., 42, 57, 1991.

77. B. Miller, P. Muri and L. Rebenfeld, Composite Sci. Tech., 28, 17,1987.

78. B. Miller, U. Gaur, and D. E. Hirt Composite Sci. Tech., 42, 207, 1991.

79. D. A. Biro, P. Mclean and Y. Deslandes, Polym. Engr. Sci., 31(17), 1250, 1991.

80 J. F. Mandell, D. H. Grande, T. H. Tsiang and F. J. McCarry, ASTM STP 893, p.87, ASTM, Philadelphia, 1986.

81. .E. J. H. Chen and J. C. Young, Composite Sci. Tech. 42, 189, 1991.

82. D. H. Grande, J. F. Mandell and K. C. C. Hong, J. Mater. Sci., 23, 311, 1988.

83. H. F. Wu and M. K. Ferber, J. Adhesion, 45, 89, 1994.

84. A. N. Netravali, R. B. Henstenburg, S. L. Phoenix and P. Schwartz, Polym. Composites, 10 (4), 226, 1989.

85. V. Rao and L. T. Drzal, Polym. Composites, 12 (1), 48, 1991.

86. M. J. Rich and L. T. Drzal, J. Reinf. Plast. and Composite, 7, 145, 1988.

87. W. D. Bascom and R. M. Jensen, J. Adhesion, 19, 219, 1986.

88. M. Desaeger, I. Verpoest and R. Robinson in Interfacial Phenomena in Composite Materials '91, I. Verpoest and R. Jones, eds., p.87, Butterworths, Oxford, 1991.

89. A. Kelley and W. R. V. Tyson, J. Mech. Phys. Solids 13, 3291965.

90. H. L. Cox, British J. Appld. Phys. 3, 721952.

91. J. Amirbayat and J. W. S. Hearle, Fiber Sci. Technol., 2(2),123, 1969. 
92. M. R. Piggott, J. Mater. Sci. 13, 1709, 1978.

93. J. M. Whitney and L. T. Drzal, in ASTM STP 937, p.179, ASTM, Philadelphia, 1987.

94. J. A. Nairn, Mech. Mater., 13, 131, 1992.

95. P. J. Herrera-Franco, V. Tao, L. T. Drzal and M. Y. M. Chiang, Composite Engr., 2(1), 31, 1992.

96. A. S. Carrara and F. J. McGarry, J. Composite. Mater., 2, 222, 1968.

97. N. R. Sottos, L. Li and G. Agrawal, J. Adhesion, 45, 105, 1994.

98. P. J. Sabat, Evaluation of the Fiber-Matrix Interfacial Shear Strength in Fiber Reinforced Plastics. Masters Thesis, Virginia Polytechnic Institute and State University, Blacksburg, Virginia, 1985.

99. D. Jacques and J. P. Favre, Proceedings of the 6th International Conference of Composite Materials (ICCM). Vol. 5, F. L. Matthews et al., eds., p. 471, 1987.

100. S. M. Lee and S. Holguin, J. Adhesion, 31, 91,1990.

101. N. Netravali, L. T. T. Topoleski, W. H. Sachse and S. L. Phoenix, Composite Sci. Technol., 35, 13, 1989.

102. M. Nardin, E. M. Asloun and J. Schultz in Controlled Interphases in Composite Materials, H. Ishida, ed., p.285, Elsevier Science, New York, 1990.

103. J. C. Figueroa, T. E. Carney, L. S. Schadler and C. Laird, Composite Sci. Tech. 42, 771991.

104. H. Hamada, N. Nishida, Z.Maekawa and N. Ikuta, J. Mater. Sci., 29(2) 3521994.

105. Hercules product data sheet.

106. Zoltek product data sheet.

107. S. A. Wood, Modern Plastics, 63(3), 44, 1986.

108. J. Schultz, C. Cazeneuve, M. E. R. Shanahan and J. B. Donnet, J. Adhesion, 12, $221,1981$.

109. F. M. Fowkes, J. Phys. Chem. 67, 2538, 1963.

110. J. Schultz, K. Tsutsumi and J. B. Donnet, J. Coll. Interf. Sci. 59, 277, 1977.

111. F. M. Fowkes in Treatise on Adhesion and Adhesives, Vol.1, R. L. Patrick, ed., p.352, Marcel Dekker, New York, 1967.

112. Y. Tamai, K. Makuuchi and M. Suzuki, J. Phys. Chem. 71, 4176, 1967.

113. D. K. Owens, and R. C. Wendt, J. Apldp. Polymer Sci. 13, 1741, 1969. 
114. M. E. R. Shanahan, C. Cazeneuve, A. Carre, and J. Schultz, J. Chem. Phys. 79, 241, 1982.

115. El. M. Asloun, J. B. Donnet, G. Guilpain, M. Nardin and J. Schultz, J. Mater. Sci. 24, 3504, 1989.

116. W. G. McDonough, J. P. Herrera-Franco, W. L. Wu, L. T. Drzal and D. L. Hunston, in 23rd International SAMPE Technical Conference, p.247, 1991.

117. G. Beamson and D. Briggs, in High Resolution XPS of Organic Polymers, John Wiley \& Sons, New York, 1992.

118. E. Desimoni, G. I. Casella, A. Morone, and A. M. Salvi, Surf. Interf. Analysis, 15, $627,1990$.

119. E. Desimoni, G. I. Casella, T. R. I. Caladi, A. M. Salvi, T. Rotunno and E. DiCroce, Surf. Interf. Analysis, 18, 623, 1992.

120 E. Sancaktar in Engineered Materials Handbook, 2nd ed., Vol. 3, p.389, ASM International, Metals Park, Ohio, 1990.

121. M. Nardin, E. M. Asloun and J. Schultz, Composite Interf., 1(2), 113, 1993.

122. W. D. Bascom and R. M. Jensen, J. Adhesion, 19, 219, 1986.

123. T. P. Skourlis and R. L. McCullough, Composite Sci. Tech, 49, 363, 1993.

124. V. Rao and L. T. Drzal, J. Adhesion, 37, 83, 1992

125. D. W. L. Tai and L. S. Penn, J. Composite. Mater., 25, 1445, 1991.

126. M. Pegoraro and L. Di. Landro, Makromol. Chem. Macromol. Symp., 70/71, 193, 1993

127. G. Gerard and A. C. Gilbert, J. Appl. Mech. ASME, 24, 355, 1957.

128. E. M. Asloun, M. Nardin and J. Schultz, J. Mater. Sci. 24, 1835, 1989.

129. R. Deiasi and J. B. Whiteside, ASTM STP 658, p.2, ASTM, Philadelphia, 1978.

130. L T. Drzal, M. J. Rich and M. F. Koenig, J. Adhesion, 18, 49, 1985.

131. C. L. Schutte, W. McDonough, M. Shioya, M. McAuliffe and M. Greenwood, Composites, 25(7), 617, 1994.

132. D. H. Kaelble and P.J.Dynes, J. Adhesion, 8,195, 1977. 